\title{
A new phylogenetic analysis of Phytosauria (Archosauria: Pseudosuchia) with the application of continuous and geometric morphometric character coding
}

\author{
Andrew S Jones ${ }^{\text {Corresp., } 1}{ }^{\text {, Richard J Butler }}{ }^{1}$ \\ ${ }^{1}$ School of Geography, Earth and Environmental Sciences, University of Birmingham, Birmingham, United Kingdom \\ Corresponding Author: Andrew S Jones \\ Email address: andrew.jones.sp@gmail.com
}

Phytosauria is a clade of large, carnivorous, semi-aquatic archosauromorphs which reached its peak diversity and an almost global distribution in the Late Triassic (c. 230-201 Mya). Previous phylogenetic analyses of Phytosauria have either focused primarily on the relationships of specific subclades, or were limited in taxonomic scope, and no taxonomically comprehensive dataset is currently available. We here present the most taxonomically comprehensive cladistic dataset of phytosaurs to date, based on extensive first-hand study, identification of novel characters and synthesis of previous matrices. This results in an almost two-fold increase in phylogenetic information scored per taxon over previous analyses. Alongside a traditional discrete character matrix, three variant matrices were analysed in which selected characters were coded using continuous and landmarking methods, to more rigorously explore phytosaur relationships. Based on these four data matrices, four tree topologies were recovered. Relationships among non-leptosuchomorph phytosaurs are largely consistent between these four topologies, whereas those of more derived taxa are more variable. Rutiodon carolinensis consistently forms a sister relationship with Angistorhinus. In three topologies Nicrosaurus nests deeply within a group of traditionally non-Mystriosuchini taxa, leading us to redefine Mystriosuchini by excluding Nicrosaurus as an internal specifier. Two distinct patterns of relationships within Mystriosuchini are present in the four topologies, distinguished largely by the variable position of Mystriosuchus. In two topologies Mystriosuchus forms the most basal clade in Mystriosuchini, whilst in the others it occupies a highly derived position within the Machaeroprosopus clade. 'Redondasaurus' is consistently recovered as monophyletic; however, it also nests within the Machaeroprosopus clade. The greatest impact on tree topology was associated with the incorporation of continuous data into our matrices, with landmark characters exerting a relatively modest influence. All topologies correlated significantly with stratigraphic range estimates. Topological variability in our results highlights clades in which further investigation may better elucidate phytosaur 
relationships. 
1 A new phylogenetic analysis of Phytosauria (Archosauria: Pseudosuchia) with

2 the application of continuous and geometric morphometric character coding

3 Andrew S. Jones ${ }^{1}$, Richard J. Butler ${ }^{1}$

$4{ }^{1}$ School of Geography, Earth and Environmental Sciences, University of Birmingham,

5 Edgbaston, Birmingham, B15 2TT, UK

6

7 Corresponding author:

8 Andrew Jones ${ }^{1}$

9

10 Email address: andrew.jones.sp@gmail.com 
11 Abstract

12

13 Phytosauria is a clade of large, carnivorous, semi-aquatic archosauromorphs which reached its

14 peak diversity and an almost global distribution in the Late Triassic (c. 230-201 Mya). either

focused primarily on the relationships of specific subclades, or were limited in taxonomic scope, and no taxonomically comprehensive dataset is currently available. We here present the most taxonomically comprehensive cladistic dataset of phytosaurs to date, based on extensive firsthand study, identification of novel characters and synthesis of previous matrices. This results in an almost two-fold increase in phylogenetic information scored per taxon over previous analyses. Alongside a traditional discrete character matrix, three variant matrices were analysed in which selected characters were coded using continuous and landmarking methods, to more rigorously explore phytosaur relationships. Based on these four data matrices, four tree topologies were recovered. Relationships among non-leptosuchomorph phytosaurs are largely consistent between these four topologies, whereas those of more derived taxa are more variable. Rutiodon carolinensis consistently forms a sister relationship with Angistorhinus. In three topologies Nicrosaurus nests deeply within a group of traditionally non-Mystriosuchini taxa, leading us to redefine Mystriosuchini by excluding Nicrosaurus as an internal specifier. Two distinct patterns of relationships within Mystriosuchini are present in the four topologies, distinguished largely by the variable position of Mystriosuchus. In two topologies Mystriosuchus forms the most basal clade in Mystriosuchini, whilst in the others it occupies a highly derived position within the Machaeroprosopus clade. 'Redondasaurus' is consistently recovered as monophyletic; however, it also nests within the Machaeroprosopus clade. The greatest impact on tree topology was associated with the incorporation of continuous data into our matrices, with landmark characters exerting a relatively modest influence. All topologies correlated significantly with stratigraphic 
35 range estimates. Topological variability in our results highlights clades in which further 36 investigation may better elucidate phytosaur relationships. 
37

38

39

40

41

42

Phytosaurs were a group of large-bodied archosauromorph reptiles that achieved an almost global distribution during the Late Triassic (c. 230-201 Mya; Stocker \& Butler, 2013). In overall morphology, they are highly convergent with modern crocodilians, and this observation, in combination with the common recovery of their fossils from fluvial and lacustrine depositional environments, indicates that phytosaurs may have occupied a semi-aquatic niche, with their dentition suggestive of piscivory and carnivory (Stocker \& Butler, 2013).

By far the most intensively investigated aspect of Phytosauria is their systematics. The phylogenetic position of phytosaurs within Archosauromorpha remains debated, having been recovered by recent analyses as either the sister group to Archosauria (Nesbitt, 2011), or as the earliest diverging clade within the crocodilian total-group Pseudosuchia (Ezcurra, 2016). Regardless of their exact phylogenetic position, time-calibration of phylogenies indicates that phytosaurs originated in the Early Triassic, soon after the Permo-Triassic mass extinction, although only one confirmed phytosaur taxon is known prior to the Late Triassic (Stocker et al., 2017). Their abundance, rich fossil record and cosmopolitan distribution indicate that phytosaurs were an important component of Late Triassic ecosystems; as a result, aspects of phytosaur palaeobiology such as ontogeny (Irmis, 2007) and neurosensory adaptions (Holloway, Claeson \& O'keefe, 2013; Lautenschlager \& Butler, 2016), as well as biogeography (e.g., Buffetaut, 1993; Brusatte et al., 2012; Stocker \& Butler, 2013), have received considerable interest. Furthermore, phytosaurs have featured heavily in biostratigraphical hypotheses for the Late Triassic terrestrial record (Long \& Ballew, 1985; Parrish \& Carpenter, 1986; Lucas \& Hunt, 1993; Lucas, 2010; Martz \& Parker, 2017). An important factor for these analyses and others is a robust 
60 understanding of evolutionary relationships within Phytosauria. Phytosaur taxonomy has a long,

61 problematic and convoluted history, adding considerable complication to later attempts at

62 understanding phytosaur evolutionary history (Hungerbühler, 2002; Stocker \& Butler, 2013).

63 However, with the advent and continued improvement of cladistic techniques, a more cohesive

64 picture has begun to form.

65 Most previous phylogenetic analyses of the ingroup relationships of Phytosauria have

66 primarily focused on elucidating the relationships of individual or specific sets of taxa (Table 1).

67 To achieve this, many analyses opted to reduce their taxonomic scope, and as such have greatly

68 enhanced current knowledge of many areas in phytosaur systematics. However, there is currently

69 no taxonomically comprehensive cladistic dataset which can be used to investigate relationships

70 across all known phytosaur species and clades. The development of such a dataset is an essential

71 prerequisite for carrying out broader evolutionary analyses. To address this gap, this paper has

72 three primary aims:

1) To present the most taxonomically comprehensive phylogeny of Phytosauria to date,

74 including nearly all currently recognized species;

75 2) To use this phylogeny to investigate the phylogenetic relationships of a number of

76 species and higher-level taxa that have previously been recognized as problematic;

77 3) To assess the utility of continuous and geometric morphometric character coding

78 techniques, as tools that can potentially expand the information available to assess phytosaur

79 interrelationships.

\section{Previous work}


82 Previous cladistic analyses. The first cladistic analysis of the ingroup relationships of

83 Phytosauria was performed by Ballew (1989). Her analysis included 11 operational taxonomic

84

85

86

87 units (OTUs) and 64 characters with the aim of establishing character polarity and revising the diagnoses and species assignments of the genera Rutiodon and 'Pseudopalatus'. The analysis generated a tree topology which, in its general structure, has changed relatively little in subsequent analyses. 'Paleorhinus' and Angistorhinus were recovered at the base of Phytosauria, and a polytomy of taxa which Ballew synonymized into Rutiodon was recovered as the sister taxon to a clade consisting of Nicrosaurus, 'Pseudopalatus' and Mystriosuchus (Fig. 1A). Ballew's phylogeny (Fig. 1A) was used as a basis for Long \& Murry (1995) to present a comprehensive taxonomic review of Phytosauria, including the erection of three new genera ('Arganarhinus', Smilosuchus, 'Arribasuchus') and the identification of numerous new anatomical characters with potential taxonomic or phylogenetic significance. No numerical phylogenetic analysis or phylogenetic tree was presented, but based on the identification of novel characters a taxonomy was constructed, differing from the phylogeny of Ballew (1989) most importantly in the separation of the taxa included in Rutiodon by Ballew into Leptosuchus Case, 1922 and the new genus Smilosuchus, and in the basal position of Mystriosuchus as the sister taxon to 'Paleorhinus' (previously suggested by Gregory [1962a] and Hunt \& Lucas [1989]). Hungerbühler (1998) increased taxonomic sampling, including 22 species-level OTUs, and presented a largely novel matrix of 49 characters, of which 12 were based on or reused from previous studies (Ballew, 1989; Long \& Murry, 1995). The aims were twofold: to test the concept of a monophyletic 'Paleorhinus' (Ballew, 1989; Hunt \& Lucas, 1991; Long \& Murry, 1995), and to more thoroughly assess the phylogenetic position of Mystriosuchus. 'Paleorhinus' was found to be paraphyletic, with the species previously assigned to the genus recovered as a 
105 grade of iteratively more derived taxa at the base of Phytosauria. In agreement with Ballew

106 (1989; Fig. 1A), Mystriosuchus was found in a more derived position than 'Paleorhinus', but

107 nested as the sister taxon to 'Pseudopalatus' rather than within this genus (Fig. 1B).

108 A substantially revised version of Hungerbühler's (1998) matrix was used by

109 Hungerbühler (2002) to further investigate the relationships of Mystriosuchus and assess the

110 phylogenetic position of the newly described species Mystriosuchus westphali. Sampling was

111 reduced to 11 taxa and 47 characters (16 taken from the previous study), to focus the analysis on

112 the clade formed of Nicrosaurus, Mystriosuchus and 'Pseudopalatus', named 'Pseudopalatinae'

113 by Long \& Murry (1995). Mystriosuchus was again recovered as the sister taxon to

114 'Pseudopalatus'; additionally, the genus 'Redondasaurus' was found to be monophyletic and

115 outside of 'Pseudopalatus', contra Hungerbühler, Chatterjee \& Cunningham (2003), but closer to

116 the latter taxon than to Mystriosuchus. Nicrosaurus was recovered as the sister-taxon of the

117 Mystriosuchus + ('Redondasaurus' + 'Pseudopalatus') clade (Fig. 1C).

118 The matrix of Hungerbühler (2002) was subsequently used to test the phylogenetic

119 position of 'Pseudopalatus' jablonskiae by Parker \& Irmis (2006). This taxon was the only

120 addition to the matrix and was found to occupy the most basal position in the genus

121 'Pseudopalatus', with no other changes in tree topology (Fig. 2A).

122 In order to better resolve the relationships of the stratigraphically important genus

123 Leptosuchus (Camp, 1930; Hunt \& Lucas, 1991; Lucas, 2010) and other associated taxa

124 (including those that were synonymized into Rutiodon by Ballew 1989), Stocker (2010)

125 produced a largely novel matrix, incorporating three characters from the matrix of Sereno

126 (1991), and 18 either taken or modified from Hungerbühler (2002). The full matrix consisted of

12743 characters scored for 24 OTUs and found Leptosuchus to be polyphyletic, with 'Leptosuchus' 
128 adamanensis forming a monophyletic group with Smilosuchus gregorii and 'Machaeroprosopus'

129 lithodendrorum (Fig. 2B). As a result, 'Leptosuchus' adamanensis and 'Machaeroprosopus'

130 lithodendrorum were reassigned to the genus Smilosuchus. Rutiodon was not found to be

131 synonymous with Angistorhinus, Brachysuchus or Leptosuchus, contra Ballew (1989), Long \&

132 Murry (1995) and Hungerbühler \& Sues (2001). The new genus and species Pravusuchus hortus

133 was recovered as the sister taxon to 'Pseudopalatinae', and 'Paleorhinus' scurriensis Langston,

1341949 was found to occupy the most basal position within Phytosauria (Fig. 2B).

135 Following this, Stocker $(2012,2013)$ presented two further studies in which she first

136 described the new taxon Protome batalaria and then redescribed 'Paleorhinus' scurriensis,

137 assigning the latter to the new genus Wannia. Phylogenetic aspects of both studies were based on

138 the dataset of Stocker (2010) with no changes or additions. In the latter study, Stocker (2013)

139 provided further discussion questioning the existence of a monophyletic 'Paleorhinus',

140 supporting the findings of Hungerbühler (1998; Fig. 1B).

141 Although not a phylogenetic study, an important taxonomic alteration was made by

142 Parker, Hungerbühler \& Martz (2012). The genus name Machaeroprosopus was previously

143 considered invalid because the sole specimen of its presumed type species (Machaeroprosopus

144 validus, UW 3807) has been lost (Gregory, 1962a); however, Parker, Hungerbühler \& Martz

145 (2012) established that the holotype specimen of the species Machaeroprosopus buceros actually

146 takes priority. The species Machaeroprosopus buceros was initially assigned to the genus

147 'Belodon', but subsequently made the type species of the genus Metarhinus (Jaekel, 1910);

148 however, when this genus was found to be preoccupied, a replacement genus,

149 Machaeroprosopus, was erected by Mehl (1915). Inexplicably, the species Machaeroprosopus

150 validus was long used as the genotype of Machaeroprosopus despite Machaeroprosopus buceros 
151 having priority. As the holotype specimen of Machaeroprosopus buceros is readily available to

152 study, the genus Machaeroprosopus was considered valid by Parker, Hungerbühler \& Martz

153 (2012), with the type species being Machaeroprosopus buceros. Furthermore,

154 Machaeroprosopus buceros has been recovered frequently as the sister taxon to 'Pseudopalatus'

155 pristinus, the type species of 'Pseudopalatus', and has taxonomic priority over that species. As a

156 result, all of the species previously assigned to 'Pseudopalatus' were reassigned to

157 Machaeroprosopus by Parker, Hungerbühler \& Martz (2012). The clade 'Pseudopalatinae' was,

158 however, retained, as its usage lies outside of the remit of the ICZN, although it has subsequently

159 been replaced by Mystriosuchini (see below, but see Martz \& Parker, 2017).

160 The monophyly of the newly diagnosed Machaeroprosopus with respect to

161 'Redondasaurus' was tested by Hungerbühler et al. (2013); the two species of 'Redondasaurus'

162 were previously found to nest paraphyletically within Machaeroprosopus (Hungerbühler,

163 Chatterjee \& Cunningham, 2003). The primary purpose of the analysis was, however, to test the

164 phylogenetic position of the newly described species Machaeroprosopus lottorum. Taxonomic

165 sampling was restricted to 12 OTUs, focussing on the group 'Pseudopalatinae', and 41 characters

166 of which 21 were to some extent based on characters from previous studies (Hungerbühler, 1998;

167 2002; Stocker, 2010). 'Redondasaurus' was found to be paraphyletic and nest within

168 Machaeroprosopus (Fig. 2C), contra Hungerbühler (2002; Fig. 1C) and Parker \& Irmis (2006;

169 Fig. 2A). Machaeroprosopus lottorum was also found to nest within Machaeroprosopus,

170 bridging the gap between the more derived species and specimens previously referred to

171 'Redondasaurus' and the specimens traditionally belonging to Machaeroprosopus.

172 Finally, two further studies were carried out based on the matrix of Stocker $(2010,2012$,

173 2013), both with the aim of redescribing basal phytosaur taxa previously assigned to 
174 'Paleorhinus' and elucidating the relationships of basal phytosaurs. Butler et al. (2014)

175 redescribed the taxa 'Paleorhinus' angustifrons (Kuhn, 1936) (formerly 'Francosuchus') and

176 Ebrachosuchus neukami Kuhn, 1936, and established a robust set of synapomorphies (which

177 were incorporated into the phylogenetic data matrix) to diagnose a revised, restricted definition

178 of 'Paleorhinus' that included the species 'Paleorhinus' bransoni and 'Paleorhinus'

179 angustifrons (Fig. 3A).

180 Kammerer et al. (2015) produced a redescription of Parasuchus hislopi Lydekker, 1885

181 and found it to be the sister taxon to 'Paleorhinus' angustifrons, supported by two unambiguous

182 synapomorphies. Given the designation by the ICZN of a neotype for Parasuchus (Chatterjee,

183 2001; ICZN, 2003), this genus takes priority over 'Paleorhinus' as the senior synonym. As a

184 result, all species in the monophyletic 'Paleorhinus' group were reassigned to the genus

185 Parasuchus (Fig. 3B). Kammerer et al. (2015) also presented an update to phytosaur family-level

186 and subfamily groups, including the following groups, from most inclusive to most exclusive:

187 Parasuchidae Lydekker, 1885, Mystriosuchinae von Huene, 1915 (formerly Phytosauridae

188 Jaeger, 1828), Leptosuchomorpha Stocker, 2010, and Mystriosuchini von Huene, 1915 (formerly

189 'Pseudopalatinae' Long \& Murry, 1995 [sensu Parker \& Irmis, 2006]). For consistency, the

190 nomenclature used by Kammerer et al. (2015) is used henceforth throughout this study, with

191 some minor modification to phylogenetic definitions (Table 2; see below).

192

193 Current consensus. Following the revision conducted by Kammerer et al. (2015), phytosaurs

194 are currently considered to fall into five successively less inclusive groups: Phytosauria,

195 Parasuchidae, Mystriosuchinae, Leptosuchomorpha and Mystriosuchini (Table 2). 
Phytosauria Jaeger, 1828, is a stem-based clade which encompasses all phytosaurs.

197 Previously the membership of the groups Phytosauria and Parasuchidae overlapped completely

198 (Kammerer et al., 2015); however, since the re-evaluation of Diandongosuchus (Stocker et al., 199 2017) this taxon has been included within Phytosauria, but excluded from Parasuchidae.

200 However, this placement remains untested in any analysis of ingroup phylogeny to date.

201 Parasuchidae Lydekker, 1885 (Chatterjee, 1978; Kammerer et al., 2015) contains the

202 basal genera Parasuchus, Ebrachosuchus and Wannia, plus all phytosaurs belonging to

203 Mystriosuchinae, Leptosuchomorpha and Mystriosuchini. Following the work of Stocker (2013),

204 Wannia has consistently been recovered as the most basal phytosaur within Parasuchidae (Fig.

205 2B), being distinct from the more derived Parasuchus clade defined by Butler et al. (2014) and

206 Kammerer et al. (2015). The latter two studies also recovered Ebrachosuchus in a more derived

207 position than Parasuchus (Fig. 3A,B).

208 Mystriosuchinae von Huene, 1915 excludes basal phytosaurs, being defined as 'the last 209 common ancestor of Mystriosuchus planirostris (Meyer, 1863) and Angistorhinus grandis Mehl, 2101913 and all of its descendants' (Kammerer et al., 2015), and is largely equivalent to

211 Phytosauridae of previous analyses. In addition to Leptosuchomorpha and Mystriosuchini, this 212 group may also contain taxa previously synonymized with 'Paleorhinus', such as 'Paleorhinus' 213 sawini, and other genera, including Rutiodon, Angistorhinus, Brachysuchus, and Protome. The 214 relationships between Angistorhinus, Brachysuchus and 'Paleorhinus' sawini are unresolved, but 215 all of these taxa have been recovered as more derived than Parasuchus and basal to Rutiodon and 216 Protome, with the latter two taxa being placed in a polytomy together with Leptosuchomorpha 217 (Figs. 2B, 3A,B). 

ancestor of Leptosuchus studeri and Machaeroprosopus pristinus and all descendants thereof'. phylogenetic results, and include 'Smilosuchus' lithodendrorum as an additional internal specifier to ensure that minor topological rearrangements between taxa that have consistently been considered as leptosuchomorphs do not jeopardize the stability of the clade. Therefore, in addition to members of Mystriosuchini, Leptosuchomorpha contains all species of Leptosuchus and Smilosuchus, as well as probably the taxa 'Phytosaurus' doughty and Pravusuchus hortus. Leptosuchus has been supported as monophyletic by recent analyses, though its possible relationship with 'Phytosaurus' doughty is unresolved. Smilosuchus has also been supported as monophyletic, and recovered as the sister taxon to Pravusuchus + Mystriosuchini. defined by Kammerer et al. (2015) as 'the last common ancestor of Mystriosuchus planirostris and all of its descendants'. We modify this definition here by excluding Nicrosaurus kapfii from the list of internal specifiers and introducing Machaeroprosopus jablonskiae as a replacement to maximize the taxonomic stability of Mystriosuchini among the trees recovered here (Table 2; see below). Mystriosuchini is largely synonymous with 'Pseudopalatinae' Long \& Murry (1995), defined phylogenetically by Parker \& Irmis (2006), with the exception of the inclusion of Mystriosuchus and the possible exclusion of Nicrosaurus. Although a basal position of Mystriosuchus within Phytosauria, such as positioned as the sister taxon to 'Paleorhinus', has been suggested in multiple studies (Gregory 1962a; Hunt \& Lucas, 1989; Long \& Murry, 1995), 
241 Mystriosuchus within Mystriosuchini has been found in all cladistic analyses thus far (Ballew,

242 1989; Hungerbühler, 1998; 2002; Parker \& Irmis, 2006; Stocker, 2010; 2012; 2013;

243 Hungerbühler et al., 2013; Butler et al., 2014; Kammerer et al., 2015), and therefore seems

244 relatively uncontroversial. The position of Mystriosuchus with respect to other taxa in

245 Mystriosuchini is less well resolved, as discussed below. The European genus Nicrosaurus has

246 been included within Mystriosuchini (Long \& Murry, 1995; Parker \& Irmis, 2006; Kammerer et

247 al., 2015); however, the validity of this is also discussed below. The remainder of Mystriosuchini

248 consists of species referred to Machaeroprosopus and 'Redondasaurus', the relationships of

249 which also differ between studies.

250

251 Current uncertainties. Although Rutiodon has been consistently found close to, but in a more

252 derived position than, Angistorhinus, this relationship has been tested in only three relatively

253 independent matrices (Ballew, 1989; Hungerbühler, 1998; Stocker, 2010), of which the two

254 earliest contain potential problems, including the use of parsimony uninformative characters, and

255 the outgroup taxon representing homoplastic, rather than ancestral morphology. It has previously

256 been suggested that Angistorhinus and Rutiodon may be synonymous (Hungerbühler \& Sues,

257 2001), although this has never been explicitly tested or fully published.

258 Aside from the study of Hungerbühler (1998), Angistorhinus has only been used as a

259 generic-level OTU, or represented by a single species (Kammerer et al., 2015). Kammerer et al.

260 (2015) used Angistorhinus grandis to score the genus; however, no further discussion of

261 relationships within the genus was presented. The systematics of the genus Angistorhinus are

262 another important area which is currently poorly understood within phytosaurs. 
264 and was used as a reference taxon in the previous phylogenetic definition of the group

265 (Kammerer et al., 2015; Table 2); however, only the early studies of Ballew (1989) and

266 Hungerbühler (1998) have tested this position. Nicrosaurus has been included in two other

267 relatively independent analyses (Hungerbühler, 2002; Hungerbühler et al., 2013); however, the

268 aims of these studies did not necessitate the inclusion of taxa from outside of Mystriosuchini, and

269 therefore the position of the genus within global phytosaur phylogeny was not tested. Therefore,

270 although the position of Nicrosaurus has not been contested, it is also not especially well

271 supported by available data.

272

The position of Mystriosuchus within Mystriosuchini remains unclear, having been

273 placed as either sister to the clade of Machaeroprosopus + 'Redondasaurus' (Hungerbühler,

274 1998; 2002; Parker \& Irmis, 2006; Hungerbühler et al., 2013) or nested within

275 Machaeroprosopus (Ballew, 1989; Stocker, 2010; Butler et al., 2014; Kammerer et al., 2015).

276 As the genus name Mystriosuchus Fraas, 1896 has priority over Machaeroprosopus Mehl, 1915,

277 this later relationship may have extensive taxonomic implications.

278 In multiple studies 'Redondasaurus' has been found to nest within Machaeroprosopus

279 (Ballew, 1989; Hungerbühler, Chatterjee \& Cunningham, 2003; Stocker, 2010; Hungerbühler et

280 al., 2013; Butler et al., 2014; Kammerer et al., 2015), whereas in others 'Redondasaurus' is

281 monophyletic to the exclusion of Machaeroprosopus (Hungerbühler, 1998; 2002; Parker \&

282 Irmis, 2006). In the most recent phylogeny of derived phytosaurs (Hungerbühler et al., 2013),

283 'Redondasaurus' was found to nest within Machaeroprosopus and the two were tentatively

284 synonymized, but this hypothesis requires further testing. 
286

287

288

289

290

291

292

293

294

295

296

297

298

299

300

301

302

303

304

305

306

307

308

\section{Materials \& Methods}

\section{Institutional abbreviations}

AMNH: American Museum of Natural History, New York, USA; GPIT: Institut für Geologie und Paläontologie Tübingen, Tübingen, Germany; KU: University of Kansas, Lawrence, USA; MB: Museum für Naturkunde, Berlin, Germany; MNHN: Muséum National d'Histoire Naturelle, Paris, France; MU: University of Missouri, Columbia, Missouri, USA; NHMW: Naturhistorisches Museum Wien, Vienna, Austria; NMMNHS: New Mexico Museum of Natural History and Science, Albuquerque, USA; OMNH: Oklahoma Museum of Natural History, Norman, USA; PEFO: Petrified Forest National Park, Arizona, USA; SMNS: Staatliches Museum für Naturkunde Stuttgart, Stuttgart, Germany; TMM: Texas Memorial Museum, Austin, USA; TTU-P: Museum of the University of Texas Tech, Lubbock, USA; UCMP: University of California Museum of Paleontology, Berkeley, USA; UMMP: University of Michigan Museum of Paleontology, Ann Arbor, USA; USNM: National Museum of Natural History, Washington D.C., USA; UW: University of Wisconsin Geological Museum, Madison, USA; YPM: Yale Peabody Museum, New Haven, USA.

\section{Material}

The analysis presented here uses species as OTUs to facilitate comparison with previous phylogenetic analyses. There has been recent interest in specimen-level phylogenetic analyses in vertebrate palaeontology (e.g., Upchurch, Tomida \& Barrett, 2004; Tschopp, Mateus \& Benson, 2015), but the validity of this approach and its results remain largely unexplored. We did not use a specimen-level phylogeny here as it would be hampered by the range of intraspecific variation 
309 found in most taxa, and would be further compounded by poor preservation in many specimens

310 resulting in high quantities of missing data and widespread polytomies due to unstable terminals.

311 The OTUs included in this analysis consist of 34 species across 18 genera which are fully

312 detailed in Appendix 1. An additional nine specimen level OTUs were also included to test their

313 affinities. We attempted to sample all phytosaur species currently regarded as taxonomically

314 valid or potentially taxonomically valid, with the exception of a number of problematic species

315 that were excluded for reasons discussed below. Euparkeria capensis was used to root the

316 analysis as it displays a generalized archosauriform cranial morphology (Sookias, 2016) which

317 has been used in previous studies for character polarization (Hungerbühler, 2002; Parker \&

318 Irmis, 2006; Stocker, 2010; 2012; 2013; Butler et al., 2014; Kammerer et al., 2015).

319 Diandongosuchus fuyuanensis, a taxon from the Middle Triassic of China initially identified as a

320 basal poposauroid (Li et al., 2012), was recently re-interpreted as the basal-most phytosaur

321 currently known (Stocker et al., 2017) and is therefore included in this analysis to verify its basal 322 position within Phytosauria.

Of the 43 OTUs included in this analysis, 39 were scored based on first-hand study of at

324 least one of the referred specimens. Photographs and published descriptions and figures were

325 also used where available. The remaining four terminals (Leptosuchus studeri, Diandongosuchus

326 fuyuanensis, Euparkeria capensis and Parasuchus hislopi) were not studied first hand for the

327 purposes of this study, and were scored from photographs and/or published descriptions and

328 figures.

329

330

Excluded taxa 
331 Although this analysis was designed to be the most comprehensive cladistic dataset for

332 phytosaurs to date, a small number of taxa were excluded for various reasons. very briefly described in the original paper, and a holotype was not formally designated, despite apparently consisting of a large skull and much of the postcrania of a single phytosaur. When ASJ visited the University of Missouri this material could not be found; however, it may be located in one of many footlockers containing the 'Mehl collection' in the basement of the department (James Schiffbauer, pers. comm. to ASJ, 2016). At present this material is considered lost with no images available other than a line drawing of the antorbital region and two photographs of an anterior thoracic vertebra (Mehl, 1915); because the proportion of missing data would likely hinder any analysis more than its inclusion would contribute, we excluded this taxon. a single skull (MU 531) from the top of the Popo Agie Formation in Wyoming. Long \& Murry (1995) noted apparent similarities between this species and Angistorhinus talainti from Morocco, but also suggested this material may represent a more derived taxon, not referable to Angistorhinus. They noted that determining the taxonomic affinities would require detailed study and the type material 'may be lost' (Long \& Murry, 1995:42). This material is also suspected to reside in the 'Mehl collection' of the University of Missouri. As this material is considered lost and no images exist aside from the five line drawings in Mehl (1928), it was excluded from analysis. skull, nine vertebrae, rib fragments and osteoderms (OMNH 733) from the Dockum Group of 
354 Texas. This species is differentiated from other Angistorhinus species primarily by the more

355 laterally directed orbits, the shape of the squamosal and the straight mediolateral frontal-parietal

356 suture (Stovall and Wharton, 1936). It has been suggested that the direction of the orbits should

357 be used cautiously due to taphonomic distortion (Gregory, 1962a; Hungerbühler, 1998) and is

358 'severely restricted' in practical use due to the difficulty in taking measurements and previous

359 scoring subjectivity (Hungerbühler, 1998: 130); therefore, a more detailed taxonomic analysis of

360 this specimen is required to verify its distinctness, which is beyond the scope of this study. Given

361 the incomplete nature of the type material, the range of better Angistorhinus material available to

362 study and the taxonomic uncertainty regarding its validity, A. alticephalus was excluded from

363 this study.

364 Angistorhinus aeolamnis Eaton, 1965 is known from a single skull, lacking

365 approximately its dorsal 50-80 millimetres (KU 11659) from the Dockum Group of Texas. As

366 far as can be seen from its original description, the skull does not preserve any of the features

367 indicative of the genus Angistorhinus, such as posterior parietal extensions or the parietal-

368 squamosal bars forming a posterolateral curve when viewed dorsally (Long \& Murry, 1995). The

369 loss of the dorsal part of the skull also greatly reduces the number of characters for which this

370 specimen could be scored, making it likely to be problematic in phylogenetic analysis; this

371 combined with its unclear taxonomic affinities leads us to exclude this taxon.

372

Brachysuchus megalodon Case, 1929 is a very robust taxon, represented by the largely

373 complete, but dorsoventrally crushed holotype skull (UMMP 10336), a likely associated

374 mandible (UMMP 10336a) and a second, well preserved, also largely complete skull (UMMP

375 14366), from the Dockum Group of Texas. B. megalodon has historically been a difficult taxon

376 to interpret, being synonymized with 'Phytosaurus' (Gregory, 1962a) and Angistorhinus (Long 
377 and Murry, 1995) before being provisionally resurrected by Stocker (2010) pending a full

378 reanalysis of the taxon. B. megalodon is excluded here because the material was unavailable for

379 study due to the redevelopment of the UMMP museum. Although the original description by

380 Case is very detailed and contains many line drawings, it was deemed unfeasible to score such a

381 taxonomically problematic specimen that has been subjected to severe taphonomic distortion

382 from images alone, especially as the less distorted referred specimen has only ever been figured

383 in palatal view (Case \& White, 1934).

'Machaeroprosopus validus' Mehl et al., 1916 was erected on the basis of an incomplete

385

386

387

388

389

390

391

392

393

394

395

396

397

398

skull (UW 3807) from the Chinle Formation of Arizona. This specimen, which has been lost

(Westphal, 1979), was long considered to be the holotype specimen for the genus

Machaeroprosopus (Case, 1920; Camp, 1930; Colbert, 1947; Ballew, 1989; Hungerbühler,

1998). However, the holotype of Machaeroprosopus buceros was recently found to take priority

(Parker, Hungerbühler \& Martz, 2012). Considering the loss of the only specimen and its now

decreased taxonomic significance and uncertain taxonomic position this taxon is here excluded.

Mesorhinosuchus fraasi (Jaekel, 1910) was named based on a single partial skull,

reportedly from the Middle Buntsandstein of Saxony-Anhalt, Germany. The supposed type

locality is dated as Olenekian in age, making this potentially the stratigraphically oldest

phytosaur, and predating even Diandongosuchus by approximately 10 million years. The

specimen, which was housed at the University of Göttingen, was destroyed in WWII and only

one photograph exists in the original description by Jaekel (1910); moreover, its stratigraphic

provenance has frequently been questioned (Gregory, 1962a; 1969; Hunt and Lucas, 1991). In

any case this species is excluded due to the loss of the type specimen.

Peer] reviewing PDF | (2018:04:27659:2:0:NEW 4 Oct 2018) 

anteroposterior length) juvenile skull (MNHN ALM 1) from the Argana Formation of Morocco. It was originally described as a unique species of 'Paleorhinus' due to (among other features) its

402

403

404

405

406

407

408

409

410

411

412

413

414

415

416

417

418

419

420

proportionately enormous orbits and small antorbital fenestrae; however, these putative

autapomorphies were later reinterpreted as a reflection of the early ontogenetic stage of the type specimen (Fara and Hungerbühler, 2000) and the species was reclassified as an indeterminate specimen of Parasuchus, a view that is shared in this study (but see Kammerer et al., 2015). This taxon is therefore excluded from this study because the inclusion of ontogenetically variable features could affect its phylogenetic placement, as has been extensively reported in dinosaurs (Rozhdestvensky, 1965; Dodson, 1975; Sampson, Ryan \& Tanke, 1997; Scanella \& Horner, 2010; Tsuihiji et al., 2011).

Promystriosuchus ehlersi (Case, 1922) is known from a poorly preserved partial skull from the Dockum Group in Texas (UMMP 7487). The specimen displays extensive dorsoventral crushing with many elements not retaining their original associations; as such, it is a difficult specimen to interpret. It has previously been referred to 'Paleorhinus' (=Parasuchus) (Gregory, 1962a; Hunt and Lucas, 1991; Long and Murry, 1995), but more recently its taxonomic position has been seen as uncertain (Kammerer et al., 2015). As with B. megalodon the sole specimen of this taxon was unavailable for study, and it represents a taxonomically uncertain specimen with challenging morphology and few images available in the literature; for these reasons Promystriosuchus ehlersi is not included in this study.

\section{Continuous data in cladistics}


421 The use of continuous characters in cladistics has historically been controversial, with many

422 researchers questioning their validity and appropriateness to cladistic methods (Crisp \& Weston,

423 1987; Pimentel \& Riggins, 1987; Cranston \& Humphries, 1988; Felsenstein, 1988; Stevens,

424 1991). The majority of concerns raised have been around the discretization of frequently

425 overlapping taxonomic ranges of continuous measurements into distinct character states using

426 methods often criticized as arbitrary (Poe \& Wiens, 2000).

427 Indeed, techniques such as gap-coding (Mickevich \& Johnson, 1976) and segment-coding

428 (Thorpe, 1984; Chappill, 1989) do suffer from elements of arbitrariness: in gap-coding the size

429 of the fundamental gap, and in segment-coding the number of segments, must be specified by the

430 researchers (Rae, 1998). These metrics may be based on various statistical concepts, such as 95\%

431 confidence intervals or standard deviations about the mean, and data may be treated on a linear

432 or logarithmic scale; however, as shown by Gift \& Stevens (1997) the choice of which metric to

433 use can have a profound effect on the final character states.

434 Despite the general rejection of continuous data by many authors, continuous ranges of

435 overlapping data have remained common in cladistic matrices, scored via character states with

436 arbitrary 'discrete' cutoffs, which are generally not explained or justified, e.g., 'ratio of femoral

437 length to width: $<6[0], \geq 6$ [1]', or 'shape of orbit: circular [0], oval [1]' (Stevens, 1991; Poe \&

438 Wiens, 2000; Wiens, 2001). These arbitrary character states have been shown to convey little

439 phylogenetic information compared to identical data ranges coded using gap-weighting (Garcia-

440 Cruz \& Sosa, 2006). Despite this, these types of characters are frequently found in modern

441 cladistic datasets, including recent analyses of phytosaur phylogeny (Hungerbühler, 2002;

442 Hungerbühler et al., 2013; Parker \& Irmis, 2006; Stocker, 2010; 2012; 2013; Butler et al., 2014;

443 Kammerer et al., 2015). This study aims to incorporate continuous morphological data, including 
444 that of 'shape', characterized in a non-arbitrary manner to increase the quantity of

445 phylogenetically useful information available to studies of phytosaur systematics, with the goal

446 of increasing their accuracy and resolution.

447 As expressed above, the main problem with many continuous coding techniques is the

448 arbitrary splitting of range data into discrete character states. The software package TNT

449 overcomes this problem by employing a similar technique to gap-weighting (Thiele, 1993) and

450 step-matrix gap-weighting (Wiens, 2001). Gap-weighting splits the range of species mean values

451 into as many character states as allowed by the software (32 in PAUP*), thus increasing coding

452 resolution and (as the characters are ordered) ensuring large changes must pass through many

453 steps in comparison to small changes, thus increasing their weight. This technique is, however,

454 hampered by the limits imposed by the software. Step-matrix gap-weighting follows a similar

455 initial procedure, but circumvents the limit on character weighting by using the sizes of the gaps

456 between unique character states, rescaled along a range from zero to the maximum steps allowed

457 by the software (1000 in PAUP*), to create step-matrix values to weight character state changes.

458 Although gap-weighting provides a higher resolution of states into which measured variation can

459 be categorized, the categorization method is still fundamentally arbitrary and, due to this, taxon

460 ranges that are significantly different may be grouped together and those that are statistically

461 identical may be split up (Farris, 1990).

462 The techniques developed in TNT (Goloboff, Mattoni \& Quinteros, 2006; Goloboff,

463 Farris \& Nixon, 2008b), and used in this study, remove arbitrary discretization by analysing the

464 taxon range values as they are, i.e. without being grouped into character states. This is possible

465 through the use of Farris' (1970) down-pass and Goloboff's (1993) up-pass algorithms which are

466 designed to use numerical differences between the states being optimized; therefore, the actual 
467 intervals between taxon data ranges, being numerical, are treated in the same way as ordered

468 character states (Goloboff, Mattoni \& Quinteros, 2006). As mentioned in Goloboff, Mattoni \&

469 Quinteros (2006), step-matrix gap-weighting would produce the same outcome as the TNT

470 technique; however, this approach becomes difficult with a large number of taxa and is not

471 capable of handling ranges of variation. As the scale of the step changes, and therefore weights,

472 are directly proportional to the measured data, the magnitude on which the original

473 measurements were made could have a large (and often unwarranted) influence on character

474 weighting. Goloboff, Mattoni \& Quinteros (2006) suggested that implied weighting (re-

475 weighting of characters based on their level of homoplasy) can reduce this issue, however, this

476 was found to be only a partial solution and a combination of implied weighting and re-scaling

477 trait measurement values to unity produced far more satisfactory results (Koch, Soto \& Ramírez, 478 2015).

\section{Geometric morphometric data}

481 Geometric morphometric (GM) characters are a relatively new development in cladistics

482 (Catalano, Goloboff \& Giannini, 2010; Goloboff \& Catalano, 2011; Goloboff et al., 2016). In

relation to phylogenetics, the use of geometric morphometrics tends to be equated with phenetic

484 studies and the use of techniques such as principal components analysis to reduce overall

485 morphology to a small number of axes of covariation. The method presented by Catalano,

486 Goloboff \& Giannini (2010) avoids this: x, y and z landmark coordinates are used, without

487 transformation, to generate ancestral state reconstructions using a spatial optimization technique

488 which minimizes displacement between individual, or configurations of, landmarks from two

489 descendants. A thorough discussion of the applicability of geometric morphometrics in 
490 phylogeny is given by Catalano, Goloboff \& Giannini (2010) in which previous arguments 491 against its use are also addressed. When integrated into a phylogenetic analysis of Vespinae

492 (Perrard, Lopez-Osorio \& Carpenter, 2015), landmark characters were generally found to 493 improve tree resolution when combined with a morphological character matrix. Landmark 494 characters still exerted a noticeable effect with the addition of molecular data, though only four 495 of the ten relationships generated by landmark data were supported in the morphological + 496 landmark + molecular data trees (Perrard, Lopez-Osorio \& Carpenter, 2015). In these trees the 497 landmark data mostly affected poorly supported nodes - allowing greater resolution, though 498 possibly only due to over-resolution due to the analysis techniques. It was also found that the landmark data alone were insufficient to reliably resolve relationships, likely due to homoplasy 500 arising from the functional unit in which the landmark characters were placed (Perrard, Lopez-

501 Osorio \& Carpenter, 2015). Although the quantity of information may be increased by using 502 landmark characters, not all information is included, which could lead to important features 503 being excluded.

505 Character coding

506 The character list (Appendix 2) was constructed by combining those used in previous analyses 507 (Ballew, 1989; Hungerbühler, 2002; Stocker, 2010; Butler et al., 2014; Kammerer et al., 2015) 508 as well as by identifying new characters based on first-hand study of specimens and published 509 literature. In order to compare the effects of different character types on phylogenetic results, all 510 characters (including continuous and GM) were scored and input into one matrix, each character 511 type as a different data block. The resulting matrix contained three blocks of data: discrete 512 scores, continuous ranges and GM coordinates. Many of the continuous and GM characters were 
513 based on discrete characters from previous analyses, for which the categorization of character

514 states seemed inappropriate, e.g., for relative linear measurements of morphological features, or

515 complex morphologies. Therefore, some characters in the discrete data block are discrete

516 versions of continuous or GM characters. Some continuous and GM characters incorporated here

517 were novel; therefore, discrete versions of these were also created in the discrete data block to

518 ensure that where phylogenies were analysed using different data types, any differences in results

519 would not be affected simply by differences in the exact morphological information included.

520 The different combinations of character types were incorporated into different analyses by

521 setting either the continuous, GM, or both character blocks to 'active' or 'inactive' in the

522 phylogenetic software TNT (see below).

523 The number of characters and proportion of missing data in each data block are

524 summarized in Table S1. No characters were excluded based on quantity of missing data in

525 scored taxa as including more characters, even if this increases the proportion of missing data,

526 has been shown to increase accuracy in phylogenetic analysis (Wiens, 1998). This technique

527 increases the possibility of long branch attraction (Swofford et al., 1996), but is less likely in a

528 dataset where missing data is distributed randomly among all taxa (Poe \& Wiens, 2000); in our

529 dataset missing data seem more likely to occur in certain taxa and certain characters, therefore

530 the possibility of long branch attraction should be kept in mind when interpreting the results.

531 A consistent discrete matrix was used as a base for each analysis, into which continuous

532 or GM characters were swapped with their discrete counterparts. The discrete data block

533 consisted of 94 characters, the continuous block 10 characters and the GM block five characters.

534 These were combined in four analyses (Table 3): 1) discrete characters only (D coding treatment)

535 (94 characters, 21 of which are ordered), 2) discrete + continuous characters (DC coding 
536 treatment) (94 characters, 21 ordered), 3) discrete + GM (DM coding treatment) (90 characters,

537 as some GM characters encompass variation described by more than one character in the discrete

538 dataset; 19 ordered), 4) discrete + continuous + GM (DCM coding treatment) (90 characters, 19

539 ordered). A full list of all characters, ordering and the correspondences of continuous and GM to

540 discrete characters is available in Appendix 2. The coding procedures used here for continuous

541 and GM characters are described below, as are the methods of character state distinction for their

542 discretized counterparts.

543 It is important to note here that when incorporating continuous and geometric

544 morphometric character scorings for analysis, the format of the TNT data file requires these

545 characters to be presented first in the file. This differs from how the characters are ordered in our

546 character list (Appendix 2). Our character list presents characters in the order in which they

547 occur for the base discrete data block; where a character possesses a continuous or GM variant

548 this is flagged next to that character. It should also be noted that characters in a TNT file begin at 549 zero, whereas we shift our characters such that the list begins at one.

550

551 Continuous characters. Measurements were taken from all referred specimens with the

552 appropriate morphology preserved, either directly, using digital callipers, or from photographs,

553 using the software ImageJ. Standard error was calculated about the mean score of each species,

554 this was then used to calculate min-max species ranges with statistically meaningful differences

555 (Goloboff, Mattoni \& Quinteros, 2006). Min-max species range values were rescaled in each

556 character using the formula: $z_{i}=x_{i}-\min (x) / \max (x)-\min (x)$ where $z_{i}$ is the rescaled value, $x_{i}$ is

557 the original value and $\min / \max (x)$ are respectively the minimum and maximum original values in

558 the range of variation across all taxa for that character. This rescales values onto a $0-1$ scale, 
559 ensuring that magnitudes of interspecific differences within characters are maintained, whilst

560 between-character weighting is standardized. The rescaled range values (and where only one

561 specimen is known, the single values) were input into the data matrix file and treated as ordered.

562

563 GM characters. Many features of phytosaur skulls that are appropriate for shape analysis

564 contain few discrete landmark positions, making traditional landmark analysis difficult, and the

565 resolution of the morphology influencing the results would be poor. For example, only two

566 sutures regularly form connections on the border of the antorbital fenestra that could be

567 landmarked in all phytosaurs, and due to the variable shape of the fenestra there are no consistent

568 'corners' or other morphological features that can be traditionally landmarked on the border,

569 aside from the most anterior and posterior extremities. Conversely, these problems can be

570 resolved by using sliding semi-landmarks to approximate outline shape; this is the technique

571 used here. In techniques such as principal components analysis, semi-landmarks require special

572 treatment, on account of their reduced dimensionality and therefore degrees of freedom

573 (Bookstein, 1996; Zelditch, Swiderski \& Sheets, 2012); however, as TNT does not use such

574 analyses and providing the user employs appropriate Procrustes alignment techniques, nothing

575 precludes their use. Semi-landmarks were digitized from photographs using the 'Draw

576 background curves' tool in the software tpsDig2 (Rohlf, 2015) to capture a detailed outline of the

577 structure; this was then resampled to contain a consistent number of equally spaced points which

578 were used for alignment. See Fig. S1 for configurations of landmarks in GM characters. Semi-

579 landmarks were subjected to sliding and Procrustes superimposition to minimize distances

580 between configurations using the R package Geomorph (Adams \& Otarola-Castillo, 2013). In

581 TNT, landmark configurations were scaled to unity using the command 'lmark rescale =*;'. 
582 Whole configurations of landmarks were used for optimization and to calculate support values,

583 rather than a pairwise approach with each individual landmark, as semi-landmarks define curves

584 and not homologous points.

585

586 Discrete characters. Characters consisting of continuous measurements such as ratios were

587 discretized into character states using primarily quantitative, but also qualitative approaches; all

588 measurements from all referred specimens were sorted numerically and character state divisions

589 were introduced where gaps occurred in their sequence. Where no substantial gaps occurred

590 character states were introduced at points between substantial transitions in the data. For

591 example: in a hypothetical dataset of four taxa, A-D, each represented by four specimens which

592 all occupy a $0-10$ continuous scale for one of their characters, if all or a substantial majority of

593 specimens from taxa A and B sit between zero and five, whereas those of taxa C and D sit

594 between five and ten, the continuous character range would be divided into two character states

595 at number five. This therefore splits the continuous range into discrete states in the absence of

596 gaps.

597 This treatment was designed to mimic the presumably qualitative techniques for dividing

598 continuous data into discrete states used in previous analyses (although the delimitation

599 technique has never been described in any previous phytosaur phylogeny), and represents a

600 similar treatment to the 'arbitrary' method of Garcia-Cruz and Sosa (2006). Discrete characters

601 used as counterparts to implicitly ordered continuous characters were also treated as ordered.

602 This means that different topologies resulting from different combinations of character types

603 reflect changes in character coding approach rather than differences in the approach to character

604 ordering. 
606 Implied weighting. Implied weighting (Goloboff, 1993) is a method of character weighting in

607 which the number of step changes a character undergoes in its current tree topology is compared 608 to the minimum possible for that character, as a metric for homoplasy. Each character in a tree 609 topology is then weighted in inverse proportion to its level of homoplasy, with a concavity 610 constant $(\mathrm{k})$ ascribing the severity of weighting. These weighted scores of 'character fit' are then 611 summed to provide an estimate of character fit for the whole tree; each tree topology in the 612 analysis undergoes the same procedure, with the 'best' overall tree(s) having the best character 613 fit score. We primarily use implied weights here for its apparent advantages in the analysis of 614 matrices high in homoplasy (Goloboff et al., 2008a); a problem well-recognized in Phytosauria 615 (Hungerbühler, 1998, 2002). Although implied weighting has been criticized recently (Congreve $616 \&$ Lamsdell, 2016) it does also have advantages when using continuous and GM character 617 scorings. Continuous characters may be measured on different scales, and this difference in 618 scaling is transferred to a character's step-matrix (arbitrarily increasing the impact of 'large619 scale' characters); accordingly, homoplasy in characters measured on large scales tends to be 620 greater and these characters are thus down-weighted in proportion with this (Goloboff, Mattoni

$621 \&$ Quinteros, 2006). In this study we further address issues of scaling by standardizing 622 continuous character ranges into a $0-1$ range, as described above. Implied weighting also 623 provides a method for weighting landmark-based characters and can be performed either for each 624 individual landmark within a configuration or for whole configurations using the average 625 homoplasy. The latter method is particularly useful in this study as we use semilandmarks; as 626 such the individual landmarks do not necessarily represent homologous points, rather it is the 
627 overall structure that is important - it is therefore the whole configuration of landmarks that

628 should be treated as a single character for weighting.

629

630 Analyses

631 All analyses were performed in the software TNT version 1.5 (Goloboff \& Catalano, 2016),

632 under extended implied weighting with the concavity constant ' $\mathrm{k}$ ' set to vary for each character

633 depending on the quantity of missing entries (using 'xpiwe (*' commands).

634 Implied weighting requires the minimum possible length for each character coding in

635 order to calculate homoplasy; however, this is problematic in landmark data (Goloboff et al.,

636 2016). Therefore, TNT provides an option to find minimum values for each landmark using

637 heuristic searches; this search function was applied before analysing any dataset incorporating

638 GM characters, then the minima were added to the file for use during tree searching.

639 Furthermore, GM characters were each weighted separately according to the average homoplasy

640 of their landmark configuration (using 'xpiwe [' commands); therefore, weighting was based on

641 entire configurations rather than the sum of component landmarks, which as stated above, may

642 not be individually homologous.

643

644 Analysis parameters. Tree searches were performed using the new technology algorithms in

645 TNT: 10,000 random addition sequences, analysed using TBR swapping with 10 iterations of

646 drift and ratchet, followed by a sectorial search and finally three rounds of tree fusing. The

647 search was performed until the minimum tree length was hit five times. The duration of tree

648 searches dramatically increased with the addition of GM characters; therefore, only 200 random

649 addition sequences were used and minimum length was found only once. Furthermore, because 
650 landmark data is relatively unstructured the perturbation phases of ratchet and drifting can

651 produce trees that are 'too suboptimal' and therefore greatly increase the search time (Goloboff

652 et al., 2016). We therefore followed the suggestion of Goloboff et al. (2016) and increased the

653 drift 'xfactor' to 5, decreased the percentage of swapping to be completed to $90 \%$, decreased the

654 number of substitutions to 45, and for ratchet, lowered the probability of reweighting (both up

655 and down) to 3 and decreased the number of substitutions to 30 .

656 Bremer supports were calculated using 10,000 (D and DC) or 1000 (DM and DCM) trees

657 suboptimal by a fit of 10; branch swapping using TBR was performed and absolute supports

658 were calculated based on the results. Robusticity analysis was carried out using symmetric

659 frequencies, with TBR swapping beginning from 10 Wagner trees and 10,000 (D, DC) or 100

660 (DM, DCM) replicates. As the matrices including GM data were exceptionally computationally

661 heavy and time consuming, parameters were altered such that trees were accepted without

662 consideration of error margin during landmark searches and that swapping distance for branch

663 swapping was reduced (commands respectively: 'Imark errmarg 0' and 'bbreak : limit 5').

664

665 Output processing and comparisons. Where more than one tree of best character fit resulted

666 from an analysis, a strict consensus was generated. With implied weighting in effect, ties in tree

667 length (resulting in multiple best fitting trees) become very uncommon due to the use of floating-

668 point character-fit calculations. Additionally, continuous data are analysed as actual numerical

669 differences, rather than categorical steps, also reducing the chance of exact ties. To avoid over-

670 resolution due to the acceptance of a single or few trees showing only an extremely small

671 difference in character fit compared to other topologies, an arbitrary Bremer support cut-off

672 value of 0.08 was implemented, below which nodes were judged to be poorly supported and 
673 were collapsed. In addition a second cut-off value was used (0.11) which was equal to the

674 average step-length of a single character following weighting. This particular number was used

675 in an attempt to emulate the procedure common in phylogenetics, to collapse nodes with a

676 Bremer support of less than one step. These cut-offs were maintained throughout the four

677 treatments, allowing the effects on tree resolution to be compared.

678 Best character fit trees resulting from each of the four analyses using different

679 combinations of character data types (see above) were compared using several techniques. CI

680 and RI were compared to assess the homoplasy present in the trees resulting from each analysis.

681 Maximum agreement subtrees were constructed for each comparison to compare the number of

682 congruent relationships between the trees; this was supplemented with a strict consensus of the

683 two trees in case lower level congruence was masked in the agreement subtree by higher level

684 polytomies (Goloboff, Mattoni \& Quinteros, 2006). Subtree pruning and regrafting (SPR)

685 distances were calculated to find the minimum number of changes under the SPR search

686 algorithm required to convert one tree topology into the other - essentially a numerical

687 description of tree similarity. The rooted Robinson-Foulds (RF) distance, which measures the

688 differential presence/absence of phylogenetic relationships between trees, was also used to

689 measure tree-similarity.

690 The effect of each coding technique was assessed and compared to its alternative

691 counterparts in several ways. Trees were initially compared using mean and summed frequency

692 and Bremer supports across each collapsed tree, alongside the number of nodes retained after

693 collapsing each tree to get a broad view of any major differences. For a more detailed view of the

694 effects of data type on the nodal support each non-collapsed best fit tree was split into five tree-

695 regions; 1) the most basal portion of the tree, including all non-Mystriosuchinae members of 
696 Phytosauria; 2) the clade formed by Rutiodon and Angistorhinus; 3) Leptosuchus-grade taxa,

697 here composed of all Leptosuchus, Smilosuchus and Nicrosaurus species, plus PEFO 34852,

698 'Phytosaurus' doughtyi, Pravusuchus hortus and Coburgosuchus goeckeli; 4) all members of

699 Machaeroprosopus and 'Redondasaurus', plus USNM V 17098, NMMNHS P-4256, NMMNHS

700 P-31094 and Protome batalaria; 5) the clade composed of named species of Mystriosuchus plus

701 NHMW 198600240001 and MB.R. 2747. The mean frequency and Bremer supports were

702 calculated within each region to investigate the effects of different character coding techniques at 703 a greater resolution.

704 The support for monophyly of groups/taxa of interest was investigated by placing them in

705 alternative positions in a constraint tree, then re-running the analysis whilst imposing those

706 constraints and observing the effect on character fit in the resulting trees.

707 The accuracy of trees, as denoted by the various nodal support metrics and comparisons

708 described above, is a measure of internal consistency; regardless of a tree's accuracy it may still

709 be spurious. Stratigraphic congruence was used here as an independent estimate of tree-validity;

710 four metrics were employed which measure stratigraphic congruence differently. (1) The

711 stratigraphic consistency index (SCI) (Huelsenbeck, 1994) measures the proportion of nodes

712 within which the first appearance datum is of the same age or younger than the sister node; these

713 nodes are considered stratigraphically consistent. (2) The relative completeness index (RCI)

714 (Benton \& Storrs, 1994) reports the ratio between the sum of ranges for taxa in the tree and the

715 sum of ghost-range length within the tree. (3) The Manhattan stratigraphic measure (MSM*)

716 (Siddall, 1998; Pol \& Norell, 2001) optimizes the difference in age between the first appearances

717 of taxa (Manhattan distance) as a Sankoff character on the proposed tree. The MSM is the ratio

718 between the minimum possible tree length based on taxon ranges (topology determined by the 
719 Manhattan distance character), and the tree length when Manhattan distance is optimized to the 720 original topology. The MSM is basically the consistency index of the distance character (Pol \&

721 Norell, 2006). Pol \& Norell (2001) introduced a correction to prevent reversals in the Manhattan

722 distance character 'states', presenting the updated metric, MSM*. (4) The gap excess ratio

723 (GER) (Wills, 1999) finds the proportion of ghost range in a tree, relative to the minimum and

724 maximum possible sum of ghost ranges for the corresponding dataset. It also optimizes age range

725 differences on the tree in the same manner as the MSM*, but is calculated as the retention index

726 for the distance character (Pol \& Norell, 2006).

727 The 'strap' package (Bell \& Lloyd, 2014) for the software R version 3.2.5 (R Core Team,

728 2016) implements all the above metrics, and was used for all analyses of stratigraphic

729 congruence in this study. The strap package also implements a test of statistical significance for

730 each metric, based on random permutations. In calculating significance values we made use of

731 two additional options offered by strap: the first is to generate random trees by swapping OTUs,

732 whilst maintaining tree shape; the second is to fix the outgroup OTU such that it is not

733 randomized. These additions respectively resolve issues of random trees being more symmetrical

734 than commonly found in fossil groups (Wills, Barrett \& Heathcote, 2008), and the deliberate

735 assignment of the outgroup prior to analysis, removing the need for its position to be tested (Bell

$736 \&$ Lloyd, 2014). The random trees therefore provide a closer estimate of the original tree

737 topology and a more robust test of significance (Bell \& Lloyd, 2014). Primarily the P-values

738 from the significance tests are used here for comparisons of stratigraphic congruence, rather than

739 the raw metrics, as the latter are strongly influenced by tree balance, the arrangement of taxon

740 stratigraphic ranges and tree size (Siddall, 1996; Willis, 1999). The results of randomization tests 
741 are free from these influences and should therefore be more directly comparable (Wills, 1999;

742 Benton, Hitchin \& Wills, 1999).

743 In this study significance tests were carried out with 1000 random permutations. The

744

745

746

747

748

749

750

751

752

753

754

755

756

757

758

759

760

761

762

763 strict consensus trees resulting from the four data treatments were analysed, as were the three most recent alternative phylogenetic hypotheses of phytosaur relationships (Parker \& Irmis, 2006; Hungerbühler et al., 2013; Kammerer et al., 2015). Where a previous analysis included specimen-level OTUs or taxa not present in this study, these terminals were removed; three terminals were removed from the tree of Kammerer et al. (2015) and two from Hungerbühler et al. (2013). Three alternate hypotheses of topology were presented by Hungerbühler et al. (2013), though with the two terminals missing from this analysis removed, two of the trees become synonymous; therefore, only two hypotheses are tested here from Hungerbühler et al. (2013).

\section{Model-based cladistic methods}

In palaeontology, parsimony-based methods of phylogenetic analysis have historically dominated the field and continue to be the preferred analysis method for morphological data. Although model-based approaches to phylogenetics, such as maximum likelihood and Bayesian methods, are relatively common in analyses including molecular data, their application to palaeontological datasets has only recently become more widespread (Lee \& Worthy, 2011). It seems likely that the tardiness with which palaeontologists have taken up probabilistic methods is linked to the ongoing debate over the relative performance of parsimony and probabilistic methods (Huelsenbeck, 1995; Lee \& Worthy, 2011; Wright \& Hillis, 2014; O’Reilly et al., 2016, 2017; Goloboff, Torres \& Arias 2017, 2018; Sansom et al., 2018), especially regarding morphological characters which constitute the vast majority of palaeontological datasets. 
764 However, theoretical criticisms have also been made against both model-based (Kolaczkowski \&

765 Thornton, 2004; Goloboff \& Pol, 2005; Livesey \& Zusi, 2007; Wagner, 2011) and parsimony

766 approaches (Felsenstein, 1978; Kuhner \& Felsenstein, 1994; Lewis, 2001).

767 Advances in the probabilistic approach to phylogeny, stemming from the Mk model of

768 discrete trait evolution (Lewis, 2001), have led to a more robust framework with which to

769 analyse morphological datasets (Ronquist \& Huelsenbeck, 2003; Wagner, 2011; Wright, Lloyd

$770 \&$ Hillis, 2015). Similarly to parsimony methods, recent advances have seen the development of

771 procedures to incorporate both continuous (Parins-Fukuchi, 2017) and geometric morphometric

772 data (Parins-Fukuchi, 2018) into probabilistic analyses of phylogeny. Both methods utilise

773 alternative models of evolution to the Mk model: Brownian motion (Felsenstein, 1973, 1985;

774 Gingerich, 1993) and Ornstein-Uhlenbeck (Hansen, 1997; Butler \& King, 2004; Beaulieu et al.,

775 2012) models simulate random, normally distributed phenotypic evolution, and stabilising

776 evolution respectively in the analysis of continuous data, while a Brownian motion model is used

777 again, with branch lengths representing morphological variation, to analyse morphometric data

778 (Parins-Fukuchi, 2017, 2018).

779 Probabilistic methods of phylogenetic analysis are not explored further in this study, largely for

780 practical reasons. We note that the use of continuous and morphometric data in probabilistic

781 methods is very new and as such lacks intuitive implementation in software packages, resulting

782 in a requirement for careful documentation and testing of methodological properties, especially

783 for an empirical dataset. Further analyses of this dataset under probabilistic methods could be

784 very illuminating, and a potentially fruitful avenue of future research, but will be explored

785 elsewhere.

786 


\section{Results}

788

789 A total of eight best fit trees were found across all four coding variants; in each of the D and DC

790 treatments three equally 'fitting' trees were found, whereas DM and DCM each returned only

791 one best fit tree. Our results are presented as the strict consensus trees of the best fit trees or

792 single best fit trees resulting from each of the four different variants of character coding (D, DC,

793 DM and DCM) with absolute and relative symmetric resampling frequencies above nodes, and

794 Bremer supports below (Figs. 4-7). We also present the strict consensus and maximum

795 agreement subtree of these four trees, to summarize the most consistent relationships across all

796 coding treatments (Fig. 8; Fig. S2).

797 The tree lengths resulting from the four coding treatments are summarized in Table 4, as

798 are the consistency and retention indices (CI and RI). Tree lengths are not directly comparable

799 between treatments including or excluding GM coding; this arises because the morphology

800 encoded in some GM characters encompasses more than one discretely coded character.

801 Therefore, analyses incorporating GM data contain fewer characters than the other scoring types

802 and will likely show lower tree lengths as a result.

803 Conversely, providing that continuous characters replace their corresponding discrete

804 characters with one-to-one equivalence (which they do here), their alternative coding method

805 alone should not affect tree length. Continuous characters are here scored as ratios and are

806 transformed to occupy a $0-1$ scale; the standard treatment of continuous characters by TNT uses

807 the numerical differences between scores to create the step-matrix. As these values are constantly

808 below 1 it may be expected that the greater proportion of continuous characters in a dataset

809 would result in lower tree length. However, due to our use of implied weighting this should not 
810 present a problem, as tree length is the sum of homoplasy-adjusted character weight. Homoplasy

811 is, in the simplest sense, calculated as a proportion of the minimum length of a character in

812 topology X, and the minimum possible length of a character in any topology. Character weight is

813 then calculated from this proportion (homoplasy) and is then summed across all characters to

814 generate tree length. As character weight is based on a character-specific proportion, the actual

815 size of changes in the character step-matrix should not affect the final tree length. Simply put, if

816 equivalent discrete and continuous characters share a consistent proportion of homoplasy, their

817 effect on tree-length under implied weighting will be identical regardless of how they are scored.

818

819 Comparisons of similarity

820 Comparisons of trees are presented in Tables 5 and 6, using the number of taxa retained by

821 maximum agreement subtrees, the SPR distance and the RF distance as metrics of similarity.

822 Maximum agreement subtrees essentially produce fully resolved consensus trees by pruning taxa

823 in conflict between the input trees; the number of taxa retained in a maximum agreement subtree

824 can be used as a measure of topological similarity between two or more trees.

825 All four trees were found to be significantly similar to each other. For all pairwise

826 comparisons between different coding treatments the number of taxa retained in the maximum

827 agreement subtrees was statistically much greater than expected by chance. Statistical

828 significance was established using 5,000 agreement subtrees constructed with randomized tree

829 topologies. None of these subtrees retained more than 14 OTUs and subtrees retaining the

830 highest number of OTUs (14) comprised only $0.96 \%$ of the data. All pairwise comparisons

831 yielded multiple maximum agreement subtrees of the same length showing alternative prunings

832 (Table 5). 

consistently found to be the most similar tree topologies using all similarity metrics. The trees

836 showed a high degree of similarity to each other. However, there is greatly reduced similarity

837 when the DC/DCM trees are compared with the D/DM trees. Broadly speaking, this suggests

838 there are two partially conflicting phylogenetic hypotheses, one represented by the DC and DCM

839 trees (Figs. 5, 7) and one by the D and DM trees (Figs. 4, 6). However, the agreement subtrees

840 suggest that the amount of overlap between these hypotheses is still greater than would be 841 expected to occur by chance.

\section{Consistent relationships}

844 A list of nodal synapomorphies for each tree is presented in Appendix 3. The following 845 relationships were found to be consistent in the trees of all four scoring treatments, and match the 846 topology of the strict consensus tree (Fig. 8).

847 Diandongosuchus is recovered as the most basal phytosaur in every tree. Its position 848 outside of all other phytosaurs is supported well by frequency and Bremer supports, and two 849 consistent synapomorphies supporting Parasuchidae (Fig. 8, node B) to the exclusion of $D$. 850 fuyuanensis in every tree $[13: 0 \rightarrow 1 ; 22: 0 \rightarrow 1]$

851 Wannia scurriensis is consistently found as the most basal member of Parasuchidae,

852 outside the clade that includes Parasuchus and Mystriosuchinae. The latter clade (Fig. 8, node C)

853 is, however, poorly supported, with only two synapomorphies supporting Parasuchus +

854 Mystriosuchinae to the exclusion of Wannia in all four trees $[36: 0 \rightarrow 1 ; 69: 0 \rightarrow 1]$. 
$858 \quad 0 \rightarrow 1]$. and their exact relationships to Mystriosuchinae are variable in the different coding treatments. Mystriosuchinae itself (Fig. 8, node G) is supported by three synapomorphies common to all trees $[9: 0 \rightarrow 1 ; 14: 1 \rightarrow 2 ; 80: 0 \rightarrow 1]$. is consistently well supported by frequency and Bremer supports (Fig. 8, node H) and is united by two synapomorphies in all trees $[22: 2 \rightarrow 1 ; 92: 0 \rightarrow 1]$. Within this clade, Rutiodon is consistently the sister taxon to Angistorhinus; the clade composed of Angistorhinus and Angistorhinus-like specimens, to the exclusion of Rutiodon carolinensis (Fig. 8, node I), is supported by two synapomorphies $[56: 0 \rightarrow 1 ; 58: 0 \rightarrow 1]$. The relationships of the species and

870 specimen-level OTUs within Angistorhinus are consistent in all coding treatments: A. talainti is

871 the most basal of the two named species and $A$. grandis is more derived, with the specimen-level

872 OTUs representing either potential additional species within the genus, or morphologically

873 diverse representatives of existing Angistorhinus species. topologies that separate it from the more basal taxa $[16: 1 \rightarrow 0 ; 25: 0 \rightarrow 1]$. Within

876 Leptosuchomorpha the four phylogenies are more variable (Fig. 8, node M). Among the 
878 tree topologies: the clade which unites Nicrosaurus kapffi and Nicrosaurus meyeri with

879 Coburgosuchus goeckeli, although the relationships between these three species are variable in

880 the different coding treatments (Fig. 8, node N). This clade is supported by a single

881 synapomorphy [57: $1 \rightarrow 2]$.

882

Although there are conflicting relationships, the majority of the leptosuchomorph taxa

883

884

885

886

887

888

889

890

891

892

893

894

895

896

897

898

899

900

that have been excluded from Mystriosuchini by previous analyses (e.g., Kammerer et al., 2015)

are also consistently excluded from Mystriosuchini as defined in the current analysis (with Mystriosuchus planirostris, Machaeroprosopus jablonskiae and Machaeroprosopus buceros as

exemplars of the clade; see Table 2). Non-Mystriosuchini leptosuchomorphs in this analysis include all members of Smilosuchus, Leptosuchus and Nicrosaurus plus 'Phytosaurus' doughty, Pravusuchus hortus, Coburgosuchus goeckeli and PEFO 34852, as well as Protome in the DC and DCM coding treatments (Figs. 5, 7) (see below).

There is only one synapomorphy of Mystriosuchini common to all trees (Fig. 8, node O) $[43: 2 \rightarrow 0]$. Much like the non-Mystriosuchini leptosuchomorphs, interrelationships within Mystriosuchini are generally inconsistent across the different coding treatments; however, as in previous analyses, the clade includes all named species of Machaeroprosopus, 'Redondasaurus' and Mystriosuchus, as well as USNM V 17098, NMMNHS P-4256, NMMNHS P-31094, MB.R. 2747 and NHMW 198600240001.

Protome batalaria has been placed close to Rutiodon by previous studies (Stocker, 2012;

Butler et al., 2014; Kammerer et al., 2015). In this study it is consistently found to be either nested just inside Mystriosuchini (Figs. 4 [node 28], 6 [node 30]) or as the sister taxon to this clade (Figs. 5 [node 24], 7 [node 27]). In both trees in which Protome is recovered within Mystriosuchini (D \& DM trees) the node is supported by the presence of 'parietal prongs' [65: 
$9010 \rightarrow 1]$; additionally, in the DM tree the node is supported by the presence of a small elongate 902 depression on the postorbital bar just posterodorsal to the orbit [29: $0 \rightarrow 1$ ], as well as all GM

903 characters. Parietal prongs are exclusive only to Protome and members of Machaeroprosopus

904 and 'Redondasaurus', whereas the groove on the descending process of the postorbital is 905 common to many taxa throughout Parasuchidae.

906 Within Mystriosuchini, Mystriosuchus (Fig. 8, node P) is the only consistently supported 907 clade. Within this clade MB. R. 2747 and NHMW 198600240001 form successive sister taxa to 908 Mystriosuchus planirostris and Mystriosuchus westphali; it is likely that these two specimen909 level OTUs also represent unnamed species of Mystriosuchus. Mystriosuchus and its internal 910 nodes are statistically well supported. The basal node of the clade and the internal nodes are each 911 supported by single synapomorphies common to all trees (Fig. 8, node P) [85: 1 $\rightarrow$ 0], (Fig. 8, 912 node Q) [2: $1 \rightarrow 2$ ], (Fig. 8, node R) [88: $0 \rightarrow 1$ ].

913

\section{Conflicting relationships}

915 As discussed above, relationships among the non-Mystriosuchinae taxa are almost

916 entirely consistent across all four trees with the exception of 'Paleorhinus' parvus, 'Paleorhinus'

917 sawini and Ebrachosuchus neukami (Fig. 8). The relationships between these taxa are poorly

918 supported statistically and variable, and the three form a polytomy together with

919 Mystriosuchinae in the strict consensus trees of the D and DC analyses (Figs. 4, 5). In the DM

920 and DCM analyses (Figs. 6, 7) the relationships are consistent, if not well supported.

921 'Paleorhinus' parvus is the sister taxon of Mystriosuchinae, with Ebrachosuchus neukami and

922 'Paleorhinus' sawini forming successively more distant sister groups. 
924 species assigned to the genera Smilosuchus, Leptosuchus, 'Phytosaurus', Pravusuchus,

925 Nicrosaurus and Coburgosuchus. Relationships between these taxa are entirely consistent in the

926 DC and DCM trees (Figs. 5, 7). However, the D and DM trees each show different topologies

927 (Figs. 4, 6). In the DC and DCM trees, 'Smilosuchus' lithodendrorum is the most basal taxon in

928 Leptosuchomorpha. Within Leptosuchomorpha there are two clades: one containing all species

929 of Leptosuchus and Nicrosaurus, in addition to Pravusuchus hortus, Coburgosuchus goeckeli

930 and PEFO 34852; and one containing 'Phytosaurus' doughtyi, Smilosuchus adamanensis,

931 Smilosuchus gregorii, Protome and Mystriosuchini.

932

In the D tree, all the aforementioned taxa with the exception of Smilosuchus gregorii

933 form an unnamed clade (Fig. 4, node 14), which forms a sister relationship within

934 Leptosuchomorpha with Smilosuchus gregorii + Mystriosuchini. The basalmost taxon within this

935 unnamed clade is Smilosuchus adamanensis, which in the other three trees presented here is

936 recovered as a branch just basal to S. gregorii; the next taxon in the clade, 'Phytosaurus'

937 doughtyi, also falls closer to S. gregorii than Leptosuchus in the DC, DM and DCM trees.

938 Above 'Phytosaurus' doughtyi, two distinct clades are present as sister taxa. One of

939 these (Fig. 4, node 17) contains Leptosuchus spp., plus 'Smilosuchus' lithodendrorum and PEFO

940 34852; the second (Fig. 4, node 20) contains Pravusuchus hortus, Nicrosaurus spp. and

941 Coburgosuchus goeckeli. Relationships in both clades have weak Bremer support, with the

942 exception of the node uniting Nicrosaurus kapffi, N. meyeri and C. goeckeli (Fig. 4, node 21), in

943 which frequency supports are generally better.

944 The topology for this region of the DM tree is very different from that of the D tree (to

945 which it is very similar in most other respects). The taxa that form a distinct clade in the D tree 
946 (Fig. 4, node 14) instead form a largely pectinate series of outgroups to Mystriosuchini in the

947 DM tree (Fig. 6, nodes 15-25). The most basally branching taxon is Leptosuchus studeri, which

948 falls outside of Leptosuchomorpha in this tree. At the base of Leptosuchomorpha is a relatively

949 poorly supported (according to frequency supports) clade including 'Phytosaurus' doughtyi,

950 Leptosuchus crosbiensis, and a sister taxon relationship between 'Smilosuchus' lithodendrorum

951 and PEFO 34852 (Fig. 6, node 17). Pravusuchus hortus, Smilosuchus adamanensis and

952 Smilosuchus gregorii form a series of outgroups to a clade consisting of Mystriosuchini and the

953 Nicrosaurus + Coburgosuchus clade. In the DM tree the Nicrosaurus species are sister taxa (Fig.

9546 , node 25). In this topology, Nicrosaurus occupies a position consistent with that recovered in

955 previous analyses of Mystriosuchini (Hungerbühler, 2002; Hungerbühler et al., 2013) and with

956 the group's previous definition (Kammerer et al., 2015).

957 The main inconsistency within Mystriosuchini is the fluctuating position of the

958 Mystriosuchus clade (Mystriosuchus spp. plus NHMW 198600240001 and MB. R. 2747). In

959 both trees incorporating continuously scored data (DC, DCM) this group is recovered as highly

960 derived within Mystriosuchini (Figs. 5, 7), as has previously been found by Stocker (2010, 2012,

961 2013), Butler et al. (2014) and Kammerer et al. (2015) (Figs. 2B; 3A, B). In the D and DM

962 coding treatments, however, the Mystriosuchus clade forms the sister group to Protome batalaria

$963+$ Machaeroprosopus (Figs. 4, 6), as has been found by Hungerbühler (2002), Parker and Irmis

964 (2006) and Hungerbühler et al. (2013) (Figs. 1A; 2A, C).

965 Relationships among other species within Mystriosuchini are highly variable, though the

966 general pattern is of a highly laddered series of sequentially more derived terminals. Although

967 the order of OTUs varies considerably, there are some similarities across different coding

968 treatments; taxa in the less derived positions are generally Protome batalaria and 
969 Machaeroprosopus andersoni, which are then followed by Machaeroprosopus pristinus,

970 Machaeroprosopus buceros and Machaeroprosopus lottorum and then a clade containing both

971 species of 'Redondasaurus' (Fig. S2).

972 As previously mentioned, the two conflicting hypotheses regarding the position of

973 Mystriosuchus (basal or derived within Mystiosuchini) split the results of the four coding

974 methods into two alternative topological hypotheses (respectively D, DM [Figs. 4, 6] and DC,

975 DCM [Figs. 5, 7]). The positions of Machaeroprosopus mccauleyi and Machaeroprosopus

976 jablonskiae also consistently differ between these topologies. In the trees in which

977 Mystriosuchus occupies a derived position within Mystriosuchini (DC, DCM),

978 Machaeroprosopus mccauleyi and Machaeroprosopus jablonskiae form successive sister taxa,

979 basal to the clade comprising Machaeroprosopus pristinus, Machaeroprosopus buceros and

980 Mystriosuchus. In topologies where Mystriosuchus is recovered basal to Machaeroprosopus (D,

981 DM), Machaeroprosopus mccauleyi and Machaeroprosopus jablonskiae are more derived than

982 the clade composed of Machaeroprosopus pristinus, Machaeroprosopus buceros and

983 Machaeroprosopus lottorum, forming successive sister taxa to 'Redondasaurus'.

984 The position of Machaeroprosopus zunii is more consistent; in three trees (D, DC and

985 DM) it is recovered basal to the clade composed of Machaeroprosopus pristinus,

986 Machaeroprosopus buceros, and all more derived taxa. In the DCM results Machaeroprosopus

987 zunii is placed more derived than than Machaeroprosopus pristinus and Machaeroprosopus

988 buceros, but less derived than Machaeroprosopus lottorum (Fig. 7, node 34).

989 Machaeroprosopus lottorum is another taxon which varies consistently between the two

990 broad topological hypotheses presented. In the trees incorporating continuously scored data, in

991 which Mystriosuchus is highly derived (DC, DCM), Machaeroprosopus lottorum forms a clade 
992 with NMMNHS P-31094 (Figs. 5, 7), closely related to 'Redondasaurus' and Mystriosuchus, as

993 was found by Hungerbühler et al. (2013). In the alternative topologies (D, DM)

994 Machaeroprosopus lottorum nests with Machaeroprosopus pristinus, to the exclusion of

995 Machaeroprosopus buceros (Figs. 4, 6). Both positions are similarly poorly supported by Bremer

996 analyses, but possess relatively good frequency scores. In this topology NMMNHS P-31094 is

997 consistently found within 'Redondasaurus', as the sister taxon of 'Redondasaurus' gregorii, to

998 the exclusion of 'Redondasaurus' bermani.

999

1000

\section{Accuracy and validity}

1001

Bremer supports. With poorly supported nodes collapsed below Bremer values of 0.08, the DM condition produced greatest tree resolution, retaining 23 nodes; however, its mean Bremer score 1003 is one of the lowest among the four trees, suggesting that the additional nodes supported in this

1004 tree only exceed the cut-off by a small amount (Table 7). When using the mean step length of a 1005 single character (0.11) as a cut-off for node-collapsing, the DM and DCM conditions were found to perform more poorly than the D and DC conditions in terms of nodes retained and total Bremer support. Mean Bremer values for the retained nodes remained almost consistent across all trees (Table 7).

When broken down into regions, it appears that the extra support in the DM tree is added in regions three and four, which are almost consistently the worst supported regions in all trees. Despite this extra support, relationships within these regions are still relatively poorly supported 1012 in the DM condition, and the support for region one also becomes among the poorest in both GM 1013 trees (DM and DCM) (Table 8). 
highest, or equal highest support in all regions except three and four, with a sum of mean support equalling 0.75. Conversely, despite maximizing support in the poorest regions of the tree, the

DM condition scored second worst for overall support, with a sum total of 0.60 ; this was

followed by the DCM condition with a score of 0.58 (Table 8 ).

1019

1020

Frequency supports. With a cut-off for node collapsing of $<10$, symmetric frequency support

1021

1022

1023

1024

1025

1026

1027

1028

1029

1030

1031

1032

1033

1034

1035

1036

produced broadly similar results for all the trees, with the DC condition producing a marginally higher resolution and mean support value. Conversely to the results from Bremer supports, the DM condition was the poorest supported topology based on symmetric resampling, although the difference between 'best' and 'worst' is minor (Table 7).

Split into regions, the overall sum of mean supports follows the same trend as that of the

Bremer supports; DC is best, with a sum of 240.56, then D (229.47), DM (213.16) and finally

DCM (199.11). The DC tree holds the highest mean support compared to the other trees in

regions one, three and five. The DM tree only holds the highest support value in region four;

however, this is one of the two poorest supported regions (three and four), and is therefore important in achieving the best possible resolution in all parts of the tree (Table 9).

Stratigraphic congruence. All tree topologies recovered under the four data conditions tested in this analysis were found to be significantly better correlated with stratigraphy than would be expected of random data. Among the raw results from each correlation metric, there is no consistent trend indicating one or more of the four topologies are optimal. The SCI metric suggests the D and DM topologies (in which Mystriosuchus is basal to Machaeroprosopus) to be 
1037 better stratigraphically correlated than the DC and DCM topologies (in which Mystriosuchus is

1038 the most derived member of Mystriosuchini); however, this finding is not borne out by any other

1039 metric. Among the other three metrics the only consistent trend is the slightly worse performance

1040 of the two datasets incorporating GM characters (DM and DCM); however, the difference in fit

1041 is almost negligible (Table 10).

1042 The previous phylogenetic analyses of Parker \& Irmis (2006) (Fig. 2A) and Kammerer et

1043 al. (2015) (Fig. 3B) (based respectively on the original matrices of Hungerbühler [2002] and

1044 Stocker [2010]), also correlate well with the stratigraphic data used in this study, generally

1045 achieving significance values equal to those of the current study. The topologies of Hungerbühler

1046 et al. (2013) (Fig. 2C) were found to correlate poorly with stratigraphy and were not statistically

1047 differentiable from random data; however, the analysis of Hungerbühler et al. (2013) focuses

1048 only on one area of the tree, roughly corresponding to 'region four' in this study. This region is

1049 poorly supported in terms of accuracy and robusticity. The poor stratigraphic correlation of the

1050 analysis of Hungerbühler et al. (2013) may indicate that this region has poor stratigraphic

1051 support, but this is masked in the stratigraphic correlations of other studies by good correlation

1052 overall in other areas of the tree.

1053

1054 Tree choice

1055 In order to carry out further investigations into the effects of alternative, or previously reported

1056 topologies, it was decided to select only two of the four topologies presented above to avoid

1057 unnecessarily long comparisons of fit between multiple alternative taxonomic relationships

1058 within multiple tree topologies. As there is a general dichotomy within the four trees, it would be

1059 arbitrary to favour one topology over the other, so a representative of each was chosen. 

topology to the DCM condition (discrete + continuous + geometric morphometric characters

1062 [Fig. 7]), but consistently outperforms the latter in the various robusticity analyses described 1063 above. Comparisons of topological similarity do not assist in selecting one of these topologies 1064 over the other as they are shown to be almost identical, with neither being more representative of 1065 all topologies.

The D and DM conditions (respectively discrete characters and discrete + geometric morphometric characters [Figs. 4, 6]) are less similar to each other than are the DC and DCM conditions, though they show largely the same topology. Between the Bremer and frequency analyses the D and DM conditions outperform each other in various aspects; when the trees are regionalized the DM condition generally provides slightly better support in the worst-supported areas of the tree, but is poorly supported in most other areas. The sum of Robinson-Foulds distances for the $\mathrm{D}$ tree in comparison to all others suggests that it is the most representative topology of the four trees recovered in this study; this was never found to be the case with the DM topology. partially on the above metrics, but partially due to the relative difficulty of undertaking multiple further GM analyses. Continuous and discrete characters boast substantial advantages in analysis duration, and the comparative simplicity of data acquisition and processing, over GM characters. Because of these reasons continuous and discrete data are far more accessible and provide a better basis on which future studies can build.

\section{Alternative taxonomic relationships}


1083 The consistent recovery of a sister-relationship between Rutiodon carolinensis and the genus

1084 Angistorhinus makes the decision of whether or not to synonymize these taxa entirely arbitrary

1085 (see below); therefore, to test for their synonymy would also be meaningless and as such these

1086 taxa were excluded from these analyses.

1087 Nicrosaurus was previously found as the basal-most member of Mystriosuchini

1088 (Hungerbühler, 2002; Hungerbühler et al., 2013) and was therefore used as an internal specifier

1089 for the most recent phylogenetic definitions of the clade, preceding this study (Parker \& Irmis,

1090 2006; Kammerer et al., 2015); however, as described in the introduction little data has been

1091 provided to support this. Here we find Nicrosaurus to group closer to Leptosuchus than to

1092 Mystriosuchus or Machaeroprosopus, and thus outside of Mystriosuchini according to our

1093 redefinition of the clade (Table 2).

1094 We tested the previously proposed position of Nicrosaurus, i.e. as the most basal group

1095 within Mystriosuchini (Kammerer et al., 2015). To achieve this, the clade of Nicrosaurus and

1096 Coburgosuchus was constrained to its previous position in relation to Mystriosuchini, such that

1097 all members of Machaeroprosopus and Mystriosuchus fell in more derived positions.

1098 Additionally, Pravusuchus hortus was constrained as the basal sister taxon to Nicrosaurus,

1099 Coburgosuchus and Mystriosuchini, to replicate the previous hypothesis that Pravusuchus is the

1100 immediate sister taxon to Mystriosuchini (Stocker, 2010). Under these topological constraints

1101 tree character fit worsened by 0.693 in the D condition, and 1.013 in the DC condition.

1102 The tree topology resulting from the D condition places Mystriosuchus as the sister clade

1103 to Machaeroprosopus; for this analysis we constrained Mystriosuchus to nest within

1104 Machaeroprosopus as found by Stocker (2010), although its exact position within the clade was

1105 left flexible. Under this condition the tree-fit worsens by 0.584 . In contrast, in the DC condition 
1106 Mystriosuchus was found to occupy a position within the Machaeroprosopus clade; therefore,

1107 we constrained it as sister to this clade, leading to a decline in tree fit by 0.714 .

1108 Unlike the findings of Hungerbühler et al. (2013), in our phylogenies the two species of

1109 'Redondasaurus' do appear to form a sister taxon relationship; however, in accordance with their

1110 findings and those of other studies (Ballew, 1989; Hungerbühler, Chatterjee \& Cunningham,

1111 2003; Stocker, 2010; Butler et al., 2014; Kammerer et al., 2015) 'Redondasaurus' remains

1112 nested within Machaeroprosopus. When the two genera are forced into a sister group

1113 relationship the tree fit deteriorated considerably by a score of 0.857 under the $\mathrm{D}$ condition, and

11141.004 in the DC condition.

1115

1116 Discussion

1117

1118 Higher-level taxonomy

1119 The recently revived family-level name Parasuchidae Lydekker, 1885 (Kammerer et al., 2015)

1120 was suggested by Stocker et al. (2017) to exclude the proposed basal phytosaur

1121 Diandongosuchus fuyuanensis. Our analysis corroborates the hypothesis of Stocker et al. (2017)

1122 that Diandongosuchus is the most basal phytosaur, and the only taxon to fall outside of

1123 Parasuchidae but within Phytosauria using current definitions (Fig. 8).

1124 The taxonomic content of Mystriosuchinae von Huene, 1915, defined as the last common

1125 ancestor of Angistorhinus grandis and Mystriosuchus planirostris and all its descendants by

1126 Kammerer et al. (2015) (Table 2), is largely compatible between the phylogenetic hypotheses

1127 presented here and that presented by Kammerer et al. (2015). However, in the phylogeny of 
1128 Kammerer et al. (2015) (Fig. 3B) 'Paleorhinus' sawini falls within Mystriosuchinae whereas

1129 here it is excluded from this clade.

1130 Stocker (2010) erected the clade Leptosuchomorpha, defined as the most recent common

1131 ancestor of Leptosuchus studeri and Machaeroprosopus pristinus, and all descendants thereof

1132 (Table 2). In the D and DM trees presented here (Figs. 4, 6) this definition is perfectly

1133 compatible with previous definitions of the clade; however, in the DC and DCM conditions

1134 (Figs. 5, 7) 'Smilosuchus' lithodendrorum is recovered in a more basal position than all other

1135 previous members of Leptosuchomorpha, and would thus be excluded from the group based on

1136 the definition of Stocker (2010), despite exhibiting numerous similarities with other members.

1137 We therefore redefine Leptosuchomorpha such that it includes the latest common ancestor of

1138 'Smilosuchus' lithodendrorum, Leptosuchus studeri and Machaeroprosopus pristinus, and all of

1139 its descendants (Table 2). In addition, Protome batalaria and 'Machaeroprosopus' zunii are

1140 consistently recovered within Leptosuchomorpha in the analyses presented here, whereas they

1141 were previously excluded (Stocker, 2010; Butler et al., 2014; Kammerer et al., 2015).

1142 The definition of Mystriosuchini von Huene, 1915 proposed by Kammerer et al. (2015)

1143 (Table 2) is problematic with regard to the results presented here, due to our general result that

1144 Nicrosaurus is deeply nested with taxa such as Leptosuchus and Smilosuchus that are

1145 traditionally excluded from Mystriosuchini. This problem is especially pronounced in the D tree

1146 (Fig. 4), in which the previous definition of Mystriosuchini renders the group entirely

1147 synonymous with Leptosuchomorpha; the DC and DCM trees produce a very similar result, 1148 though excluding 'Smilosuchus' lithodendrorum from Mystriosuchini (Figs. 5, 7). In the DM tree

1149 (Fig. 6) the taxonomic content of Mystriosuchini using the previous phylogenetic definition is 
1150 essentially the same as in previous studies, with the inclusion of a few additional taxa such as 1151 Protome batalaria.

1152 To resolve this taxonomic issue, we propose that Nicrosaurus kapffi is removed from the 1153 definition of Mystriosuchini due to its conflicting phylogenetic position, and is replaced with 1154 Machaeroprosopus jablonskiae to stabilize the taxonomic content of the clade (see above; Table 1155 2). Without the addition of Machaeroprosopus jablonskiae as a specifier, Machaeroprosopus mccauleyi and Machaeroprosopus jablonskiae would be variably excluded from Mystriosuchini,

1157 despite consistent previous findings of their inclusion in the clade. A number of other taxa would 1158 also be variably included in Mystriosuchini, leading to increased instability of the clade. Machaeroprosopus jablonskiae is recovered in a similar position to that found by 1160 previous phylogenetic analyses (Parker \& Irmis, 2006; Hungerbühler et al., 2013; Butler et al., 1161 2014; Kammerer et al., 2015) in all of our trees. In the DC and DCM trees Machaeroprosopus jablonskiae is recovered as one of the most basal taxa within Machaeroprosopus (Figs. 5, 7), as in the studies of Parker \& Irmis (2006) and Hungerbühler et al. (2013) (Fig. 2A,C). In the D and DM trees Machaeroprosopus jablonskiae is placed in a more derived position in the Machaeroprosopus clade (Figs. 4, 6), similar to the findings of Butler et al. (2014) and Kammerer et al. (2015) (Fig. 3A,B); however, as this coincides with the migration of Mystriosuchus to a more basal position with respect to Machaeroprosopus, the taxa retained in Mystriosuchini remain largely identical among our four trees. Crucially, Machaeroprosopus jablonskiae consistently nests within Mystriosuchini in previous studies (Parker \& Irmis, 2006;

1170 Hungerbühler et al., 2013; Butler et al., 2014; Kammerer et al., 2015), and in this sense our 1171 proposed definition errs on the side of caution in ensuring the definition of Mystriosuchini used 1172 here is as compatible as possible with the phylogenetic topologies of previous studies. 
1174 data could disagree with our findings, in which case a definition that maximizes compatibility

1175 between recent studies may be the most useful. We therefore tentatively suggest Mystriosuchini

1176 should henceforth be defined as the most recent common ancestor of Mystriosuchus planirostris,

1177 Machaeroprosopus jablonskiae and Machaeroprosopus buceros, and all its common ancestors

1178 (Table 2).

1179

\section{Lower-level taxonomy}

Synonymy of Rutiodon and Angistorhinus. The results of this analysis depart from both

1182

1183

1184

1185

1186

1187

1188

1189

1190

1191

1192

1193

1194

previously proposed hypotheses of the relative phylogenetic positions of these taxa.

Hungerbühler \& Sues (2001) found Rutiodon to occupy a derived position within the monophyletic clade of Angistorhinus, whereas other studies recovered Rutiodon in a more derived position than Angistorhinus, closer to Leptosuchus (Hungerbühler, 1998; Stocker, 2010). Supporting character data were not provided for the proposal of synonymy made by Hungerbühler \& Sues (2001), which was published in an abstract only. In our results the two taxa form a monophyletic group, supported by two synapomorphies common to all four best-fit trees [22: $2 \rightarrow 1 ; 92: 0 \rightarrow 1]$. However, the fact that Rutiodon consistently forms the sister group to Angistorhinus makes the decision of whether or not to synonymize the genera entirely arbitrary. Unfortunately, we were unable to study any material of Brachysuchus megalodon, which has been suggested to be synonymous with Angistorhinus (Long \& Murry, 1995), but which was also found to be distinct by Stocker (2010). 
1195 Angistorhinus. In her discussion of the relationships of Angistorhinus, Stocker (2010) advocated

1196 the necessity for future in-depth analysis of Angistorhinus and its affinities. We do not present a

1197 detailed analysis or redescription of any species within Angistorhinus; however, our analysis is

1198 only the second to include more than one species (Hungerbühler, 1998), and the first to

1199 incorporate further specimens that have been identified previously as Angistorhinus. Our results

1200 provide a stable and consistently well-supported phylogenetic position for Angistorhinus that

1201 future descriptive and taxonomic work can build on. Furthermore, we provide additional

1202 synapomorphies for both the Angistorhinus clade, and relationships within it.

1203 The Angistorhinus clade (Figs. 4, 5, node 9; Figs. 6, 7, node 11) is distinguished by two

1204 unambiguous synapomorphies common to all trees, pertaining to the parietal/squamosal bars

1205 being medially convex, and at least as wide as the postorbital/squamosal bars [56: $0 \rightarrow 1 ; 58:$

$12060 \rightarrow 1]$. Both of these characters have previously been suggested to be diagnostic features of 1207 Angistorhinus Mehl, 1913 (Mehl, 1915; Gregory, 1962a; Stocker, 2010) or 'Angistorhininae’ 1208 Camp, 1930 (Long \& Murry, 1995).

1209 The next most inclusive clade contains Angistorhinus talainti, A. grandis, TMM 31100-

12101332 and USNM V 21376. This group is distinguished by the presence of a sulcus running

1211 longitudinally along the postorbital/squamosal bar [42: $0 \rightarrow 1]$, and the partial or total squaring of 1212 the medial rim of the postorbital/squamosal bar and posterior process [51: $0 \rightarrow 1]$.

1213 The next most inclusive clade excludes $A$. talainti, leaving only $A$. grandis, TMM $31100-$

12141332 and USNM V 21376. This clade is well supported by four unambiguous synapomorphies,

1215 though within the clade the basal-most member (TMM 31100-1332) shows no autapomorphies

1216 and the sister grouping of $A$. grandis with USNM V 21376 is supported by only one

1217 synapomorphy [69: $2 \rightarrow 1]$ and displays poor support values. Given the strong support for the 
1218 wider clade, but the relatively poor differentiation of the OTUs within it, there may be a case for

1219 referring both TMM 31100-1332 and USNM V 21376 to $\mathrm{A}$. grandis. The synapomorphies of this

1220 clade are: the division of the narial openings into an anterior 'anteriorly opening' section and a

1221 posterior 'dorsally opening' section [12: $0 \rightarrow 1]$; the raising of the external nares above the level

1222 of the skull roof [17: $0 \rightarrow 1]$; the posttemporal fenestra being moderately wide and dorsoventrally

1223 compressed [66: $0 \rightarrow 1$ ]; and the presence of an anteroposteriorly oriented ridge on the midline of

1224 the basioccipital between the basitubera [70: $0 \rightarrow 1]$.

1225 Based on these results we suggest $A$. grandis to be one of the most derived members of

1226 Angistorhinus, and A. talainti to be less derived. At face value, there does not appear to be any

1227 clear relationship between palaeogeography and phylogeny; A. talainti, from Morocco, nests

1228 amongst the specimens known from the west and south central USA. This finding should be

1229 expected as these locations were placed at broadly similar palaeolatitudes and were closely

1230 connected in the Late Triassic.

1231

1232 Monophyly of Leptosuchus. Stocker (2010) found a strongly supported monophyletic

1233 relationship between Leptosuchus crosbiensis and Leptosuchus studeri; in our analysis, we found

1234 almost all nodes relating to Leptosuchus-grade taxa were extremely poorly supported in each

1235 tree. Only in the D tree did we find an arrangement approaching a monophyletic Leptosuchus

1236 (Fig. 4, node 17), though with the addition of 'Smilosuchus' lithodendrorum and PEFO 34852 as

1237 a sister clade to L. crosbiensis. In the DC and DCM trees Leptosuchus studeri forms the sister

1238 group to a clade containing Leptosuchus crosbiensis, but also Pravusuchus, Coburgosuchus and

1239 Nicrosaurus (Fig. 5, node 15; Fig. 7, node 17). Support values are generally poor. In the DM tree 
1240 Leptosuchus-grade taxa occur as a paraphyletic grade of sequentially more derived branches

1241 (Fig. 6).

1242 Stocker (2010) found one synapomorphy to support the monophyly of Leptosuchus and 1243 one further potential apomorphy under DELTRAN optimization.

Distal end of paroccipital process of opisthotic rounded, distal edge is curved rather than

1245

1246

1247

1248

1249

1250

1251

1252

1253

1254

1255

1256

1257

1258

1259

1260

1261

1262

Monophyly of Smilosuchus. The previously proposed taxonomic content of Smilosuchus is not monophletic in any of our best-fit trees. In the D tree (Fig. 4) all three species are found in different locations: S. adamanensis forms the basal-most taxon in a clade containing all leptosuchomorph taxa excluded from Mystriosuchini except $S$. gregorii (Fig. 4, node 14); 'S'. lithodendrorum is deeply nested within this group, forming a close relationship with Leptosuchus crosbiensis (Fig. 4, node 18); S. gregorii forms its own distinct branch forming a sister relationship with Mystriosuchini (Fig. 4, node 23).

In none of the trees presented here does 'Smilosuchus' lithodendrorum form a close relationship with any other member of Smilosuchus. Instead, its relationships are divergent, being recovered in two trees as the most basal member of the newly defined Leptosuchomorpha 
1263 (DC \& DCM; Figs. 5, 7) and in the other two nesting closely with Leptosuchus crosbiensis (D \&

1264 DM; Figs. 4, 6). The similarity to Leptosuchus crosbiensis has previously been noticed, leading

1265 Long \& Murry (1995) to regard 'S'. lithodendrorum as a junior synonym of the former taxon,

1266 though without a written justification (see Appendix 1 for more details). We do not here revise

1267 the taxonomy of ' $S$ '. lithodendrorum, as the instability of its position does not allow any

1268 consistent hypothesis of its relationships to be reached. Instead, we consider the phylogenetic

1269 position of this taxon as uncertain pending a more detailed investigation into its similarity to $L$.

1270 crosbiensis.

1271 In Stocker's (2010) analysis, the monophyly of Smilosuchus was supported on the basis

1272 of two synapomorphies and a further possible apomorphy under ACCTRAN optimization.

$1273 \quad$ Ventral margin of squamosal gently sloping anteroventrally from posterior edge of

1274 posterior process to opisthotic process $(28: 1 \rightarrow 0)$. In contrast to the scorings of Stocker $(2010)$,

1275 we found no specimen of ' $S$ '. lithodendrorum with a gently sloping posteroventral squamosal

1276 margin. This state was, however, found to be present in both S. adamanensis and S. gregorii. The

1277 latter taxon displays polymorphism for this character as AMNH FR 3060 displays a morphology

1278 that is neither a gentle slope, nor a sharp shelf, but sits somewhere between.

1279 In the D and DM trees (Figs. 4, 6) S. adamanensis and S. gregorii apparently gain this

1280 character state $(0)$ independently, though because the latter taxon is polymorphic for this

1281 character, the ancestral state (1) is partially retained. In the DC and DCM trees (Figs. 5, 7) the

1282 ancestral state is polymorphic; therefore, depending on the tree in question this character is either

1283 partially consistent or inconsistent with the hypothesis of monophyly between S. adamanensis

1284 and S. gregorii. 
consistently form a monophyly in the D tree, whereas they were previously relatively distant

1287

1288

1289

1290

1291

1292

1293

1294

1295

1296

1297

1298

1299

1300

1301

1302

1303

1304

1305

1306

1307

phylogenetically from each other. This was also tested in the DC tree (which shares the same relative phylogenetic positions of $S$. adamanensis and $S$. gregorii as in the DM and DCM trees).

However, the phylogenetic positions of these two taxa were not modified, and state ' 0 ' was also reconstructed as ancestral to the clade including Protome batalaria and Mystriosuchini.

Squamosal fossa extends to posterior edge of squamosal $(30: 1 \rightarrow 0)$. The scores for this

character in the current analysis are inconsistent with those of Stocker (2010); we observed a polymorphic state in both 'S'. lithodendrorum (TMM 31173-121: 0; UCMP 26688: 1) and $S$.

gregorii (UCMP 27200: 0; AMNH FR 3060: 1). Our character optimization is inconsistent with the hypothesis of a monophyletic Smilosuchus, given that character state '0' is ancestral to the majority of taxa (excluding many basal taxa for which the character is inapplicable and most species of Machaeroprosopus) in all four of our trees.

Lateral border of posttemporal fenestra formed by the contact of the parietal process of

the squamosal and the paroccipital process of the opisthotic $(37: 1 \rightarrow 0)$ (potential apomorphy under ACCTRAN). Our scoring for this character differs from that of Stocker (2010); we concur that 'S'. lithodendrorum displays state '0', whereas both $S$. adamanensis and S. gregorii are scored as possessing a thin lamina of squamosal that slightly undercuts the border of the fenestra ventrolaterally (character state '2'). The latter condition is ancestral to both species of $S$. adamanensis and S. gregorii, all species of Machaeroprosopus and closely related taxa in all four trees (though in the D tree the ancestral state is polymorphic ' 0,2 '). In trees D, DC and DCM character state ' 2 ' independently characterizes the clade formed by Nicrosaurus and Coburgosuchus. Character state '0' is the ancestral condition for 'Smilosuchus' lithodendrorum 
1308 in all four trees presented here. None of the optimizations of this character presented here

1309 support the monophyly of Smilosuchus.

1310

1311 Position of Pravusuchus hortus. Pravusuchus hortus has previously been indirectly implied to potentially form a close relationship with Nicrosaurus: Pravusuchus was found to form the immediate outgroup to Mystriosuchini by Stocker (2010), while Nicrosaurus has long been hypothesized to form a close relationship with Mystriosuchus and Machaeroprosopus (Ballew, 1989) as the most basal taxon within Mystriosuchini (Long \& Murry, 1995; Hungerbühler, 2002; Parker \& Irmis, 2006; Hungerbühler et al., 2013). Thus our a priori assumption was that these taxa would be closely related. Our results corroborate this view, with Pravusuchus forming the outgroup to a clade containing Nicrosaurus and Coburgosuchus in three of the four analyses (D, DC, DCM); however, these taxa are found here to nest deeply within a clade of nonMystriosuchini leptosuchomorph taxa in all but the DM analysis. containing Pravusuchus, Machaeroprosopus mccauleyi, Machaeroprosopus pristinus and Mystriosuchus westphali. In the three trees in which Pravusuchus is the immediate outgroup of Nicrosaurus we found two consistent synapomorphies supporting the clade of Pravusuchus, Nicrosaurus and Coburgosuchus: presence of an infranasal recess, and absence of a furrow or ridge on the lateral surface of the squamosal/post-orbital bar $[21: 0 \rightarrow 1 ; 29: 1 \rightarrow 0]$. The synapomorphy identified by Stocker (2010) is discussed below. 
1331 is that the absence may be attributable to poor preservation (William Parker, pers. comm. to ASJ,

1332 2018)]; AMNH FR 30646:1), as was the case in Machaeroprosopus mccauleyi (UCMP 126999:

1333 0; PEFO 31219: 1), Machaeroprosopus pristinus (PEFO 382: 0; MU 525: 1; AMNH FR 7222: 1;

1334 NMMNHS P-50040: 1), and Mystriosuchus westphali (AMNH FR 10644: 0; GPIT 261/001: 1).

In all four trees presented here, the most exclusive clade that contains Pravusuchus is not

1336

1337

1338

1339

1340

1341

1342

1343

1344

1345

1346

1347

1348

1349

1350

1351

1352

1353

supported by the synapomorphy of Stocker (2010); instead, character optimization finds the absence of the subsidiary opisthotic process [47: 0] to be symplesiomorphic for this clade. Here

we find that the presence of a subsidiary opisthotic process of the squamosal [47: 1] primarily optimizes in two alternative positions depending on tree topology. In the D and DM trees (in which Mystriosuchus is basal within Mystriosuchini) (Figs. 4, 6), the presence of this character is a synapomorphy of the clade formed by USNM V 17098 and all more derived taxa. This clade includes Machaeroprosopus mccauleyi and Machaeroprosopus pristinus, but excludes Mystriosuchus westphali and Pravusuchus hortus. Therefore in these topologies, this synapomorphy is partially consistent with the aforementioned clade of Stocker (2010), though fundamentally excludes Pravusuchus and therefore does not provide support for its position in our trees.

In the DC and DCM trees (in which Mystriosuchus westphali occupies a more derived position within the Machaeroprosopus clade) (Figs. 5, 7), the presence of a subsidiary opisthotic process is optimized as polymorphic for the clade that includes Machaeroprosopus mccauleyi and all more derived taxa (including Machaeroprosopus pristinus and Mystriosuchus westphali, but excluding Pravusuchus). At the node one step more derived, (thus excluding Machaeroprosopus mccauleyi) the character is optimized as 'present' (1) however cannot be regarded as a synapomorphy due to the uncertain optimization of the previous node. This is also 
1354 partially consistent with the optimization of this character by Stocker (2010); however, the clade

1355 supported by this character state excludes Pravusuchus, and is inconsistent with Stocker's

1356 phylogenetic hypothesis.

1357

1358

1359

Position of Nicrosaurus. The most recent novel cladistic analysis to investigate the position of Nicrosaurus was that of Hungerbühler (2002). The analysis found Nicrosaurus as the sister taxon to a clade formed by Mystriosuchus, 'Redondasaurus' and Machaeroprosopus - congruent with the later definition of Mystriosuchini by Kammerer et al. (2015); however, no synapomorphies were reported in support of this clade.

In three of the four trees identified in this study (D, DC, DCM) Nicrosaurus groups more closely with a number of non-Mystriosuchini leptosuchomorph taxa than with Mystriosuchini.

Nicrosaurus differs from Mystriosuchini in all trees due to the possession of a relatively long

free-section of the postorbital/squamosal bar, rather than a short bar as is synapomorphic for the latter clade [43: $2 \rightarrow 0$ ] (although Nicrosaurus meyeri independently acquires a short postorbital/squamosal bar). Character optimization suggests that the relatively long 'free-section' is plesiomorphic to almost all phytosaurs. This character therefore provides no support for the hypothesized position of Nicrosaurus suggested by Hungerbühler (2002).

Position of Mystriosuchus. The dichotomy of topologies regarding the position of Mystriosuchus, as presented in the results section, reflects the dichotomy seen in the literature. The two most recent hypotheses of the position of Mystriosuchus, based on independent datasets, 1375 are those of Hungerbühler (2002) and Stocker (2010), which respectively place Mystriosuchus in 1376 the less and more derived positions found in this analysis. 
Less derived position. In the analysis of Hungerbühler (2002), the clade in which

1379

1380

1381

1382

1383

1384

1385

1386

1387

1388

1389

1390

1391

1392

1393

1394

1395

1396

1397

1398

1399

Mystriosuchus is the basal member is diagnosed with three synapomorphies.

Presence of a pre-infratemporal shelf (18: 1). We find this character in three trees (D,

DC, DCM) (Figs. 4, 5, 7) to be a synapomorphy of the clade containing Mystriosuchus,

'Redondasaurus' and many members of Machaeroprosopus - generally matching the clade

membership of Mystriosuchini as it was previously defined in both Hungerbühler (2002) and

Stocker (2010). This character is therefore largely unaffected by the placement of Mystriosuchus, and thus supports both hypotheses.

Presence of the pre-infratemporal shelf is restricted in our analysis almost exclusively to the clade discussed above, however this character state independently arises as a polymorphic state in Nicrosaurus and Pravusuchus, and also in Parasuchus hislopi.

Presence of a parietal ledge (21: 2). This character was not included in this analysis as the morphology described is dependent on the morphology of the depressed squamosal processes of the parietal, which is scored elsewhere (character 75). The morphology of this area of the skull is partially considered in character 74 , which scores the ratio of width to length of the parietals between the supratemporal fenestrae. Regardless, this morphology appears to be present in all leptosuchomorph phytosaurs, and would thus be unlikely to support the clade detailed above. Parieto/squamosal bar is strongly depressed (23: 2). We find this character to be synapomorphic for a more inclusive group than that of Hungerbühler (2002), consisting of Smilosuchus gregorii, Mystriosuchus planirostris, their common ancestor and all its descendants [49: $1 \rightarrow 2]$. In three of the trees presented here (D, DC and DCM) (Figs. 4, 5, 7) this transformation independently occurs in Nicrosaurus and Coburgosuchus, whereas in the DM tree 
1400 Nicrosaurus and Coburgosuchus are included in the clade described above. This character

1401 distribution therefore is not found here to support the clade described by Hungerbühler (2002).

1402 No synapomorphies were listed by Hungerbühler (2002) for the clade from which

1403 Mystriosuchus was immediately excluded; therefore, we are unable to comment of the

1404 consistency of our synapomorphies with those of Hungerbühler (2002), for a clade containing

1405 Machaeroprosopus and 'Redondasaurus' but excluding Mystriosuchus. The characters

1406 supporting this phylogenetic arrangement in our study are detailed in the results section.

More derived position. Stocker (2010) identified eight synapomorphies (and two

potential synapomorphies under ACCTRAN) supporting a clade consisting of

Machaeroprosopus mccauleyi, Machaeroprosopus pristinus and Mystriosuchus westphali,

which, in her analysis, represented Mystriosuchini.

restricted only to Mystriosuchus and NHMW 19860024 0001, which consistently sits within the

same clade as Mystriosuchus (and probably represents an unnamed species within this this genus), and is a synapomorphy of the node uniting these taxa in all four trees [2: $1 \rightarrow 2]$. It therefore does not provide support in our analysis for the topology hypothesized by Stocker. inconsistent with Stocker's hypothesis of this character's optimization. 
1423 Machaeroprosopus lottorum, both species of 'Redondasaurus', and Mystriosuchus [3: 0 $\rightarrow 1]$.

1424 This synapomorphy, however, describes a morphological reversal, i.e. state $1 \rightarrow 0$, rather than

$1425 \quad 0 \rightarrow 1$ as suggested by Stocker. In the two trees in which Mystriosuchus occupies a more basal

1426 position (D, DM) (Figs. 4, 6), this character is optimized as a $0 \rightarrow 1$ synapomorphy, as suggested

1427 by Stocker (2010), of a clade similar to that described above, though differing by containing all

1428 members of Machaeroprosopus and excluding Mystriosuchus. In summary, we find this

1429 character to contradict the hypothesized optimization of Stocker (2010), in that a $0 \rightarrow 1$ change is

1430 only found when Mystriosuchus is one of the sister taxa to Machaeroprosopus, rather than

1431 nesting within the clade.

1432 Postorbital squamosal articulation approximately transverse $(22: 1 \rightarrow 2)$. The distribution

1433 of character state (2) is here restricted to members of Machaeroprosopus, Mystriosuchus and

1434 'Redondasaurus', though it twice arises independently in the Leptosuchus-grade OTUs PEFO

143534852 and Coburgosuchus. Despite its restricted occurrence, this trait change [33: $1 \rightarrow 2]$ is not

1436 optimized as a synapomorphy here, though the change from $0 \rightarrow 1$ is optimized in two trees (DC,

1437 DCM) (Figs. 5, 7) as a synapomorphy of the node linking Smilosuchus adamanensis with all

1438 more derived members of Leptosuchomorpha. In the DM tree a $0 \rightarrow 1$ change is a defining feature

1439 of the most recent node linking the clade of Nicrosaurus and Coburgosuchus with all more

1440 derived members of Leptosuchomorpha.

1441 Although not optimized as a synapomorphy, the distribution of this character state is

1442 broadly supportive of not only the hypothesis of Stocker (2010), but also that of Hungerbühler

1443 (2002), as in both topologies, character state (2) is optimized as being plesiomorphic to the clade

1444 containing Machaeroprosopus and Mystriosuchus. 

squamosal as two raised ridges $(23: 1 \rightarrow 2)$. This character state was removed from the analysis

1447

1448

1449

as it could not be reliably identified in any species of phytosaur. A similar character state was added by Butler et al. (2014), referring specifically to the bifurcation of the lateral ridge in species of Parasuchus, though this state has not been observed in any other phytosaurs. Here we find the presence of a ridge to occur sporadically throughout the tree, though with a greater frequency in more derived members of Machaeroprosopus. In Mystriosuchus a ridge is only found as a polymorphism within Mystriosuchus westphali, and it is otherwise entirely absent within the genus. In topologies in which Mystriosuchus is a sister group of Machaeroprosopus the absence state is plesiomorphic to the group. When Mystriosuchus is found within Machaeroprosopus, the clade containing Machaeroprosopus mccauleyi, Machaeroprosopus pristinus and Mystriosuchus westphali is plesiomorphically polymorphic for this character. Furthermore, the presence of any form of ridge is only found as a synapomorphy of derived members of Machaeroprosopus in the D tree; in this topology Mystriosuchus is in any case excluded from the Machaeroprosopus clade.

Posterior process of squamosal dorsoventrally expanded in lateral view $(25: 2 \rightarrow 1)$. This character was altered to use the terminology of Ballew (1989) and Hungerbühler (2002) for the 'knob-like' posterior process found in Machaeroprosopus pristinus, Machaeroprosopus buceros and some specimens of Machaeroprosopus mccauleyi; this was done to reduce ambiguity in character scoring.

This character is not optimized as a synapomorphy of any node close to either the base of Mystriosuchus or Machaeroprosopus in any of the trees presented here. State (1) (which here refers to the same morphology as Stocker's character) is here found to be more frequent in 
1468 derived members of Machaeroprosopus, (excluding Machaeroprosopus pristinus and

1469 Machaeroprosopus buceros which are characterized by a state change of $1 \rightarrow 2$ ) and is

1470 plesiomorphic for the clade. Although the general character distribution generally supports

1471 Stocker's (2010) topological hypothesis for all other members of Stocker's 'Pseudopalatus'

1472 clade, this character does not convey any information regarding the position of Mystriosuchus as

1473 the taxon lacks a posterior process and optimization of this character at the base of

1474 Mystriosuchus relies entirely on its position in the phylogeny. This character therefore provides

1475 no support for the inclusion of Mystriosuchus within Machaeroprosopus.

$1476 \quad$ Supratemporal fenestrae fully depressed, posterior process of parietal and entire

1477 parietal/squamosal bar below level of skull roof $(32: 1 \rightarrow 2)$. Rather than forming a

1478 synapomorphy of only the Mystriosuchini clade used by Stocker (2010), we find this character to

1479 be synapomorphic for the node uniting Smilosuchus gregorii with all more derived taxa (D, DC

1480 (Figs. 4, 5): node 23; DM (Fig. 6): node 22; DCM (Fig. 7): node 25) [49: 1 $\rightarrow$ 2]. Mystriosuchus

1481 is included within this clade regardless of its position with respect to Machaeroprosopus, thus

1482 this character does not provide any support for the inclusion of Mystriosuchus within

1483 Machaeroprosopus.

1484

Border of posttemporal fenestra formed laterally and slightly ventrally by process of

1485

1486

1487

1488

1489

1490 squamosal that extends onto paroccipital process $(37: 1 \rightarrow 2)$. Mystriosuchus is scored here as

polymorphic for this character. In the trees in which it occupies a more derived position

Mystriosuchus forms a sister group to 'Redondasaurus', which consistently displays character state (0); the plesiomorphic state is, in this situation, also polymorphic - providing only limited support for the hypothesis of a derived placement for Mystriosuchus. This character is more consistent here with the hypothesis that Mystriosuchus is sister to Machaeroprosopus, as 
1491 character state (2) alone is plesiomorphic for Mystriosuchus in this position, and forms a

1492 synapomorphy in three of our trees (DC, DM and DCM) (Figs. 5, 6, 7) for the clade formed by

1493 all descendants of the common ancestor of Smilosuchus adamanensis and Mystriosuchus

1494 planirostris $[67: 0 \rightarrow 2]$.

1495 Skull shape boxy in posterior view, width across squamosals approximately equal to

1496 width across ventral edge of quadrates $(38: 1 \rightarrow 0)$. This character was excluded in this analysis

1497 as it is extremely sensitive to taphonomic distortion, and is highly subjective. The most basal

1498 taxon in Mystriosuchini identified by Stocker (2010) is Machaeroprosopus mccauleyi, which

1499 contrary to Stocker's scoring would here be considered to possess a trapezoidal skull shape, as

1500 would Machaeroprosopus buceros and all taxa in 'Redondasaurus', none of which were

1501 included in Stocker's analysis. Despite the exclusion of this character, the inclusion of multiple

1502 additional taxa in this analysis may have affected the optimization of synapomorphies in the

1503 clade.

1504

Rostral crest present, continuous and sloping steeply anteroventrally from nares to

1505 terminal rosette (19: $0 \rightarrow 1$ ) (Possibly additional apomorphy under ACCTRAN). The above

1506 character was altered slightly in this analysis (Appendix 2); however, character state (1) of

1507 Stocker (2010) is still represented by character state (2) here. We find a wide range of

1508 synapomorphy optimizations of this character in our trees, none of which are consistent with the 1509 results of Stocker (2010).

1510 In the DCM tree (Fig. 7) a clade containing Mystriosuchus, 'Redondasaurus' and more

1511 derived members of Machaeroprosopus are partially defined by this character as a

1512 synapomorphy; however, Machaeroprosopus mccauleyi is excluded from the group and the state

1513 transformation is from the presence of a steep, continuous slope posteriorly from the terminal 
1514 rosette, to the presence of a narial crest - the relatively abrupt rise from a thin, tubular snout to

1515 the nares [7:2 $\rightarrow 1]$. Within this clade, 'Redondasaurus' undergoes a state reversal back to the

1516 morphology of a steep, continuous crest [7: $1 \rightarrow 2]$.

1517 The D and DM trees (Figs. 4, 6) both optimize this character as a synapomorphy of a

1518 clade including all species of Machaeroprosopus and 'Redondasaurus'; in these trees, the state

1519 transformation is from the presence of a narial crest, to the presence of a partial rostral crest [7:

$15201 \rightarrow 4]$. A more exclusive clade within the former, containing Machaeroprosopus mccauleyi,

1521 Machaeroprosopus jablonskiae and 'Redondasaurus' again features this character as a

1522 synapomorphy, with a state change from a partial rostral crest, to presence of a continuous steep

1523 slope [7: 4 $\rightarrow 2$ ]; however, this feature is not preserved in Machaeroprosopus jablonskiae - its

1524 presence is inferred by the analysis based on the morphology present in Machaeroprosopus

1525 mccauleyi and 'Redondasaurus' (the holotype of Machaeroprosopus mccauleyi is missing the

1526 anterior end of its rostrum, however the presence of a continuous crest is verified by referred

1527 specimens e.g., PEFO 31219). Mystriosuchus, however, occurs in none of these clades in the two

1528 trees and this character is not found to support any relatively exclusive clade containing

1529 Mystriosuchus.

1530 In the DC tree (Fig. 5) this character is not found to define any clade in which

1531 Mystriosuchus is placed; within close proximity to Mystriosuchus the only clade featuring this as

1532 a synapomorphy is 'Redondasaurus', displaying a change from a narial crest to a continuous,

1533 steep rostral crest [7: $1 \rightarrow 2]$.

1534

Supratemporal fenestrae mostly covered/completely closed dorsally, at most only

1535

anteromedial corners of supratemporal fenestrae visible in dorsal view (33: $1 \rightarrow 2$ ) (Possible

1536 additional apomorphy under ACCTRAN). In the trees in which Mystriosuchus is recovered in a 
1537 derived position this character was only found as a synapomorphy of the clade of Mystriosuchus

1538 + NHMW 198600240001 + MB.R. 2747; specifically, the synapomorphy denotes a character

1539 transformation from state $(2)$ to state $(1)$ [57:2 $\rightarrow 1]$. This does not provide support for the

1540 hypothesis of relationships within Mystriosuchini proposed by Stocker (2010); however, the

1541 majority of nodal optimizations and scorings for this character in the other members of

1542 Mystriosuchini (and for all those included in Stocker's analysis), display character state (2). The

1543 state change observed by Stocker (2010) is likely not found here due to a polymorphic

1544 optimization of states (1) and (2) at the base of the Machaeroprosopus clade (Machaeroprosopus

1545 andersoni and all more derived taxa); at the node one step more derived (Machaeroprosopus

1546 jablonskiae and all more derived taxa) the character is optimized as state (2), as are the majority

1547 of following nodes. It is therefore likely that a state change of (1) to (2) [57: $1 \rightarrow 2]$ is

1548 synapomorphic at the base of Machaeroprosopus which, in the DC and DCM topologies (Figs.

1549 5, 7), is consistent with the phylogenetic hypothesis of Stocker's 'Mystriosuchini' clade.

1550 In the D and DM trees (Figs. 4, 6) (i.e. where Mystriosuchus occupies a less derived

1551 position), this character is only optimized as a synapomorphy of 'Redondasaurus' + NMMNHS

1552 P-31094, as a state change from the supratemporal fenestrae being mostly covered (state 2), to

1553 being fully covered (state 3). However, the synapomorphy suggested by Stocker (2010) is

1554 probably again suppressed due to two nodes optimized as polymorphisms bracketing the base of

1555 Machaeroprosopus. Using the D tree as an example: the two nodes directly basal to

1556 Machaeroprosopus (Fig. 4, nodes 28, 29) are optimized as state (1) and (1 or 2) respectively; in

1557 the following node (the most basal in Machaeroprosopus [node 30]), this character is again

1558 optimized as ( 1 or 2 ). In the next node (node 31$)$ the character is optimized as state (2), as are the

1559 majority of other nodes within the clade. Therefore, we suggest that the topology in the D and 
1560 DM trees is also mostly consistent with the reduction in supratemporal fenestra visibility

1561 identified by Stocker (2010), except that Mystriosuchus is excluded from the supported clade in

1562 the D and DM trees.

1563 Relatively few of the synapomorphies identified in previous analyses to support

1564 particular clades containing Mystriosuchus are corroborated here, despite the dichotomy of tree 1565 topologies presented in this analysis being broadly consistent with each of the previous studies 1566 discussed above.

Implications from the position of Protome. A common component of previous phylogenetic and biostratigraphic work relating to phytosaurs was the distinction between taxa (in particular Leptosuchus and Machaeroprosopus) on the basis of isolated squamosals (Ballew, 1989; Long \& Murry, 1995; Parker \& Irmis, 2006). This was possible because all non-Mystriosuchini members of Leptosuchomorpha possessed generally 'Leptosuchus-like' squamosals and all members of Mystriosuchini possessed more 'Machaeroprosopus-like' squamosals (with the exception of Mystriosuchus which possesses a distinctive squamosal morphology of its own), providing a clear distinction between two 'grades' of phytosaur with no overlap. (D and DM trees) (Figs. 4, 6), and possessing a 'Leptosuchus-like' squamosal, is to preclude the use of isolated squamosals to distinguish between Mystriosuchini and non-Mystriosuchini

1579 leptosuchomorphs. Conversely, in the DC and DCM trees Protome remains outside of 1580 Mystriosuchini (Figs. 5, 7) and is thus consistent with the distinction of Mystriosuchini from 1581 non-Mystriosuchini taxa using only squamosal morphology. 

phylogenetic or biostratigraphic purposes is far from lost; Protome was never recovered within

1584

1585

1586

1587

1588

1589

1590

1591

1592

1593

1594

1595

1596

1597

1598

1599

1600

1601

1602

1603

1604

the Machaeroprosopus or Mystriosuchus clades in any of our trees, and as such has no bearing on the identification of members of Machaeroprosopus or Mystriosuchus based on isolated squamosals. Likewise, the presence of a Machaeroprosopus-like or Mystriosuchus-like squamosal is still consistent only with members of Mystriosuchini. The placement of Protome in all trees in this analysis (i.e. excluded from the main Leptosuchus clade, and distinct from Smilosuchus) does, however, suggest that isolated 'Leptosuchus-like' squamosals should no longer be automatically assigned to Leptosuchus or Smilosuchus, and depending on which phylogeny is used, they should not be used as unequivocal evidence of non-Mystriosuchini taxa. In essence, this means that Machaeroprosopus- and Mystriosuchus-like squamosals remain indicative of Mystriosuchini, whereas Leptosuchus-like squamosals may not be indicative of non-Mystriosuchini Leptosuchomorpha, and further details should be investigated, such as presence/absence of parietal prongs, which are exclusive to Protome, Machaeroprosopus and 'Redondasaurus'.

\section{Relationship of Machaeroprosopus pristinus and Machaeroprosopus buceros.}

Machaeroprosopus pristinus and Machaeroprosopus buceros have previously been suggested to be conspecific, representing sexual dimorphs (Zeigler, Lucas \& Heckert, 2002); a good summary of the current state of this debate is given in Hungerbühler et al. (2013). This hypothesis was supported by the phylogenies of Hungerbühler (2002), Parker \& Irmis (2006) and Hungerbühler et al. (2013) in that they recovered the two taxa as monophyletic, although the hypothesis is inconsistent with the analysis of Ballew (1989). Once again, we find a divergence in our results, 
1605 with the DC and DCM trees (Figs. 5, 7) supporting the hypothesis of conspecificity by resolving

1606 the taxa as sister taxa within the largely pectinate clade of Machaeroprosopus. The D and DM

1607 trees (Figs. 4, 6) do not support this grouping - each finding a clade within Machaeroprosopus

1608 consisting of Machaeroprosopus buceros as the sister taxon to a clade of Machaeroprosopus

1609 pristinus and Machaeroprosopus lottorum.

1610 The monophyly of the two taxa is supported at node 32 in the DC tree by two

1611 synapomorphies: [39: $1 \rightarrow 2$ ] the posterior process of the squamosal is modified into a 'terminal

1612 knob', and [90: $0 \rightarrow 1$ ] the presence of an additional ridge on the lateral surface of the posterior

1613 process of the squamosal, ventral to the ridge or rugosity from the po/sq bar. The relationship in

1614 the DCM tree was also supported by character 90, but character 39 was incorporated into the GM

1615 character defining the lateral shape of the squamosal; this landmark character does support the

1616 node, though all other landmark characters also support the node, and almost every other node in

1617 the tree. The node was also supported in the DCM tree by a continuously measured

1618 synapomorphy: [38: 0.442-0.457 $\rightarrow 0.077-0.319$ ] representing an elongation of the posterior

1619 process of the squamosal.

1620 No synapomorphies were given in support of the sister relationship between

1621 Machaeroprosopus pristinus and Machaeroprosopus buceros in any of the three studies that

1622 found this relationship; however, it was proposed by Zeigler, Lucas \& Heckert (2002) that the

1623 two taxa (or sexual variants) differed only in the lengths and robustness of the premaxillae and

1624 septomaxillae. Our scoring generally agrees with this assertion. In fact, of the 94 characters

1625 included in our analysis, Machaeroprosopus pristinus and Machaeroprosopus buceros were

1626 found to differ in only five characters - four of which are directly related to snout shape,

1627 robustness or length (7: rostral crest; 8: relative transverse width of rostrum; 11: ratio of rostral to 
1628 narial + postnarial length; 79: dorsal surface of snout - cross-sectional shape). The remaining

1629 character (89) scores the diagonal aspect ratio of the infratemporal fenestra, with

1630 Machaeroprosopus pristinus possessing an infratemporal fenestra with a higher aspect ratio, i.e.

1631 the fenestra is more compressed/acute.

1632 In the D and DM trees, the relationship between Machaeroprosopus pristinus and

1633 Machaeroprosopus lottorum to the exclusion of Machaeroprosopus buceros is supported

1634 consistently by three characters: $[7: 4 \rightarrow 1]$ presence of a narial crest; $[8: 2 \rightarrow 1]$ relative transverse

1635 width of the rostrum - moderate; and [89: $0 \rightarrow 1$ ] infratemporal fenestra has a high aspect ratio

1636 (although this is represented as a GM character in the DM tree). As is the case for almost all

1637 nodes of the trees containing GM data, all landmark-based characters also support this node. It

1638 would appear to be a justifiable hypothesis to suggest that in these trees Machaeroprosopus

1639 buceros and Machaeroprosopus pristinus are only separated due to rostral morphology, as

1640 suggested by Zeigler, Lucas \& Heckert (2002). It would seem likely that if rostral robusticity

1641 was assumed to be a sexually dimorphic character, and excluded from analysis, that

1642 Machaeroprosopus buceros and Machaeroprosopus pristinus would be recovered together in all

1643 tree topologies, thus providing support to the hypothesis of conspecificity.

1644

1645 Monophyly of 'Redondasaurus'. 'Redondasaurus' was originally diagnosed by Hunt \& Lucas

1646 (1993) solely on the basis of the lack of visibility of the supratemporal fenestrae in dorsal view.

1647 The genus was re-diagnosed by Spielmann \& Lucas (2012) with a broader complement of

1648 characters: 1) supratemporal fenestrae concealed in dorsal view; 2) reduced antorbital fenestrae;

1649 3) a prominent pre-infratemporal shelf at the anteroventral margin of the lateral temporal

1650 fenestra; 4) septomaxillae wrap around the outer margin of the external narial opening; 5) 
1651 thickened orbital margin; 6) inflated posterior nasal behind the external narial opening; 7)

1652 thickened dorsal osteoderms.

1653 Hungerbühler et al. (2013) were unable to recover 'Redondasaurus' gregorii and

1654 'Redondasaurus' bermani as a monophyletic group in any of their trees; however, we find a

1655 monophyletic 'Redondasaurus' (albeit nested within Machaeroprosopus) in all of our trees. A

1656 possible contributory factor in this difference is that species in the analysis of Hungerbühler et al.

1657 (2013) were scored only with reference to holotype specimens - resulting in an increased

1658 proportion of missing data in some taxa. Total proportions of missing character data in

1659 Hungerbühler et al. (2013) are unavailable, and therefore cannot be compared with those of taxa

1660 surrounding 'Redondasaurus' in the present study; a further difference between these studies,

1661 however, that may be discussed is the inclusion of different characters.

1662

Many of the characters proposed by Spielmann \& Lucas (2012) were not implemented in

1663

the analysis of Hungerbühler et al. (2013); however, in this analysis we included some of these

1664 characters that were used in previous phylogenetic studies and independently identified others

1665 which overlap to a considerable extent with those proposed synapomorphies of 'Redondasaurus'.

1666 The consistency of the characters included in our analysis with the hypothesis of a monophyletic

1667 'Redondasaurus' are discussed below.

1668 Supratemporal fenestrae concealed in dorsal view. As was briefly mentioned above, this

1669 character is found as a synapomorphy of the 'Redondasaurus' clade in all trees presented in this

1670 study [57: $2 \rightarrow 3$ ], and is therefore entirely consistent with the hypothesis of Hunt \& Lucas

1671 (1993). This character state occurs in no other taxon, though is found in NMMNHS P-31094

1672 (referred to 'Redondasaurus' gregorii by Spielmann \& Lucas 2012), which in the D and DM

1673 trees is included within the 'Redondasaurus' clade, but in the other trees is recovered as the 
1674 sister taxon of Machaeroprosopus lottorum, the character state having arisen independently of 1675 'Redondasaurus'.

1677

1678

1679

1680

1681

1682

1683

1684

1685

1686

1687

1688

1689

1690

1691

1692

1693

1694

1695

1696

corner of the antorbital fenestra. The presence of this character state is restricted almost entirely

to 'Redondasaurus' and Mystriosuchus; unsurprisingly, where these two groups form a clade this character is consistently optimized as a synapomorphy. However, in the D and DM trees, where Mystriosuchus is placed basally, distant from 'Redondasaurus', the character only constitutes a synapomorphy for Mystriosuchus rather than 'Redondasaurus'; this may be due to the polymorphic condition of 'Redondasaurus' gregorii for this character. Despite this inconsistency between trees the distribution of this character still broadly supports a monophyletic 'Redondasaurus'.

The diagnostic characters proposed by Spielmann \& Lucas (2012) for 'Redondasaurus' but not included in our analysis are discussed briefly below. We agree that several of these support a sister taxon relationship between 'Redondasaurus' gregorii and 'Redondasaurus' bermani, and are therefore consistent with our results.

Reduced antorbital fenestrae. Whether or not the antorbital fenestrae are substantially reduced may be subjective; in more robust specimens of 'Redondasaurus' (NMMNHS P-4256) the antorbital fenestra does appear smaller than in closely related taxa. However, in more gracile specimens (YPM 3294) the fenestra appears similar in proportions to those of other phytosaurs such as Mystriosuchus. The antorbital fenestrae do appear to exhibit a unique shape in most specimens of 'Redondasaurus'; the general shape is roughly triangular, as is common in Mystriosuchus and Machaeroprosopus, but the anterior- and posterior-most corners of the fenestra are sharp angles, rather than smooth curves. 
1698

1699

1700

1701

1702

1703

1704

1705

1706

1707

1708

1709

1710

1711

1712

1713

1714

1715

1716

1717

1718 1719

studied was observed to possess 'septomaxillae' that extend onto the lateral surface of the external nares. Stocker (2010) noted the presence of this character state in 'Redondasaurus' and suggested it may also occur in Pravusuchus hortus; however, upon inspection of the holotype and referred specimens of Pravusuchus hortus it seems equally likely that the morphology described by Stocker pertains to cracks on the holotype, with the true sutures covered by iron oxide. Rather than a lateral extension of the 'septomaxillae' the feature identified in 'Redondasaurus' and Pravusuchus may represent the paranasals, identified in Machaeroprosopus lottorum by Hungerbühler et al. (2013).

Thickened orbital margin. We here concur with Spielmann \& Lucas (2012); in all specimens of 'Redondasaurus' examined by us, the descending process of the postorbital appears to be greatly thickened to an extent not seen in any other group. For this particular character Spielmann \& Lucas (2012) suggested it is also shared with Coburgosuchus; however, we see no observable expansion of the postorbital in the latter taxon to distinguish it from the condition present in most other phytosaurs.

The descending process of the postorbital in Coburgosuchus has a roughly rectangular cross-section, with the external face relatively thin, but facing anterolaterally. If Spielmann and Lucas (2010) measured this feature in Coburgosuchus diagonally between the anterolateral and posteromedial corners (i.e. the full width observable in direct lateral view), this could account for the increased width, especially given the oblique angle of the process in direct lateral view.

An alternative possibility is that the character is intended to describe a general thickening of the circumorbital bones, resulting in a more blunt appearance and the elevation of the orbital rim; the orbital rim in Coburgosuchus is dorsally elevated, but shows no other evidence of 
1720 thickening (Axel Hungerbühler, pers. comm. to ASJ, 2018). This interpretation would put this 1721 character partially in conflict with character 31, 'Medial margins of orbits', and given that this

1722 morphology is measured in all other taxa based on only the flat lateral-most face of the

1723 descending process, this procedure was also applied here to preserve homology within the 1724 character.

1725 Inflated posterior nasal behind the external narial opening. Although this entire area of 1726 skull is missing in the type specimen of 'Redondasaurus' gregorii (YPM 3294), it is common to 1727 a variable extent in many other specimens referred to the genus by Spielmann \& Lucas (2012). 1728 This feature is not, however, restricted to 'Redondasaurus', as the morphology of specimens 1729 from other taxa frequently overlap with the range of variation observed in 'Redondasaurus'. 1730 Examples include: Nicrosaurus kapffi (SMNS 4379), Machaeroprosopus mccauleyi (PEFO 1731 31219) and Machaeroprosopus lottorum (TTU-P 10076). It may be valid to say that 1732 'Redondasaurus' is the only taxon in which this character state consistently occurs; however, its 1733 variability makes the taxonomic utility of this feature unclear. Given the variable presence of this 1734 character in more than one species of Machaeroprosopus, this character is likely to support the 1735 hypothesis that 'Redondasaurus' is nested within Machaeroprosopus, though verification would 1736 require the inclusion of this character in phylogenetic analyses.

$1737 \quad$ Thickened dorsal osteoderms. The osteoderms of some large phytosaur taxa are also 1738 strongly thickened, e.g., Smilosuchus gregorii (AMNH FR 3060); however, we have not carried 1739 out any sufficiently detailed study of osteoderms to fully assess this proposed synapomorphy. 1740 Until more detailed work emerges on phytosaur osteoderm variation we tentatively accept this 1741 character, though emphasize that potential size correlation should be borne in mind. 
1743 Synonymy with Machaeroprosopus. Hungerbühler et al. (2013) presented three lines of

1744 reasoning in support of the synonymization of 'Redondasaurus' into Machaeroprosopus. First,

1745 they argued that Machaeroprosopus lottorum 'bridges the morphological gap' between other

1746 members of Machaeroprosopus and 'Redondasaurus' gregorii and 'Redondasaurus' bermani in

1747 a number of features, and possesses a combination of characters formerly considered exclusive to 1748 one or other group.

1749 Second, in all trees recovered by Hungerbühler et al. (2013), both species of

1750 'Redondasaurus' were found within the clade of Machaeroprosopus; in analyses that were 1751 constrained to recover 'Redondasaurus' as a monophyletic sister group to Machaeroprosopus,

1752 tree fit lengthened by five extra steps.

1753 Third, they did not find 'Redondasaurus' gregorii and 'Redondasaurus' bermani to form 1754 a clade to the exclusion of species of Machaeroprosopus in any of their trees; instead, the two 1755 taxa were interspersed with members of Machaeroprosopus, with 'Redondasaurus' gregorii 1756 being recovered in a substantially more derived position than 'Redondasaurus' bermani in every 1757 tree.

1758

The first two points are consistent with our results; however, with regard to their third

1759

1760

1761

1762

1763

1764

1765

point we find the exact opposite - that these taxa are always monophyletic to the exclusion of species of Machaeroprosopus. In all trees this clade is supported by two to four synapomorphies, with one (supratemporal fenestra completely obscured in dorsal view) consistently present in all trees. One exception is NMMNHS P-31094, which was previously referred to 'Redondasaurus' (Heckert et al., 2001), yet in half of our trees is found to form a monophyly with Machaeroprosopus lottorum. This observation corresponds well with the findings of Hungerbühler et al. (2013). On this basis, and due to 'Redondasaurus' consistently being 
1766 resolved within Machaeroprosopus, we agree with the suggestions of Long \& Murry (1995) and

1767 Hungerbühler et al. (2013) that 'Redondasaurus' should be synonymized with

1768 Machaeroprosopus. It is clear, however, from our phylogenies, differences in cranial

1769 morphology and the general difference in stratigraphic age, that the species attributed to

1770 'Redondasaurus' represent some of the most derived taxa within Machaeroprosopus.

1771

1772 Specimen-level OTUs. A number of specimens were included as individual OTUs in our

1773 analyses in order to test their affinities. Here we report on those of particular importance and

1774 those which occupy an interesting phylogenetic position.

1775

NMMNHS P-4781. This specimen was originally assigned to Angistorhinus by Hunt,

1776

1777

1778

1779

1780

1781

1782

1783

1784

1785

1786

1787

1788
Lucas \& Bircheff (1993) (see Appendix 1); our analyses corroborate that view, recovering the specimen as the most basal member of the Angistorhinus clade in all analyses, with the node supported by some of the highest Bremer and frequency support scores in the entire tree. The node is additionally supported by a number of synspomorphies: two synapomorphies were consistent between the D, DC and DM trees [56: $0 \rightarrow 1$ ] parietal-squamosal bars curved medially before attaching to squamosal; [58: $0 \rightarrow 1$ ] parietal-squamosal bars wide - approximately the same width as the po/sq bar. One further synapomorphy was only present in the DC and DCM trees, being scored continuously [87: 0.106-0.110 (0.106-0.132 in DCM tree $) \rightarrow 0.103$ ] relatively robust jugal - becoming slightly more robust. Despite being less derived than all other members of the Angistorhinus clade, this specimen is potentially younger than the others - being from the early Norian (225-218 Mya), rather than the Carnian to early Norian (232-225 Mya).

PEFO 34852. This specimen has previously been identified as 'Smilosuchus' adamanensis (Griffin et al., 2017); however, we disagree with their diagnosis (see Apendix 1), 
1789 suggesting the specimen shares more similarities with Leptosuchus crosbiensis. Our analysis in 1790 part supports our hypothesis, as PEFO 34852 forms a monophyletic group with L. crosbiensis in 1791 half of our trees (DC and DCM). In the other half (D and DM), PEFO 34852 forms a relationship 1792 with 'Smilosuchus lithodendrorum'; however, this group's closest sister taxon is L. crosbiensis in 1793 both trees, and in addition ' $S$. lithodendrorum' has previously been suggested to be synonymous 1794 with L. crosbiensis (Long \& Murry, 1995). The specimen's relationship with L. crosbiensis in the DC and DCM trees was supported by two consistent synapomorphies: [48: $0 \rightarrow 1$ ] squamosal fossa does not reach posterior edge of

1797

1798

1799

1800

1801

1802

1803

1804

1805

1806

1807

1808

1809

1810 squamosal; [89: $0.457 \rightarrow 0.462]$ increase in the aspect ratio of the infra-temporal fenestra, however the latter synapomorphy is represented as a GM character in the DCM tree, and all other landmark-based characters also support the node. Griffin et al. (2017) scored character 48 in the opposite way to which we did here and could represent some subjectivity with regards to the delimitation of this character's states. This was one of the characters that was used to identify the specimen as ' $S$ '. adamanensis; however, only very few verifiable specimens of ' $S$ '. adamanensis exist and all other 'Smilosuchus' taxa were observed to be polymorphic with regards to this character, so this may not be an ideal species identifier.

In the D and DM trees, PEFO 34852 forms a relationship with ' $S$. lithodendrorum' to the exclusion of L. crosbiensis - this relationship is supported by two consistent synapomorphies: [3: $0 \rightarrow 1$ ] alveolar ridges inconsistently visible or entirely hidden in lateral view; [33: $0 \rightarrow 2$ ] sutural articulation of postorbital and squamosal in dorsal view - approximately transverse. In the D tree only a further synapomorphy is given: [7:4 $\rightarrow 2$ ] a straight, steep slope from the nares to the premaxilla; although the crest does undulate to an extent, we feel that this scoring was most 
1811 appropriate, given the continuous anterior slope of the rostrum, with no horizontally level

1812 portions. In the DM condition all landmark-based characters are also found to support the node.

PEFO 34852 is the first phytosaur specimen that has been recorded as possessing three

1814

1815

1816

1817

1818

1819

1820

1821

1822

1823

1824

1825

1826

1827

1828

1829

1830

1831

1832

1833

sacral vertebrae (Griffin et al., 2017); however, in their discussion the authors make it clear that

this apparent novel morphology is likely widespread throughout Phytosauria, being present in

members of non-leptosuchomorph Mystriosuchinae (Angistorhinus), other non-Mystriosuchini

leptosuchomorphs (holotype of ' $S$ '. adamanensis) and members of Mystriosuchini

('Machaeroprosopus' zunii, 'Redondasaurus'), and was previously misinterpreted in past

studies. The morphologies only appeared to differ in the extent to which various sutures had

fused, which may be due to ontogenetic factors. Given this feature is seemingly homogeneous

within phytosaurs, the different taxonomic position for this specimen that we propose here

should not affect the conclusions drawn by Griffin et al. (2017).

MB.R.2747. This specimen represents the only substantial Rhaetian phytosaur material from Europe, and by a considerable margin is also the largest phytosaur currently known from that continent. We consistently recovered this specimen as the basalmost taxon in the Mystriosuchus clade in all our trees; given the two conflicting positions in which the Mystriosuchus clade has been found in our trees, we also find two independent suites of synapomorphies supporting MB.R.2747 at the base of this clade.

Only one character was found consistently in all trees: [85: $1 \rightarrow 0]$ the pre-infratemporal shelf merges dorsally into the lateral face of the jugal, rather than continuing as a ridge to contribute to the descending process of the postorbital. In the D and DM trees in which Mystriosuchus occupies a more basal position, there are two additional consistent synapomorphies: [59: 1, 2 $\rightarrow 3$ ] dorsal edge of the parietal/squamosal bar entirely, or in parts 
1834 vertical; [84: $0 \rightarrow 1$ ] the pre-infratemporal shelf extends anteriorly past the posteriormost corner 1835 of the antorbital fenestra. In addition, in the DM condition all GM characters support this node. In the DC and DCM trees the Mystriosuchus clade is also supported by two additional

1837

1838

1839

1840

1841

1842

1843

1844

1845

1846

1847

1848

1849

1850

1851

1852

1853

1854

1855 1856 synapomorphies: [57:2 $\rightarrow 1$ ] supratemporal fenestrae mostly visible in dorsal view; [61: $2 \rightarrow 1]$ lateral wall of the supraoccipital shelf is low and continuously thin. The node is additionally supported by all landmark-based characters in the DCM tree.

Similarly, to Angistorhinus and NMMNHS P-4781, MB.R. 2747 is basal to the Mystriosuchus clade, yet is younger in age (Appendix 1), suggesting a ghost range for this taxon extending to the middle-late Norian. This specimen was originally referred to 'Angistorhinopsis ruetimeyeri'; however, the type specimen of that genus and species contains no diagnostic material and may be chimaeric, and as such has been widely accepted as a nomen dubium. The placement of this specimen at the base of the Mystriosuchus somewhat corroborates the speculative cranial reconstruction of the specimen by Huene (1923), in which the depressed temporal arcade and the posterior processes of the squamosals are modelled after Mystriosuchus. Further investigation into this specimen, including a thorough redescription, is currently underway.

USNM V 17098. This specimen was referred to Leptosuchus sp. by Long \& Murry (1995), yet in our analyses it is constantly recovered in a more derived position than other members of non-Mystriosuchini Leptosuchomorpha; in three of our trees it is recovered within Mystriosuchini. The specimen is labelled as 'Machaeroprosopus zunii' without any written justification, though in support of this we recover this specimen in a similar position to the holotype of 'Machaeroprosopus zunii' in three of our trees, in one of which the two OTUs form a clade. 
The single clade that supports the identification of 'Machaeroprosopus zunii' (DC tree,

1858

1859

1860

1861

1862

1863

1864

1865

1866

1867

1868

1869

1870

1871

1872

1873

1874

1875

1876

1877

1878

1879

Fig. 5, node 30) has a relatively good frequency support score, and possesses two

synapomorphies: [39: $1 \rightarrow 0$ ] posterior process of the squamosal greatly dorsoventrally expanded;

[53: $1 \rightarrow 2]$ dorsally expressed ridge present around anterior and medial edge of the

supratemporal fenestra. Whether or not USNM V 17098 is referable to 'Machaeroprosopus

zunii' does, however, remain problematic due to the erection and decription of the species based

on many cranial and mandibular fragments, grouped on the basis of their geographic area of

discovery, rather than morphological similarity (Camp, 1930). To produce a comprehensive

reanalysis of this taxon would require intensive study of all material referred by Camp (1930);

however, this is well beyond the scope of this study.

The consistently derived position of 'Machaeroprosopus zunii' does suggest that it may not be simply a species of Leptosuchus as suggested by Long \& Murry (1995). The phylogenetic position of USNM V 17098, and of the holotype of 'Machaeroprosopus zunii' (where they occupy a similar placement [Figs. $4,5,6]$ ) is supported by five consistent synapomorphies in the D and DM trees (Figs. 4, 6): [3: $0 \rightarrow 1$ ] alveolar ridges inconsistently visible or entirely hidden in lateral view; [4: $0 \rightarrow 1$ ] presence of a ventral alveolar bulge between the premaxilla and maxilla;

$[7: 1 \rightarrow 4]$ rostral crest extends horizontally from nares for less than half the length of the nares, then becomes tubular; [46: $1 \rightarrow 0$ ] (incorporated into landmark character in DM tree) ventral margin of squamosal slopes continuously anteroventrally from the posterior edge of the posterior process to the opisthotic process, without any horizontal edge; [47: $0 \rightarrow 1]$ presence of a subsidiary opisthotic process of the squamosal.

In the DC tree the position of the clade of USNM V 17098 and the holotype is supported by two different synapomorphies: [22: $3 \rightarrow 2$ ] reduced antorbital fossa in which the lacrimal, 
1880 1881 ridge.

maxillary and jugal fossae are not touching; [75: $0 \rightarrow 1]$ presence of a prominent, sharp palatal

The character states scored in USNM V 17098, regarding characters 3, 4 and 46 are almost exclusively restricted to members of 'Smilosuchus' and robust taxa in Machaeroprosopus. The states in characters 47 and 75 are almost exclusively limited to most members of Machaeroprosopus, though these states also occur in 'Smilosuchus' gregorii and Mystriosuchus (in character 47), and in Rutiodon, Nicrosaurus and Mystriosuchus (in character 75). The character states recorded for characters 7 and 22 occur frequently in many taxa throughout the tree, including many members of Leptosuchus and 'Smilosuchus'. Further study is required to ascertain the taxonomic validity of 'Machaeroprosopus zunii', but we do find a reasonable quantity of evidence to support it as being distinct from Leptosuchus.

NMMNHS P-4256 \& P-31094. These specimens have both been previously referred to 'Redondasaurus' (Hunt, 1994; Heckert et al., 2001); however, their positions in our trees produce some uncertainty regarding this. NMMNHS P-31094 was found to form a clade with both species of 'Redondasaurus' in two of our trees (D and DM) (Figs. 4, 6), whilst in the same trees NMMNHS P-4256 falls basal to Machaeroprosopus jablonskiae, and slightly more derived than Machaeroprosopus mccauleyi. The supratemporal arcade of Machaeroprosopus jablonskiae is robust, and also possesses some of the features of 'Redondasaurus', such as broad and proportionately short postorbital/squamosal bars and the lack of a knob-like posterior process of the squamosal; its phylogenetic proximity to 'Redondasaurus' is therefore unsurprising, furthermore NMMNHS P-4256 has also been referred to Machaeroprosopus mccauleyi (Hunt, Lucas \& Spielmann 2006), so the proximity of this specimen to Machaeroprosopus mccauleyi is also understandable. 
Machaeroprosopus mccauleyi and Machaeroprosopus jablonskiae are recovered at the base of

1905

1906

1907

1908

1909

1910

1911

1912

1913

1914

1915

1916

1917

1918

1919

1920

1921

1922

1923

1924

the Machaeroprosopus clade, suggesting that rather than being closely associated with

'Redondasaurus', NMMNHS P-4256 appears to be more closely linked to Machaeroprosopus mccauleyi and Machaeroprosopus jablonskiae. In these tree topologies, NMMNHS P-31094 remains one of the more derived members of the Machaeroprosopus clade; however, it forms a clade with Machaeroprosopus lottorum exclusive to the slightly more derived clade formed by the two species of 'Redondasaurus'.

The node uniting NMMNHS P-31094 and Machaeroprosopus lottorum is supported by five synapomorphies in the DC tree (Fig. 5), and three synapomorphies (plus all five landmarkbased characters) in the DCM tree (Fig. 7), with all synapomorphies at this node in the DC tree overlapping with those in the DCM tree. The synapomorphies are as follows: [25: 0.439-0.514 (DCM: $0.325-0.439) \rightarrow 0.113$ ] antorbital fenestra is relatively short anteroposteriorly; [34: $1 \rightarrow 2$ ] anteroventral corner of infra-temporal fenestra in front of anterior rim of the orbit; [53: $1 \rightarrow 0$ ] absence of a dorsally expressed ridge around the anterior or medial edges of the supratemporal fenestra; [54: 0.180-0.197 $\rightarrow$ 0.039-0.095 (DCM: landmark-based)] relatively wide postorbital/squamosal bar; [89: 0.550-0.620 $\rightarrow 0.710(\mathrm{DCM}$ : landmark-based)] relatively high aspect-ratio of the infra-temporal fenestra.

In the D and DM trees (Figs. 4, 6) the 'Redondasaurus' clade (if defined to include both conventional species plus NMMNHS P-31094), is consistently supported by only four synapomorphies (and all landmark-based characters in the DM tree): [19: $1 \rightarrow 0$ ] interorbitalnasal area is flat in lateral view; [57:2 $\rightarrow 3$ ] supratemporal fenestra completely obscured in dorsal 
1925 view; [59: $2 \rightarrow 3$ ] dorsal edge of the parietal/squamosal bar is either entirely or in parts vertical;

$1926[63: 1 \rightarrow 0]$ supraoccipital shelf is shallow and its longitudinal axis is predominantly vertical.

Martz \& Parker (2017) in part defined the base of the Apachean biozone (207-202 Ma)

1928

1929

1930

1931

1932

1933

1934

1935

1936

1937

1938

1939

1940

1941

1942

1943

1944

1945

1946

as the stratigraphically lowest occurrence of 'Redondasaurus'; NMMNHS P-31094 is dated to the Rhaetian (208.5-201.3 Mya), which largely overlaps the Apachean biozone; however, NMMNHS P-4256 does not, being instead dated to the late Norian (c. 218-208 Mya). If the latter specimen was found to be consistently recovered within 'Redondasaurus' it would extend the age range of this taxon, thus invalidating the definition of the Apachean given by Martz \& Parker (2017). Given that NMMNHS P-4256 was never recovered within 'Redondasaurus' in our analysis, and was separated from 'Redondasaurus' by Machaeroprosopus jablonskiae, we find no reason to doubt the biozones of Martz \& Parker (2017).

\section{Effects of scoring method}

CI and RI. The consistency indices calculated for the four character coding variables (D, DC, DM and DCM) were broadly similar; though as noted above, those which incorporated continuous data produced slightly better scores than the others. Regardless, all CI values displayed a significantly higher consistency than expected of random data (for a dataset of 43 taxa and between 90 and 94 characters), based on comparisons with simulated data in Klassen, Mooi \& Locke (1991). Differences in the retention indices (RI) were marginal between all conditions, indicating that despite the increased homoplasy in GM datasets, the same proportion of synapomorphic information was retained as in datasets excluding GM data. As the RIs of the continuous and non-continuous datasets are almost identical, it is unlikely that the difference in 
1947 homoplasy indicated by CI between the datasets can be ascribed to a greater proportion of

1948 uninformative or autapomorphic characters in the continuous dataset.

Tree length. When comparing the tree-length (weighted homoplasy) produced by datasets with equal numbers of characters, trees that incorporate continuous data are consistently shorter than those which exclude it. The D tree (94 characters) produced a tree-length of 31.90 , whereas the DC tree (94 characters) produced a length of 27.46. Likewise, the DM tree (90 characters) recovered a length of 30.52, while the DCM (90 characters) tree-length was 25.44 .

The effects of including GM data cannot be interpreted in the same way as above; the base D dataset contains more characters than the DM dataset, and we would therefore naturally assume that the DM tree would be shorter just by virtue of having fewer characters. It is, however, possible to say that the continuous characters in this study do have a shortening effect on tree-length when compared to the standard discrete data tree (D vs DC tree-length). Furthermore, the incorporation of continuous data into the DM dataset (DM vs DCM tree-length) resulted in a greater reduction in tree length than was produced by the combined effect of incorporating GM data into the $\mathrm{D}$ dataset and the associated reduction in the number of characters (D vs DM). This may indicate that the continuous characters in this dataset produced a stronger influence on tree length than the GM characters. Additionally, as extended implied weighting was in effect the shorter tree lengths equate to reduced homoplasy. Considering the higher consistency index of the continuous datasets, it is unsurprising that the continuous 1967 datasets also produce the shortest tree lengths when compared to D and DM, as under implied 1968 weighting, the 'length' of each character is partially calculated using the same technique as the 
1969 consistency index. The overall tree-length is an ensemble score of estimated homoplasy within

1970 the dataset - similarly the CI measures ensemble consistency.

1971

1972 Topological similarity. In analyses of topological similarity (maximum agreement subtrees, 1973 SPR distances and Robinson-Foulds distance) the DC tree differed from the base discrete data 1974 tree by $37.2 \%, 32.5 \%$ and by 0.45122 in each respective metric, whereas the DM tree only 1975 differed from the base tree by $23.3 \%, 15 \%$ and 0.23171 respectively. This suggests that the 1976 incorporation of continuous characters into the base dataset altered the topology of the output 1977 tree to a greater extent than by incorporating GM characters. Within our overall dataset, continuous characters appear to exert a stronger influence on

1979

1980

1981

1982

1983

1984

1985

1986

1987

1988

1989

1990 tree topology and tree length than GM characters, and the incorporation of continuous rather than GM characters produces a tree that is found to be slightly less homoplastic by consistency index and implied weighting.

It should be noted that the elevated influence of continuous data may be related to variations in our dataset rather than an inherent property of the scoring method. For example, in the DC condition continuous data accounted for $10.64 \%$ of the characters used, but in the DM condition GM data only accounted for $5.56 \%$ of the total characters; therefore, continuous data may have more influence as it constituted a greater proportion of the data. Alternatively, it is possible that the characters scored as continuous data may, by chance, have been less homoplastic than those scored using GM techniques. It should also be noted that these two influences are not mutually exclusive. 
1991 Support metrics. A slightly different finding to the above was obtained when investigating

1992 Bremer and frequency supports. When collapsing nodes with Bremer scores less than that of the

1993 average character step length (0.11), the datasets incorporating GM data (DM and DCM)

1994 produced consistently poorer total Bremer support for the collapsed tree, and retained less nodes

1995 than the non-GM datasets (D and DC). The mean Bremer support values for nodes exceeding the

1996 cut-off were almost entirely consistent between all four data treatments, whereas at the lower

1997 cut-off (0.08) these means were more variable. This suggests that the cut-off of 0.11 largely

1998 retained the nodes for which the Bremer support values were more resistant to the effects of data

1999 treatment.

2000 In contrast to Bremer scores, frequency supports performed more consistently between

2001 scoring techniques in terms of number of nodes retained; however, similarly to the results of

2002 Bremer supports, the DCM treatment produced the worst results. The pattern of summed

2003 frequency values matched the general trend of the Bremer supports, i.e. the GM conditions

2004 produced lower total support for the collapsed tree; although, the mean frequency supports across

2005 the four collapsed trees were again relatively constant.

2006 When the Bremer and frequency support values were averaged in five tree regions and

2007 summed within each tree, in both metrics the DC condition produced the best values and the two

2008 GM conditions produced the worst.

2009

2010 Conclusions

2011

2012 Our analyses, split between D+DM and DC+DCM trees, broadly support the partially conflicting

2013 phylogenetic relationships recovered by previous studies (Hungerbühler \& Sues, 2001; 
2014 Hungerbühler, 2002; Parker \& Irmis, 2006; Stocker, 2010, 2012, 2013; Hungerbühler et al., 2015 2013; Butler et al., 2014; Kammerer et al., 2015). In particular, a close relationship between 2016 Rutiodon and Angistorhinus, suggested by Hungerbühler \& Sues (2001) was recovered in all of 2017 our trees, as was the paraphyly of 'Paleorhinus' (Wroblewski, 2003; Parker \& Irmis, 2006; 2018 Butler et al., 2014), the monophyly of Parasuchus (Kammerer et al., 2015), the placement of 2019 Wannia as the basalmost member of Parasuchidae (Stocker, 2013; Kammerer et al., 2015), the 2020 recovery of Diandongosuchus as the most basal member of Phytosauria (Stocker et al., 2017), and the synonymy of 'Redondasaurus' and Machaeroprosopus (Hungerbühler et al., 2013). The conflicting positions of Mystriosuchus were also recovered in our trees; the D and DM trees found Mystriosuchus as a clade basal to Machaeroprosopus (Hungerbühler, 2002; Parker \& Irmis, 2006; Hungerbühler et al., 2013), whereas the DC and DCM trees placed Mystriosuchus as one of the most derived clades within Mystriosuchini, and within the Machaeroprosopus clade (Ballew, 1989; Stocker, 2010, 2012, 2013; Butler et al., 2014; Kammerer et al., 2015). our recovery of Nicrosaurus nested deeply within leptosuchomorph taxa, as opposed to being a basal member of Mystriosuchini; this led us to redefine Mystriosuchini, by excluding Nicrosaurus as an internal specifier. Machaeroprosopus pristinus and Machaeroprosopus buceros were found to form a monophyly in half of our trees (DC and DM), supporting the hypothesis of conspecificity 2033 (Zeigler, Lucas \& Heckert, 2002). Furthermore, in the trees in which Machaeroprosopus 2034 pristinus instead formed a relationship with Machaeroprosopus lottorum to the exclusion of Machaeroprosopus buceros (D and DM), the relationship was predominantly supported by 
2037 gender rather than species (Abel, 1922; Colbert, 1947; Zeigler, Lucas \& Heckert, 2002; Hunt, 2038 Lucas \& Spielmann 2006; Kimmig, 2009), and if so would be irrelevant to phylogenetic 2039 analysis.

2040 Protome was recovered in a far more derived position than before, being consistently 2041 found within Leptosuchomorpha, and in two trees within Mystriosuchini. This has wide ranging 2042 implications for the use of isolated phytosaur squamosals in biostratigraphy; Leptosuchus-type 2043 squamosals have previously been restricted to non-Mystriosuchini taxa, however the potential 2044 inclusion of Protome (which possesses Leptosuchus-type squamosals) in Mystriosuchini 2045 indicates this distinction between phytosaur 'grades' may not be justified. Machaeroprosopustype squamosals, however, remain a potential identifier for membership of Mystriosuchini.

We found a great deal of inconsistency in the relationships of leptosuchomorph phytosaurs, especially non-Mystriosuchini leptosuchomorphs. In contrast to the findings of Stocker (2010), we found inconsistent support for a monophyletic Leptosuchus (present only in condition D), and no support for the monophyly of Smilosuchus. The inconsistency among these phytosaurs is reminiscent of their difficult taxonomic and phylogenetic history, in which these taxa were shuffled between genera including Rutiodon, Leptosuchus, Smilosuchus and Machaeroprosopus, in various combinations (Camp, 1930; Colbert, 1947; Gregory, 1962b; Ballew, 1989; Long \& Murry, 1995; Stocker, 2010). Although the overall consensus tree (Fig. 8) suggests most derived phytosaurs could be classified as numerous monospecific genera, it seems more likely that the true phylogenetic relationships are masked by wildcard taxa/specimens and uncertainties in intra/interspecific variation. Further work, investigating the relationships of leptosuchomorph phytosaurs, building on the studies of Stocker (2010) and Hungerbühler et al. 
2059 (2013) and including predominantly well-known, morphologically complete taxa would be very

2060 useful.

2061 To broadly summarize our findings regarding character use - for our dataset it appears

2062 that continuous characters consistently exert a greater influence over the results than GM

2063 characters, and in comparison to datasets excluding continuous characters, they also appear to

2064 reduce homoplasy. GM characters in this study produced trees with generally worse nodal

2065 support values, and despite the lack of polytomies within the best-fit trees, when collapsing

2066 nodes to adjust for over-resolution of the tree the GM datasets retained fewer nodes at a

2067 reasonable cut-off value than the continuous and discrete trees.

2068

A potential drawback of using GM data in particular is the relative difficulty, in

2069

comparison to discrete characters, of interpreting morphological changes in a way that is useful

2070

for producing written diagnoses. For synapomorphic continuous characters it is possible to

2071

express the character 'state' of a taxon or group as a numerical range and transformations as

2072

shifts from one range to another; however, describing subtle, but apparently phylogenetically

2073

relevant changes in shape according to geometric morphometrics necessitates either multiple

2074

diagrams of landmark displacements at supported nodes, or long breakdowns of morphology,

2075

and an elevation of analytical complexity for relatively little gain (at least in the case of this

2076

dataset). An example of the perplexity caused by GM data may be seen in the nodal

2077

synapomorphies in the treatments which incorporate GM data (Appendix 3); in both trees (DM

and DCM) almost all GM characters are optimized as synapomorphies for almost every node.

2079

A further obstacle to incorporating substantial amounts of GM data into phylogenetic

2080

analyses is that in palaeontological datasets, and especially with phytosaurs, it is relatively

2081

uncommon to find the pristine, non-deformed morphologies necessary for geometric 
2082 morphometric comparisons. Furthermore, GM characters may inherently encompass multiple

2083 discrete characters; if one aspect of a morphological feature is deformed (thus rendering the

2084 feature unusable for GM), all associated morphological features to be scored by the same

2085 configuration of landmarks would also have to be excluded from the analysis. In this sense, the

2086 addition of GM characters into a dataset may actually increase the quantity of missing data in a

2087 dataset where the characters could be alternatively scored with discrete or continuous methods.

2088 For the various reasons outlined above we prefer the D and DC trees as they either

2089 incorporate continuous data, exclude GM data, or both. These trees are also representative of the

2090 two conflicting topologies found in this study and are generally consistent with previous analyses

2091 of ingroup Phytosauria. On the basis of statistical comparisons and similar nodal support values

2092 we suggest that either tree would be equally valid for use in further study; however, we find the

2093 D tree to be potentially less computationally and systematically problematic.

2094 First, the D matrix uses only discrete characters and is therefore more easily implemented 2095 into a broad range of phylogenetic software packages, allowing new data to be easily added and

2096 analysed in the future, rather than the DC matrix which (in its current form) is restricted to the

2097 software TNT. Additionally, whilst neither tree recovers high support values for non-

2098 Mystriosuchini Leptosuchomorpha, the D tree does retain a monophyletic Leptosuchus clade

2099 (with the addition of 'Smilosuchus lithodendrorum'). The D tree also recovers Mystriosuchus as

2100 distinct from Machaeroprosopus, thus maintaining a valid distinction between genera

2101 respectively endemic to Europe or the USA. The genus 'Redondasaurus' forms a clade within

2102 Machaeroprosopus in both trees, but in the D tree the specimen NMMNHS P-31094, (diagnosed

2103 as 'Redondasaurus' on the basis of possessing many of the group's synapomorphies) is also a

2104 member of the clade, as expected, rather than forming a sister-group with Machaeroprosopus 
2105 lottorum as in the DC tree. The position of Machaeroprosopus lottorum in the D tree, in a sister-

2106 group with Machaeroprosopus pristinus, supports the validity of the latter taxon, suggesting it is

2107 not a sexual dimorph of Machaeroprosopus buceros. For these reasons, we tentatively suggest

2108 the use of the discrete-character tree for further analyses.

2109

\section{Acknowledgements}

2111

2112 We thank the following people for access to, and assistance with, specimens in their care: Carl

2113 Mehling (AMNH), Oliver Rauhut (BSPG), William Simpson (FMNH), Philipe Havlik and Davit

2114 Vasilyan (GPIT), Daniela Schwarz and Thomas Schossleitner (MB), Ronan Allain (MNHN),

2115 Casey Holliday and James Schiffbauer (MU), Lorna Steel (NHMUK), Ursula Göhlich (NHMW),

2116 Eckhard Mönnig (NMC), Amanda Cantrell (NMMNHS), William Parker and Matthew Smith

2117 (PEFO), Rainer Schoch (SMNS), Kenneth Bader and Matthew Brown (TMM), Bill Mueller

2118 (TTU-P), Patricia Holroyd (UCMP), Michael Brett-Surman (USNM), Daniel Brinkman (YPM),

2119 and Robert Bronowicz and Tomasz Sulej (ZPAL). We are also grateful to Pablo Goloboff for

2120 TNT script suggestions and bug fixes, and to Octavio Mateus for useful discussion of

2121 phylogenetic characters. Finally, we thank Mark Young, Caroline Parins-Fukuchi, William

2122 Parker \& Axel Hungerbühler for constructive comments that greatly improved the manuscript. 
2125 References

2126

2127 Abel, O. 1922. Die Schnauzenverletzungen der Parasuchier und ihre biologische Bedeutung.

2128 Paläontologische Zeitschrift, 5, 26-57 DOI: 10.1007/BF03041524

2129

2130

Adams, D. C., \& Otárola-Castillo, E. 2013. Geomorph: an R package for the collection and

2131

2132 analysis of geometric morphometric shape data. Methods in Ecology and Evolution, 4, 393399 DOI: $10.1111 / 2041-210 X .12035$

2133

2134

2135

Ballew, K. L. 1989. A phylogenetic analysis of Phytosauria (Reptilia: Archosauria) from the Late Triassic of the western United States. Unpublished MA thesis, University of California,

2136 Berkeley, 73 pp.

2137

2138

2139

2140

Beaulieu, J. M., Jhwueng, D. C., Boettiger, C., \& O’Meara, B. C. 2012. Modeling stabilizing selection: expanding the Ornstein-Uhlenbeck model of adaptive evolution. Evolution: International Journal of Organic Evolution, 66, 2369-2383 DOI: 10.1111/j.1558-

2141 5646.2012.01619.x

2142

2143

2144

Bell, M. A., \& Lloyd, G. T. 2014. strap: an R package for plotting phylogenies against

2145 stratigraphy and assessing their stratigraphic congruence. Palaeontology, 58, 379-389 DOI:

2145 $10.1111 /$ pala. 12142

2146 
2147 Benton, M. J., \& Storrs, G. W. 1994. Testing the quality of the fossil record: paleontological

2148 knowledge is improving. Geology, 22, 111-114 DOI: 10.1130/0091-

2149 7613(1994)022<0111:TTQOTF $>2.3 . \mathrm{CO} ; 2$

2150

2151

2152

Benton, M. J., Hitchin, R., \& Wills, M. A. 1999. Assessing congruence between cladistic and

2153

2154

2155

2156

2157 stratigraphic data. Systematic Biology, 48, 581-596.

Bookstein, F. L. 1996. Landmark methods for forms without landmarks: localizing group differences in outline shape. Mathematical Methods in Biomedical Image Analysis, 1996, Proceedings of the Workshop on Mathematical Methods in Biomedical Image Analysis, 279289.

2158

2159

2160

2161

2162 biogeography. Geological Magazine, 150, 110-122 DOI: 10.1017/S0016756812000428

2163

2164

Buffetaut, E. 1993. Phytosaurs in time and space. Paleontolol Lombarda Nuova serie, 2, 39-44.

2165

2166

2167

Butler, M. A., \& King, A. A. 2004. Phylogenetic comparative analysis: a modeling approach for adaptive evolution. The American Naturalist, 164, 683-695 DOI: 10.1086/426002

2168

2169

Butler, R. J., Rauhut, O. W., Stocker, M. R., \& Bronowicz, R. 2014. Redescription of the 2170 phytosaurs Paleorhinus ('Francosuchus') angustifrons and Ebrachosuchus neukami from 
2171 Germany, with implications for Late Triassic biochronology. Zoological Journal of the 2172 Linnean Society, 170, 155-208 DOI: 10.1111/zoj12094

2173

2174 Camp, C. L. 1930. A study of the phytosaurs with description of new material from western 2175 North America. Memoirs of the University of California, 10, 1-174.

2176

2177 Case, E. C. 1920. Preliminary description of a new suborder of phytosaurian reptiles with a 2178 description of a new species of Phytosaurus. The Journal of Geology, 28, 524-535 DOI:

$2179 \quad 10.1086 / 622732$

2180

2181

2182

Case, E. C. 1922. New reptiles and stegocephalians from the Upper Triassic of western Texas. Carnegie Institute of Washington Publication, 321, 1-84.

2183

2184 Case, E. C. 1929. Description of the skull of a new form of phytosaur: with notes on the 2185 characters of described North American phytosaurs. University of Michigan Studies, Memoirs 2186 of the University of Michigan Museums, 2, 1-56.

2187

2188

Case, E. C., \& White, T. E. 1934. Two new specimens of phytosaurs from the Upper Triassic of 2189 western Texas. Contributions from the Museum of Paleontology, University of Michigan, 4, 2190 133-142. 
2192 Catalano, S. A., Goloboff, P. A., \& Giannini, N. P. 2010. Phylogenetic morphometrics (I): the 2193 use of landmark data in a phylogenetic framework. Cladistics, 26, 539-549 DOI:

2194 10.1111/j.1096-0031.2010.00302.x

2195

2196

2197

Chappill, J. A. 1989. Quantitative characters in phylogenetic analysis. Cladistics, 5, 217-234

2198

2199

2200

Chatterjee, S. 1978. A primitive parasuchid (phytosaur) reptile from the Upper Triassic Maleri Formation of India. Palaeontology, 21, 83-127.

2201

2202

Chatterjee, S. 2001. Parasuchus hislopi Lydekker, 1885 (Reptilia, Archosauria): Proposed

2203 replacement of the lectotype by a neotype. Bulletin of Zoological Nomenclature, 58, 34-36.

2204

2205

Colbert, E. H. 1947. Studies of the phytosaurs Machaeroprosopus and Rutiodon. Bulletin of the

2206 American Museum of Natural History, 88, 53-96.

2207

2208

2209

2210

Congreve, C. R., \& Lamsdell, J. C. 2016. Implied weighting and its utility in palaeontological datasets: a study using modelled phylogenetic matrices. Palaeontology, 59, 447-462 DOI: $10.1111 /$ pala. 12236

2211

2212

Cope, E. D. 1881. Belodon in New Mexico. American Naturalist, 15, 922-923. 
2214 Cranston, P. S., \& Humphries, C. J. 1988. Cladistics and computers: a chironomid

2215 conundrum? Cladistics, 4, 72-92 DOI: 10.1111/j.1096-0031.1988.tb00469.x

2216

2217

2218

2219

2220

2221

2222

2223

2224

2225

2226

2227

2228

2229

2230

2231

2232

2233

2234

2235

2236

Crisp, M. D., \& Weston, P. H. 1987. Cladistics and legume systematics, with an analysis of the Bossiaeeae, Brongniartieae and Mirbelieae. Advances in Legume Systematics, 3, 65-130.

Dodson, P. 1975. Taxonomic implications of relative growth in lambeosaurine hadrosaurs. Systematic Biology, 24, 37-54 DOI: 10.1093/sysbio/24.1.37

Dutuit, J. M. 1977. Paleorhinus magnoculus, phytosaure du Trias supérieur de l'Atlas marocain. Géologie Méditerranéenne, 4, 255-268.

Eaton, T. H. Jr 1965. A new Wyoming phytosaur. The University of Kansas Paleontological Contributions, 2, 1-6.

Ezcurra, M. D. 2016. The phylogenetic relationships of basal archosauromorphs, with an emphasis on the systematics of proterosuchian archosauriforms. PeerJ, 4, e1778 DOI: $10.7717 /$ peerj. 1778

Fara, E., \& Hungerbühler, A. 2000. Paleorhinus magnoculus from the Upper Triassic of Morocco: a juvenile primitive phytosaur (Archosauria). Comptes Rendus de l'Académie des Sciences-Series IIA-Earth and Planetary Science, 331, 831-836 DOI: 10.1016/S12518050(00)01481-6 
2238 Farris, J. S. 1970. Methods for computing Wagner trees. Systematic Biology, 19, 83-92 DOI:

$2239 \quad 10.1093 /$ sysbio/19.1.83

2240

2241

2242

Farris, J. S. 1990. Phenetics in camouflage. Cladistics, 6, 91-100 DOI: 10.1111/j.1096-

0031.1990.tb00528.x

2243

2244

2245

Felsenstein, J. 1973. Maximum-likelihood estimation of evolutionary trees from continuous characters. American journal of human genetics, 25, 471-492.

2246

2247

2248

Felsenstein, J. 1978. Cases in which parsimony or compatibility methods will be positively misleading. Systematic zoology, 27, 401-410 DOI: 10.1093/sysbio/27.4.401

2249

2250

Felsenstein, J. 1985. Phylogenies and the comparative method. The American Naturalist, 125, 2251 1-15 DOI: $10.1086 / 284325$

2252

2253

2254

Felsenstein, J. 1988. Phylogenies and quantitative characters. Annual Review of Ecology and Systematics, 19, 445-471 DOI: 10.1146/annurev.es.19.110188.002305

2255

2256

Garcia-Cruz, J., \& Sosa, V. 2006. Coding quantitative character data for phylogenetic analysis:

2257 a comparison of five methods. Systematic Botany, 31, 302-309 DOI:

2258

$10.1600 / 036364406777585739$

2259 
2260 Gift, N., \& Stevens, P. F. 1997. Vagaries in the delimitation of character states in quantitative 2261 variation - an experimental study. Systematic Biology, 46, 112-125 DOI:

$2262 \quad 10.1093 /$ sysbio/46.1.112

2263

2264

2265

Gingerich, P. D. 1993. Quantification and comparison of evolutionary rates. American Journal of Science, 293, 453-478.

2266

2267

2268 10.1111/j.1096-0031.1993.tb00209.x

2269

2270

2271

Goloboff, P. A., \& Pol, D. 2005. Parsimony and Bayesian phylogenetics. Pp. 148-159 in V. A. 2272

Goloboff, P. A., Mattoni, C. I., \& Quinteros, A. S. 2006. Continuous characters analyzed as such. Cladistics, 22, 589-601 DOI: 10.1111/j.1096-0031.2006.00122.x

2275

2276

2277

2278

Goloboff, P. A., Carpenter, J. M., Arias, J. S., \& Esquivel, D. R. M. 2008a. Weighting against homoplasy improves phylogenetic analysis of morphological data sets. Cladistics, $\mathbf{2 4}$, 758-773 DOI: 10.1111/j.1096-0031.2008.00209.x

2279

2280

Goloboff, P. A., Farris, J. S., \& Nixon, K. C. 2008b. TNT, a free program for phylogenetic 2281 analysis. Cladistics, 24, 774-786 DOI: 10.1111/j.1096-0031.2008.00217.x 
2283 Goloboff, P. A., \& Catalano, S. A. 2011. Phylogenetic morphometrics (II): algorithms for 2284 landmark optimization. Cladistics, 27, 42-51 DOI: 10.1111/j.1096-0031.2010.00318.x

2285

2286

2287

Goloboff, P. A., \& Catalano, S. A. 2016. TNT version 1.5, including a full implementation of phylogenetic morphometrics. Cladistics, 32, 221-238 DOI: 10.1111/cla.12160

2288

2289

2290

2291

Goloboff, P. A., Torres, A., \& Arias, J. S. 2017. Weighted parsimony outperforms other methods of phylogenetic inference under models appropriate for morphology. Cladistics, 34, 407-437 DOI: 10.1111/cla.12205

2292

2293

Goloboff, P. A., Torres Galvis, A., \& Arias, J. S. 2018. Parsimony and model-based

2294

2295 phylogenetic methods for morphological data: comments on O'Reilly et al. Palaeontology, 61, 625-630 DOI: 10.1111/pala.12353

2296

2297

2298

Gregory, J. T. 1962a. The genera of phytosaurs. American Journal of Science, 260, 652-690 DOI: $10.2475 /$ ajs.260.9.652

2299

2300

2301

Gregory, J. T. 1962b. The relationships of the American phytosaur Rutiodon. American Museum Novitates, 2095, 22 pp.

2302

2303

Gregory, J. T. 1969. Evolution und interkontinentale Beziehungen der Phytosauria

2304 (Reptilia). Paläontologische Zeitschrift, 43, 37-51 DOI: 10.1007/BF02987926

2305 
2306 Griffin, C. T., Stefanic, C. M., Parker, W. G., Hungerbühler, A., \& Stocker, M. R. 2017.

2307 Sacral anatomy of the phytosaur Smilosuchus adamanensis, with implications for pelvic

2308 girdle evolution among Archosauriformes. Journal of Anatomy, 231, 886-905 DOI:

$2309 \quad 10.1111 /$ joa.12681

2310

2311

2312

Hansen, T. F. 1997. Stabilizing selection and the comparative analysis of adaptation. Evolution, 51, 1341-1351 DOI: 10.1111/j.1558-5646.1997.tb01457.x

2313

2314

2315

2316

Heckert, A. B., Lucas, S. G., Hunt, A. P., \& Harris, J. D. 2001. A giant phytosaur (Reptilia: Archosauria) skull from the Redonda Formation (Upper Triassic: Apachean) of east-central New Mexico. New Mexico Geological Society Guidebook, 52, 171-178.

2317

Holloway, W. L., Claeson, K. M., \& O'keefe, F. R. 2013. A virtual phytosaur endocast and its implications for sensory system evolution in archosaurs. Journal of Vertebrate Paleontology, 33, 848-857 DOI: 10.1080/02724634.2013.747532

2321

2322

2323

Huelsenbeck, J. P. 1994. Comparing the stratigraphic record to estimates of phylogeny. Paleobiology, 20, 470-483 DOI: 10.1017/S009483730001294X

2324

2325

2326

Huelsenbeck, J. P. 1995. Performance of phylogenetic methods in simulation. Systematic biology, 44, 17-48 DOI: 10.1093/sysbio/44.1.17 
2328 Huene, F. von. 1915. On reptiles of the New Mexican Trias in the Cope Collection. Bulletin of 2329 the American Museum of Natural History, 34, 485-507.

2330

2331

2332

Hungerbühler, A. 1998. Cranial anatomy and diversity of the Norian phytosaurs of Southwestern Germany. Unpublished PhD thesis, University of Bristol, 464 pp.

2333

2334

2335

Hungerbühler, A. 2002. The Late Triassic phytosaur Mystriosuchus westphali, with a revision 2336 of the genus. Palaeontology, 45, 377-418 DOI: 10.1111/1475-4983.00242

Hungerbühler, A., \& Sues, H. D. 2001. Status and phylogenetic relationships of the Late Triassic phytosaur Rutiodon carolinensis. Journal of Vertebrate Paleontology, 21, 64A.

2339

Hungerbühler, A., Chatterjee, S., \& Cunningham, D. P. 2003. A new phytosaur species from the Triassic of west Texas: new information on cranial anatomy, taxonomy, and sexual 2343 dimorphism in Pseudopalatinae. Journal of Vertebrate Paleontology, 23, 63A-64A.

2348

Hungerbühler, A., Mueller, B., Chatterjee, S. \& Cunningham, D. P. 2013. Cranial anatomy of the Late Triassic phytosaur Machaeroprosopus, with the description of a new species from West Texas. Earth and Environmental Science Transactions of the Royal Society of Edinburgh, 103, 269-312 DOI: 10.1017/S1755691013000364

Hunt, A P. 1994. Vertebrate paleontology and biostratigraphy of the Bull Canyon Formation (Chinle Group, Upper Triassic), east-central New Mexico with revisions of the families 
2351

2352

2353

2354

2355

2356

2357

2358

2359

2360

2361

2362

2363

2364

2365

2366

2367

2368

2369

2370

2371

2372

2373

Metoposauridae (Amphibia: Temnospondyli) and Parasuchidae (Reptilia: Archosauria).

Unpublished $\mathrm{PhD}$ thesis, University of New Mexico, $404 \mathrm{pp}$.

Hunt, A. P., \& Lucas, S. G. 1989. New genotype designations for the phytosaurs Mystriosuchus and Rutiodon with a discussion of the taxonomic status of Mystriosuchus, Clepsysaurus and Rutiodon. Pp. 340-348 in S. G. Lucas \& A. P. Hunt (eds) Dawn of the Age of Dinosaurs in the American Southwest. New Mexico Museum of Natural History and Science, Albuquerque.

Hunt, A. P., \& Lucas, S. G. 1991. The Paleorhinus biochron and the correlation of the nonmarine Upper Triassic of Pangaea. Palaeontology, 34, 487-501.

Hunt, A. P., \& Lucas, S. G. 1993. A new phytosaur (Reptilia: Archosauria) genus. New Mexico Museum of Natural History and Science Bulletin, 3, 193-196.

Hunt, A. P., Lucas, S. G., \& Bircheff, P. 1993. Biochronological significance of the cooccurrence of the phytosaurs (Reptilia: Archosauria) Angistorhinus and Rutiodon in the Los Esteros Member of the Santa Rosa Formation, Santa Fe County, New Mexico, USA. New Mexico Museum of Natural History and Science Bulletin, 3, 203-204.

Hunt, A. P., Lucas, S. G., \& Spielmann, J. A. 2006. Sexual dimorphism in a large brachyrostral phytosaur (Archosauria: Crurotarsi) from the Late Triassic of western North America. New Mexico Museum of Natural History and Science Bulletin, 37, 563-567. 
2374 ICZN 2003. Parasuchus hislopi Lydekker, 1885 (Reptilia, Archosauria): lectotype replaced by a 2375 neotype. Bulletin of Zoological Nomenclature, 60, Opinion 2045.

2376

2377 Irmis, R. B. 2007. Axial skeleton ontogeny in the Parasuchia (Archosauria: Pseudosuchia) and 2378 its implications for ontogenetic determination in archosaurs. Journal of Vertebrate Paleontology, 27, 350-361 DOI: 10.1671/0272-4634(2007)27[350:ASOITP]2.0.CO;2

2380

2381

2382

Jaeger, G. F. 1828. Über die fossilen Reptilien, welche in Würtemberg aufgefunden worden sind. Metzler, Stuttgart, 48 pp.

2383

2384

2385

Jaekel O. 1910. Über einen neuen Belodonten aus dem Buntsandstein von Bernberg. Sitzungsberichte Gesellschaft naturforschender Freunde zu Berlin, 5, 197-229.

2386

2387

2388

2389

Kammerer, C. F., Butler, R. J., Bandyopadhyay, S., \& Stocker, M. R. 2015. Relationships of the Indian phytosaur Parasuchus hislopi Lydekker, 1885. Papers in Palaeontology, 2, 1-23 DOI: $10.1002 / \operatorname{spp} 2.1022$

2390

2391 2392

Kimmig, J. 2009. Functional morphology and systematic palaeontology of the Phytosauria (Archosauria; Crurotarsi) and the development of their Late Triassic habitats. Unpublished MSc Thesis, Imperial College, London, UK. 118 pp.

2394

Klassen, G. J., Mooi, R. D., \& Locke, A. 1991. Consistency indices and random data. Systematic Biology, 40, 446-457 DOI: 10.1093/sysbio/40.4.446 
2398 Koch, N. M., Soto, I. M., \& Ramírez, M. J. 2015. First phylogenetic analysis of the family 2399 Neriidae (Diptera), with a study on the issue of scaling continuous characters. Cladistics, 31, $2400 \quad$ 142-165 DOI: 10.1111/cla.12084

2401

2402

Kolaczkowski, B., \& Thornton, J. W. 2004. Performance of maximum parsimony and 2403 likelihood phylogenetics when evolution is heterogeneous. Nature, 431, 980-984 DOI:

2404 10.1038 /nature02917

2405

2406

2407

Kuhn, O. 1936. Weitere Parasuchier und Labyrinthodonten aus dem Blasensandstein des mittleren Keuper von Ebrach. Palaeontographica Abteilung A, 83, 61-98.

2408

2409

2410

Kuhner, M. K., \& Felsenstein, J. 1994. A simulation comparison of phylogeny algorithms under equal and unequal evolutionary rates. Molecular biology and evolution, 11, 459-468

2412

2413

2414 DOI: 10.1093/oxfordjournals.molbev.a040126

2415

Langston, W. 1949. A new species of Paleorhinus from the Triassic of Texas. American Journal of Science, 247, 324-341 DOI: 10.2475/ajs.247.5.324

2417 phytosaurian reptiles and convergence with fossil and modern crocodylians. PeerJ, 4, e2251 DOI: $10.7717 /$ peerj.2251 
2420 Lee, M. S., \& Worthy, T. H. 2012. Likelihood reinstates Archaeopteryx as a primitive bird.

2421 Biology letters, 8, 299-303 DOI: 10.1098/rsbl.2011.0884

2422

2423

2424

Lewis, P. O. 2001. A likelihood approach to estimating phylogeny from discrete morphological character data. Systematic biology, 50, 913-925 DOI: 10.1080/106351501753462876

2425

2426

2427

2428

Li, C., Wu, X. C., Zhao, L. J., Sato, T., \& Wang, L. T. 2012. A new archosaur (Diapsida, Archosauriformes) from the marine Triassic of China. Journal of Vertebrate

Paleontology, 32, 1064-1081 DOI: 10.1080/02724634.2012.694383

2429

2430

Livesey, B. C., \& Zusi, R. L. 2007. Higher-order phylogeny of modern birds (Theropoda, Aves:

2431 Neornithes) based on comparative anatomy. Zool J Linn Soc, 149, 1-95.

2432

2433

2434

2435

Long, R. A., \& Ballew, K. L. 1985. Aetosaur dermal armor from the Late Triassic of southwestern North America, with special reference to material from the Chinle Formation of Petrified Forest National Park. Museum of Northern Arizona Bulletin, 47, 45-68.

2436

2437

Long, R. A., \& Murry, P. A. 1995. Late Triassic (Carnian and Norian) tetrapods from the 2438 southwestern United States. New Mexico Museum of Natural History and Science Bulletin, 4, 2439 1-254.

2440 
2441 Lucas, S. G. 2010. The Triassic timescale based on nonmarine tetrapod biostratigraphy and 2442 biochronology. Geological Society, London, Special Publications, 334, 447-500 DOI: $10.1144 / \mathrm{SP} 334.15$

2444

2445

2446

Lucas, S. G., \& Hunt, A. P. 1993. Tetrapod biochronology of the Chinle Group. New Mexico (446 Museum of Natural History and Science Bulletin, 3, 327-329.

2447

2448

2449

Lydekker, R. 1885. The Reptilia and Amphibia of the Maleri and Denwa groups. Palaeontologia Indica, Series 1, 1, 1-38.

2450

2451

2452

2453

2454

2455

2456

2457

2458

Mehl, M. G. 1913. Angistorhinus, a new genus of Phytosauria from the Trias of Wyoming. The

Martz, J. W., \& Parker, W. G. 2017. Revised Formulation of the Late Triassic Land Vertebrate "Faunachrons" of Western North America: Recommendations for Codifying Nascent Systems of Vertebrate Biochronology. Pp. 39-125 in K. E. Zeigler \& W. G. Parker (eds) Deciphering complexities through multiple stratigraphic methods. Terrestrial Depositional Systems, 1st Edition, Elsevier.

$$
\text { Journal of Geology, 21, 186-191 DOI: 10.1086/622049 }
$$

2459

2460

2461

Mehl, M. G. 1915. The Phytosauria of the Trias. The Journal of Geology, 23, 129-165 DOI: $10.1086 / 622217$ 
2463 Mehl, M. G. 1916. New or little known phytosaurs from Arizona. Pp. 5-28 in M. G. Mehl, W.

2464 C. Toepelmann and G. M. Schwartz (eds) New or Little Known Reptiles from the Trias of

2465

2466 Arizona and New Mexico with Notes on the Fossil Bearing Horizons near Wingate, New Mexico. Quarterly Bulletin of the University of Oklahoma, New Series, 103, 5-44.

2467

2468

2469

Mehl, M. G. 1928. The Phytosauria of the Wyoming Triassic. Journal of the Denison University Laboratories, Denison University, 23, 141-172.

2470

2471

2472

Meyer, H. von. 1860. Briefliche Mittheilung an Prof. Bronn. Neues Jahrbuch fur Mineralogie,

2473

2474

Meyer, H. von. 1863. Der Schädel des Belodon aus dem Stubensandstein des oberen Keupers. Geognosie, Geologie und Petrefakten-Kunde, 556-560.

2476 Palaeontographica, 10, 227-246.

2480

2481

Mickevich, M. F., \& Johnson, M. S. 1976. Congruence between morphological and allozyme data in evolutionary inference and character evolution. Systematic Zoology, 25, 260-270 DOI: $10.2307 / 2412494$

Nesbitt, S. J. 2011. The early evolution of archosaurs: relationships and the origin of major clades. Bulletin of the American Museum of Natural History, 352, 1-292 DOI: 10.1206/352.1

2483

2484

2485

O'Reilly, J. E., Puttick, M. N., Parry, L., Tanner, A. R., Tarver, J. E., Fleming, J., Pisani, D., \& Donoghue, P. C. 2016. Bayesian methods outperform parsimony but at the expense of 
2486 precision in the estimation of phylogeny from discrete morphological data. Biology Letters, 12, 20160081 DOI: $10.1098 /$ rsbl.2016.0081

2488

2489

2490

2491

2492

2493

2494

2495

2496

2497

2498

2499

2500

2501

2502

2503

2504

2505

2506

2507

O'Reilly, J. E., Puttick, M. N., Pisani, D., \& Donoghue, P. C. 2017. Probabilistic methods surpass parsimony when assessing clade support in phylogenetic analyses of discrete morphological data. Palaeontology, 61, 105-118 DOI: 10.1111/pala.12330

Parins-Fukuchi, C. 2017. Use of Continuous Traits Can Improve Morphological Phylogenetics. Systematic biology, 67, 328-339 DOI: 10.1093/sysbio/syx072

Parins-Fukuchi, C. 2018. Bayesian placement of fossils on phylogenies using quantitative morphometric data. Evolution, (accepted article) DOI: 10.1111/evo.13516

Parker, W. G., \& Irmis, R. B. 2006. A new species of the Late Triassic phytosaur Pseudopalatus (Archosauria: Pseudosuchia) from Petrified Forest National Park, Arizona. Museum of Northern Arizona Bulletin, 62, 126-143.

Parker, W. G., Hungerbühler, A., \& Martz, J. W. 2012. The taxonomic status of the phytosaurs (Archosauriformes) Machaeroprosopus and Pseudopalatus from the Late Triassic of the western United States. Earth and Environmental Science Transactions of the Royal Society of Edinburgh, 103, 265-268 DOI: 10.1017/S1755691013000339 
2508 Parrish, J. M., \& Carpenter, K. 1986. A new vertebrate fauna from the Dockum Formation 2509 (Late Triassic) of eastern New Mexico. Pp. 151-160 in K. Padian (ed) The Beginning of the 2510 Age of Dinosaurs: Faunal Change Across the Triassic-Jurassic Boundary. Cambridge 2511 University Press, Cambridge.

2512

2513

2514

2515

Perrard, A., Lopez-Osorio, F., \& Carpenter, J. M. 2016. Phylogeny, landmark analysis and the use of wing venation to study the evolution of social wasps (Hymenoptera: Vespidae: Vespinae). Cladistics, 32, 406-425 DOI: 10.1111/cla.12138

2516

2517

2518

Pimentel, R. A., \& Riggins, R. 1987. The nature of cladistic data. Cladistics, 3, 201-209 DOI:

$$
\text { 10.1111/j.1096-0031.1987.tb00508.x }
$$

2519

Poe, S., \& Wiens, J. J. 2000. Character selection and the methodology of morphological phylogenetics. Pp. 20-36 in J. J. Wiens (ed) Phylogenetic Analysis of Morphological Data. Smithsonian Institution Press, Washington, D.C.

2523

Pol, D., \& Norell, M. A. 2001. Comments on the Manhattan stratigraphic measure. Cladistics, 17, 285-289 DOI: 10.1111/j.1096-0031.2001.tb00125.x

2526

Pol, D., \& Norell, M. A. 2006. Uncertainty in the age of fossils and the stratigraphic fit to 2528 phylogenies. Systematic Biology, 55, 512-521 DOI: 10.1080/10635150600755446 
2530 Rae, T. C. 1998. The logical basis for the use of continuous characters in phylogenetic

2531 systematics. Cladistics, 14, 221-228 DOI: 10.1111/j.1096-0031.1998.tb00335.x

2532

2533

2534

2535

R Core Team. 2016. R: A language and environment for statistical computing. R Foundation for Statistical Computing, Vienna, Austria. Updated at: https://www.R-project.org/, accessed 11 January 2018.

2536

2537

2538

Rohlf, F. J. 2015. The tps series of software. Hystrix, the Italian Journal of Mammalogy, 26, 912.

2539

2540

2541

Ronquist, F., \& Huelsenbeck, J. P. 2003. MrBayes 3: Bayesian phylogenetic inference under mixed models. Bioinformatics, 19, 1572-1574 DOI: 10.1093/bioinformatics/btg180

2542

2543

Rozhdestvensky, A. K. 1965. Growth changes in Asian dinosaurs and some problems of their 2544 taxonomy. Palaeontologicheskii Zhurnal, 3, 95-109.

2545

2546

2547

2548

Sampson, S. D., Ryan, M. J., \& Tanke, D. H. 1997. Craniofacial ontogeny in centrosaurine dinosaurs (Ornithischia: Ceratopsidae): taxonomic and behavioral implications. Zoological Journal of the Linnean Society, 121, 293-337 DOI: 10.1111/j.1096-3642.1997.tb00340.x

2549

2550

Sansom, R. S., Choate, P. G., Keating, J. N., \& Randle, E. 2018. Parsimony, not Bayesian 2551

2552 analysis, recovers more stratigraphically congruent phylogenetic trees. Biology letters, 14, 20180263 DOI: 10.1098/rsbl.2018.0263 
2554 Scannella, J. B., \& Horner, J. R. 2010. Torosaurus Marsh, 1891, is Triceratops Marsh, 1889

2555 (Ceratopsidae: Chasmosaurinae): synonymy through ontogeny. Journal of Vertebrate

2556 Paleontology, 30, 1157-1168 DOI: 10.1080/02724634.2010.483632

2557

2558

2559

2560

Sereno, P. C. 1991. Basal archosaurs: phylogenetic relationships and functional implications. Journal of Vertebrate Paleontology, 11(S4), 1-53 DOI:

$$
10.1080 / 02724634.1991 .10011426
$$

2561

2562

2563

Siddall, M. E. 1996. Stratigraphic consistency and the shape of things. Systematic Biology, 45,

$$
\text { 111-115 DOI: } 10.2307 / 2413516
$$

2564

2565

2566

Siddall, M. E. 1998. Stratigraphic fit to phylogenies: a proposed solution. Cladistics, 14, 201208 DOI: 10.1111/j.1096-0031.1998.tb00333.x

2567

2568

Sookias, R. B. 2016. The relationships of the Euparkeriidae and the rise of Archosauria. Royal 2569 Society open science, 3, 150674 DOI: 10.1098/rsos.150674

2570

2571 Spielmann, J. A., \& Lucas, S. G. 2012. Tetrapod fauna of the Upper Triassic Redonda 2572 Formation, east-central New Mexico: the characteristic assemblage of the Apachean land2573 vertebrate faunachron. New Mexico Museum of Natural History and Science Bulletin, 55, 1$2574 \quad 119$. 
2576 Stevens, P. F. 1991. Character states, morphological variation, and phylogenetic analysis: a

2577 review. Systematic Botany, 16, 553-583 DOI: 10.2307/2419343

2578

2579 Stocker, M. R. 2010. A new taxon of phytosaur (Archosauria: Pseudosuchia) from the Late 2580 Triassic (Norian) Sonsela Member (Chinle Formation) in Arizona, and a critical reevaluation 2581 of Leptosuchus Case, 1922. Palaeontology, 53, 997-1022 DOI: 10.1111/j.1475-

$2582 \quad 4983.2010 .00983 . x$

2583

2584

2585

2586

2587

Stocker, M. R. 2012. A new phytosaur (Archosauriformes, Phytosauria) from the Lot's Wife beds (Sonsela Member) within the Chinle Formation (Upper Triassic) of Petrified Forest National Park, Arizona. Journal of Vertebrate Paleontology, 32, 573-586 DOI:

$10.1080 / 02724634.2012 .649815$

2588

2589

2590

2591

Stocker, M. R. 2013. A new taxonomic arrangement for Paleorhinus scurriensis. Earth and Environmental Science Transactions of the Royal Society of Edinburgh, 103, 1-13 DOI: $10.1017 / \mathrm{S} 1755691013000340$

2592

2593

2594

Stocker, M. R., \& Butler, R. J. 2013. Phytosauria. Geological Society, London, Special Publications, 379, 91-117 DOI: 10.1144/SP379.5

2595

2596

Stocker, M. R., Zhao, L. J., Nesbitt, S. J., Wu, X. C., \& Li, C. 2017. A short-snouted, Middle 2597 Triassic phytosaur and its implications for the morphological evolution and biogeography of 2598 Phytosauria. Scientific Reports, 7, 46028 DOI: 10.1038/srep46028 
2599

2600 Stovall, J. W., \& Wharton Jr, J. B. 1936. A new species of phytosaur from Big Spring, 2601 Texas. The Journal of Geology, 44, 183-192 DOI: 10.1086/624416

2602

2603

2604

2605

Swofford, D., Olsen, G., Paddell, P., \& Hills, D. 1996. Phylogenetic inference. Pp. 407-514 in

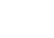
D. Hillis, C. Moritz, \& B. Mable (eds) Molecular Systematics. Sinauer, Sunderland, Massachusetts.

2606

2607

2608

Thiele, K. 1993. The holy grail of the perfect character: the cladistic treatment of morphometric data. Cladistics, 9, 275-304 DOI: 10.1111/j.1096-0031.1993.tb00226.x

2609

2610

2611

Thorpe, R. S. 1984. Coding morphometric characters for constructing distance Wagner networks. Evolution, 38, 244-255 DOI: 10.1111/j.1558-5646.1984.tb00282.x

2612

2613

2614

2615

Tschopp, E., Mateus, O., \& Benson, R. B. J. 2015. A specimen-level phylogenetic analysis and taxonomic revision of Diplodocidae (Dinosauria, Sauropoda). PeerJ, 3, e857 DOI: $10.7717 /$ peerj. 857

2616

2617

2618

2619

Tsuihiji T, Watabe M, Tsogtbaatar K, Tsubamoto T, Barsbold R, Suzuki S, Lee AH,

Ridgely RC, Kawahara Y, Witmer LM. 2011. Cranial osteology of a juvenile specimen of

Tarbosaurus bataar (Theropoda, Tyrannosauridae) from the Nemegt Formation (Upper

2620

Cretaceous) of Bugin Tsav, Mongolia. Journal of Vertebrate Paleontology, 31, 497-517 DOI:

2621

$10.1080 / 02724634.2011 .557116$ 
2623 Upchurch, P., Tomida, Y., \& Barrett, P. M. 2004. A new specimen of Apatosaurus ajax

2624 (Sauropoda: Diplodocidae) from the Morrison Formation (Upper Jurassic) of Wyoming,

$2625 \quad$ USA. National Science Museum Monographs, 26, 1-118.

2626

2627

2628

Wagner, P. J. 2012. Modelling rate distributions using character compatibility: implications for morphological evolution among fossil invertebrates. Biology Letters, 8, 143-146 DOI:

2629 $10.1098 / \mathrm{rsbl} .2011 .0523$

2630

2631

2632

Walker, A. D. 1968. Protosuchus, Proterochampsa, and the origin of phytosaurs and crocodiles. Geological Magazine, 105, 1-14 DOI: 10.1017/S0016756800046434

2633

2634

2635

Westphal, K. W. 1979. Missing holotype of Machaeroprosopus validus (Mehl, 1916). Journal of Paleontology, 53, 741.

2636

2637

2638

2639

Wiens, J. J. 1998. Testing phylogenetic methods with tree congruence: phylogenetic analysis of polymorphic morphological characters in phrynosomatid lizards. Systematic Biology, 47, 427-444 DOI: 10.1080/106351598260806

2640

2641

2642 solutions. Systematic Biology, 50, 689-699 DOI: 10.1080/106351501753328811 
2644 Wills, M. A. 1999. Congruence between phylogeny and stratigraphy: randomization tests and the

2645 gap excess ratio. Systematic Biology, 48, 559-580 DOI: 10.1080/106351599260148

2646

2647 Wills, M. A., Barrett, P. M., \& Heathcote, J. F. 2008. The modified gap excess ratio (GER*)

2648 and the stratigraphic congruence of dinosaur phylogenies. Systematic Biology, 57, 891-904

2649 DOI: $10.1080 / 10635150802570809$

2650

2651

2652

2653

Wright, A. M., \& Hillis, D. M. 2014. Bayesian analysis using a simple likelihood model outperforms parsimony for estimation of phylogeny from discrete morphological data. PLoS One, 9, e109210 DOI: 10.1371/journal.pone.0109210

2654

2655

2656

Wright, A. M., Lloyd, G. T., \& Hillis, D. M. 2015. Modeling character change heterogeneity in

2657 phylogenetic analyses of morphology through the use of priors. Systematic biology, $\mathbf{6 5}, 602-$ 611 DOI: $10.1093 /$ sysbio/syv122

2658

2659

2660

2661

Wroblewski, A. 2003. Application of cladistic analysis towards resolving biostratigraphic uncertainty; an example from the Upper Triassic. Geological Society of America Abstracts with Programs, 35 (5), p. 15

2662

2663

2664

Zeigler, K. E., Lucas, S. G., \& Heckert, A. B. 2002. The Late Triassic Canjilon quarry (Upper Chinle Group, New Mexico) phytosaur skulls: evidence of sexual dimorphism in phytosaurs. New Mexico Museum of Natural History and Science Bulletin, 21, 179-188.

2666 
2667 Zelditch, M., Swiderski, D. L., \& Sheets, H. D. 2012. Geometric Morphometrics for

2668 Biologists: A Primer. Academic Press. 
Figure 1

Phylogenetic trees from the analyses of (A) Ballew (1989); (B) Hungerbühler (1998); (C) Hungerbühler (2002). 
A

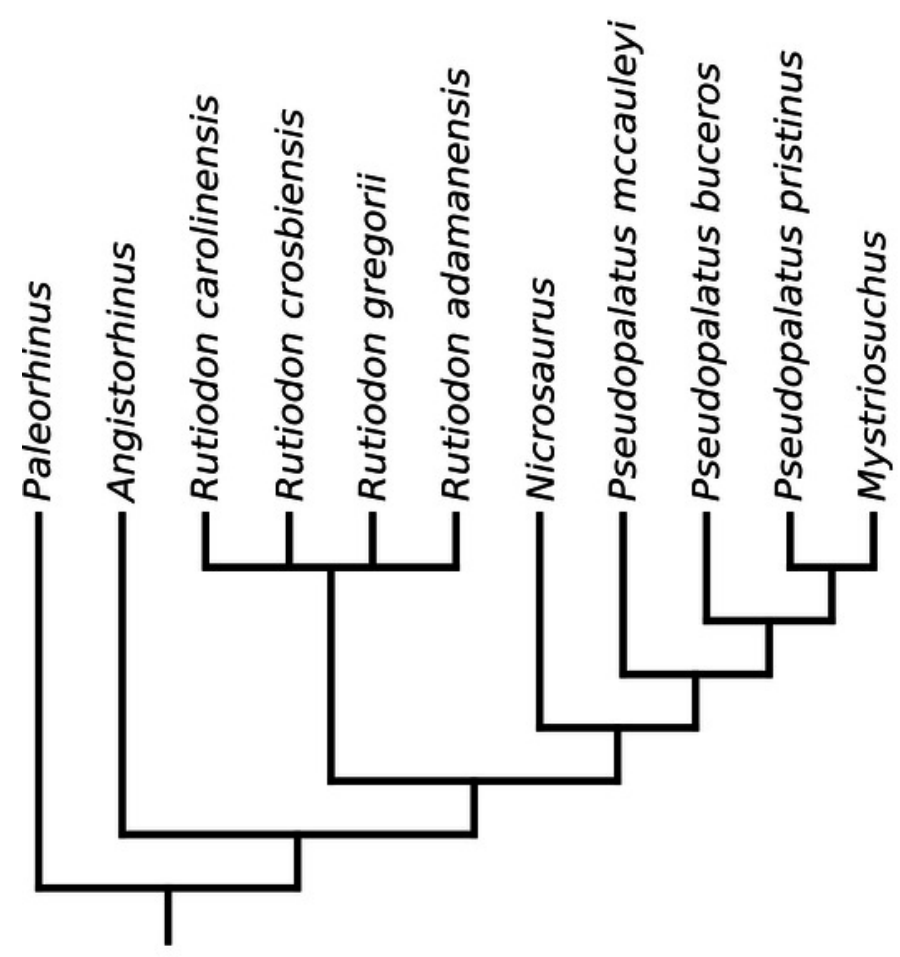

C

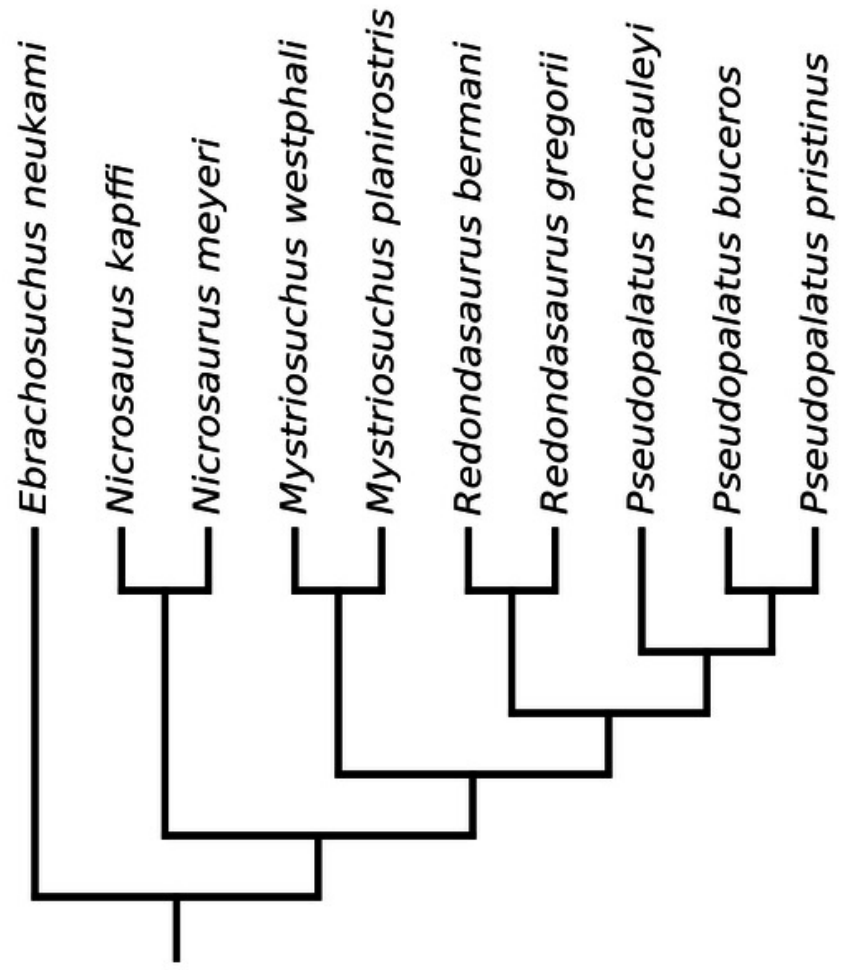

B

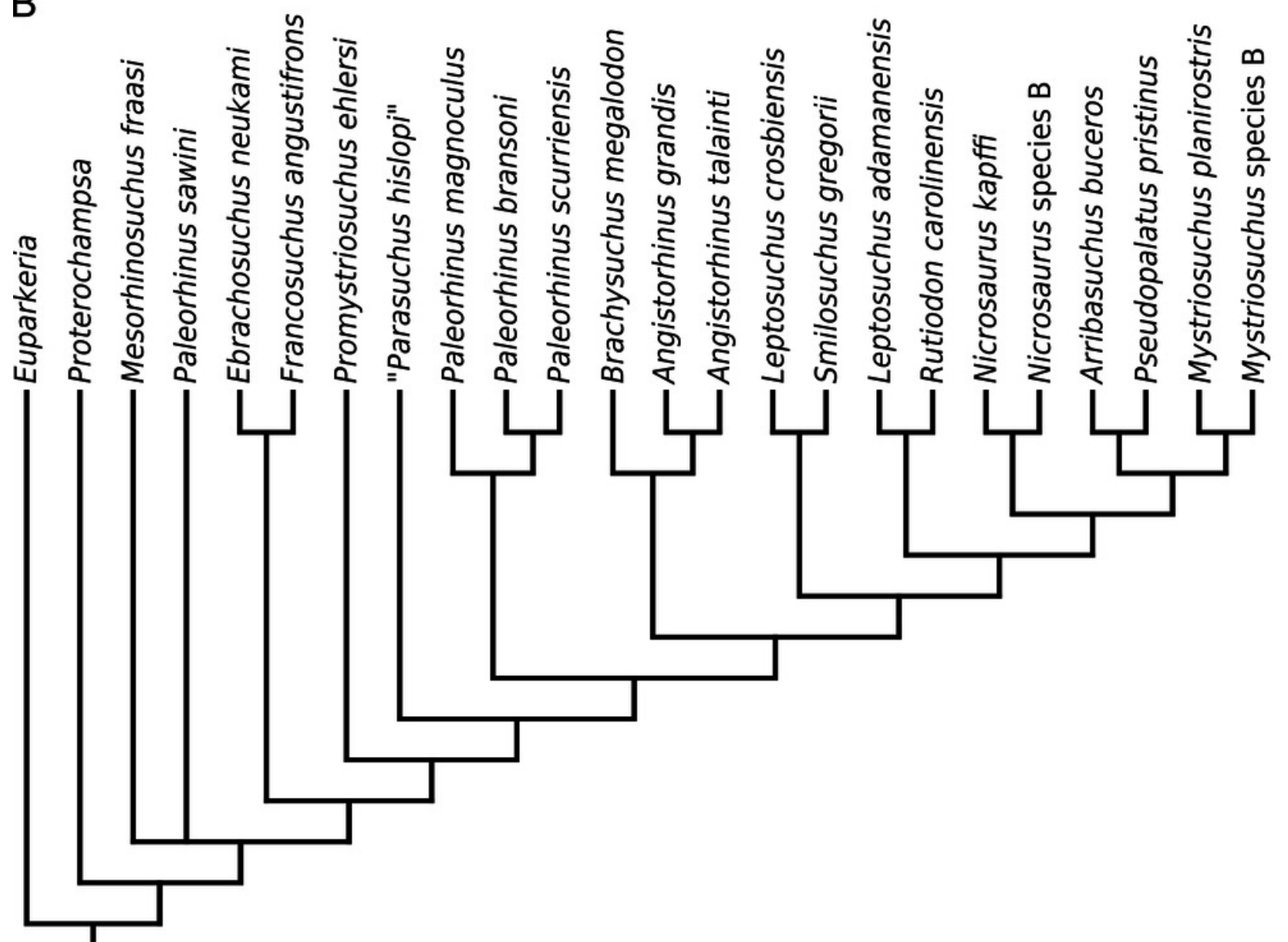


Figure 2

Phylogenetic trees from the analyses of (A) Parker \& Irmis (2006); (B) Stocker (2013) (topology identical to Stocker, 2010 and 2012); (C) Hungerbühler et al. (2013). 


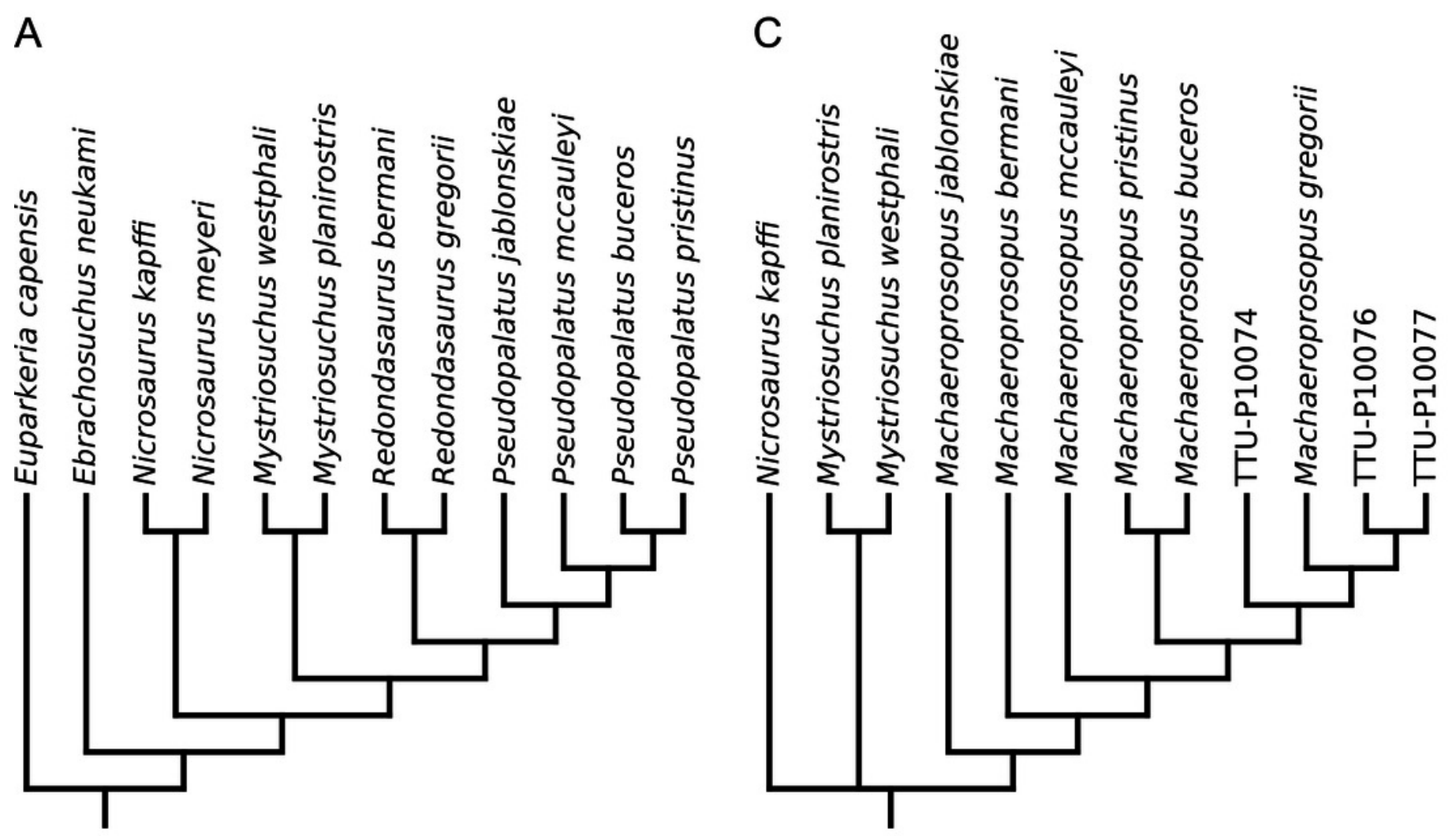

B

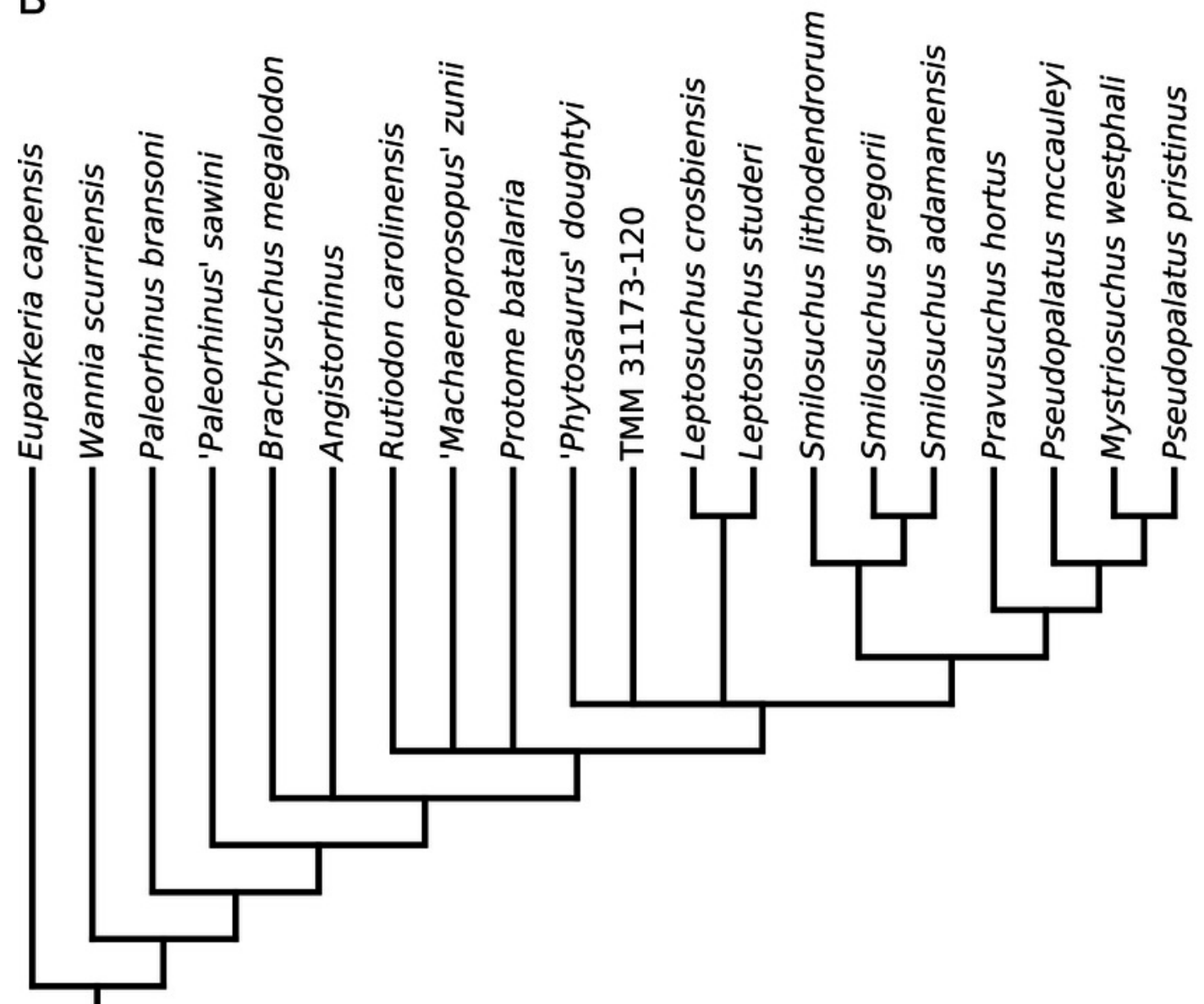


Figure 3

Phylogenetic trees from the analyses of (A) Butler et al. (2014); (B) Kammerer et al. (2015). 
A

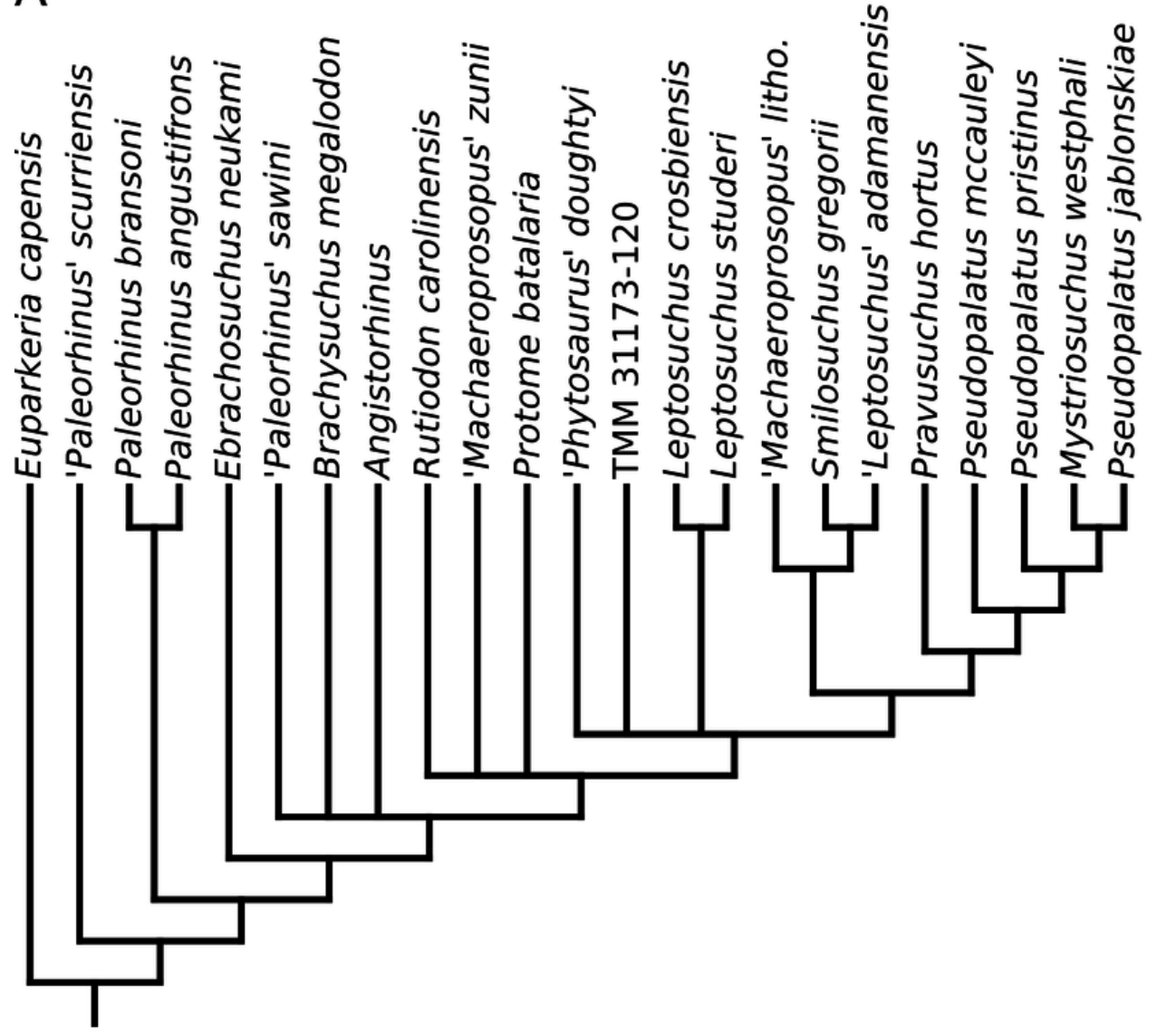

B

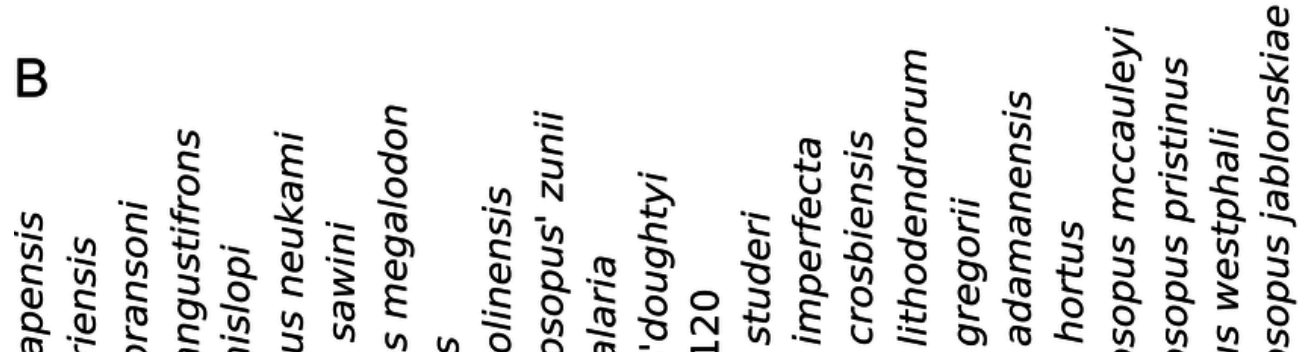

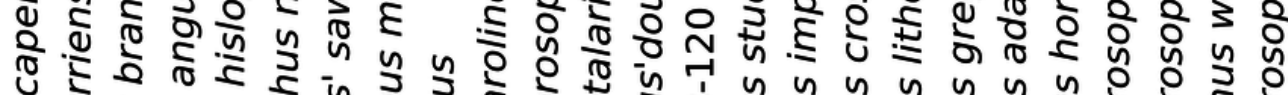
ช

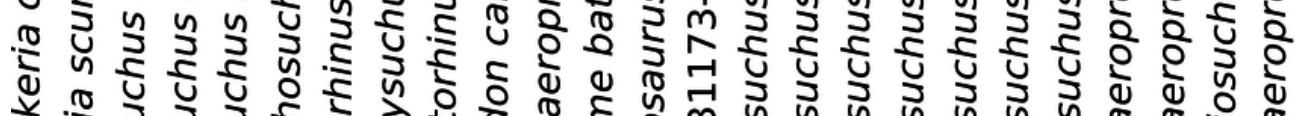

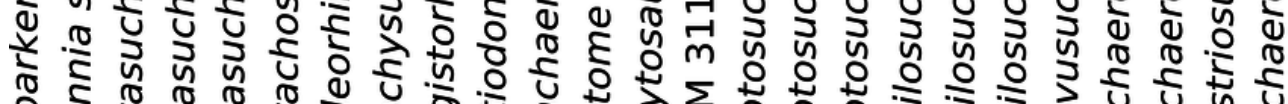

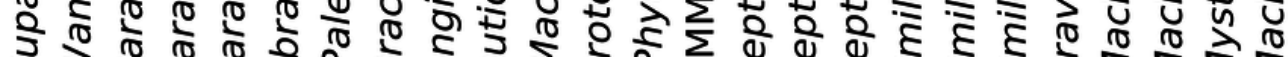

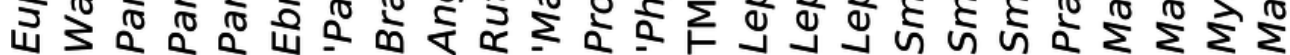

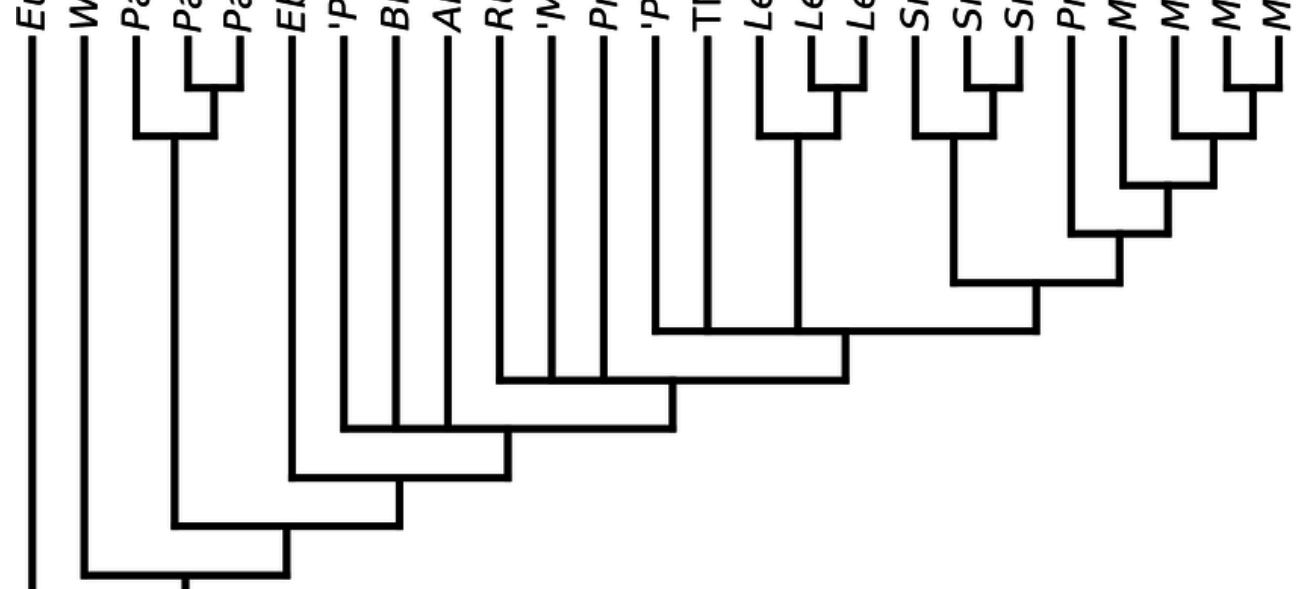




\section{Figure 4}

Strict consensus of the three trees resulting from the analysis treatment incorporating discrete characters only (D).

Node numbers are labelled within black circles. Absolute frequencies/frequency differences are presented to the left of the node's stem; Bremer support values are reported to the right of the node's stem.

*Note: Auto Gamma Correction was used for the image. This only affects the reviewing manuscript. See original source image if needed for review. 


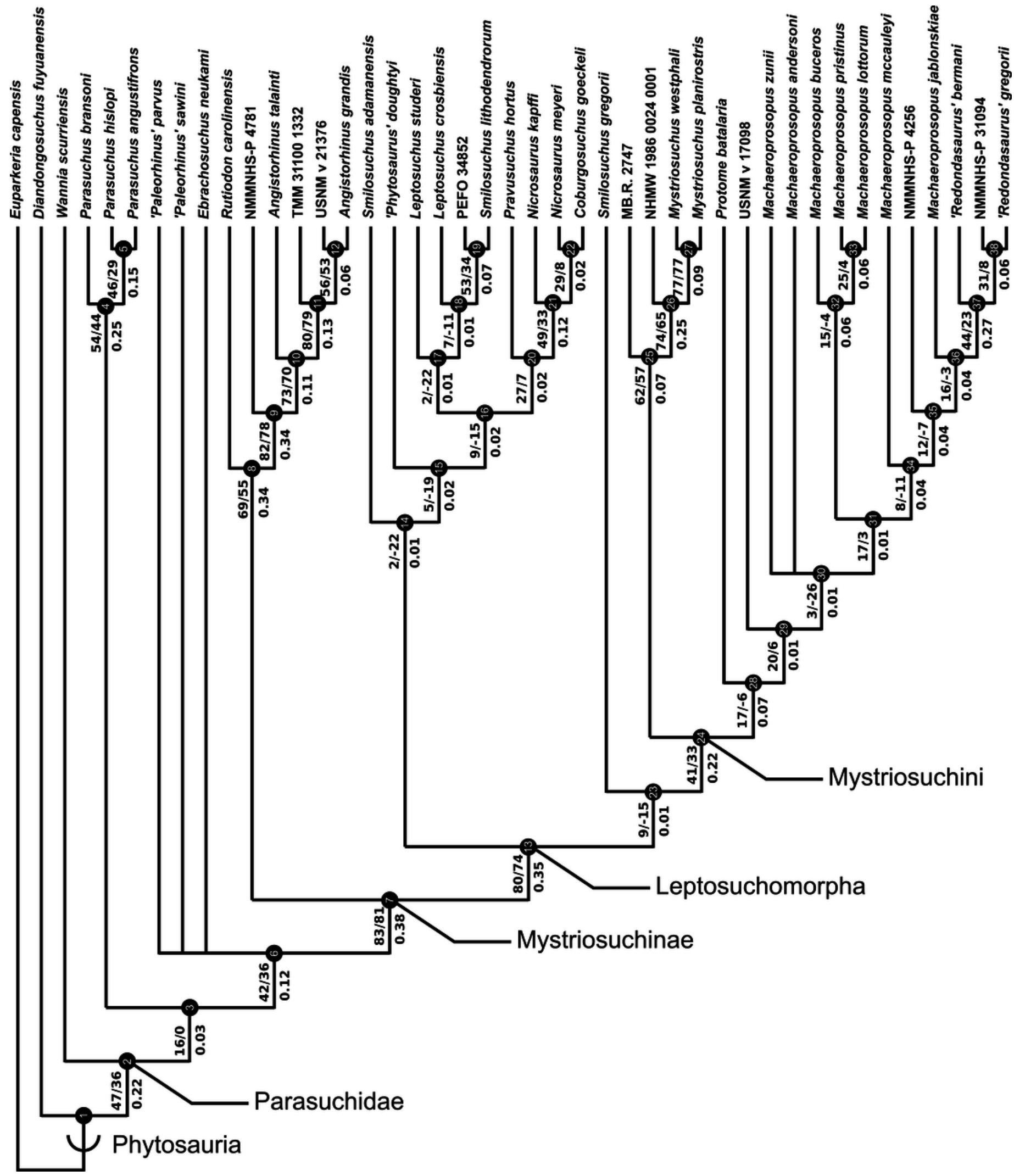




\section{Figure 5}

Strict consensus of the three trees produced by the treatment incorporating discrete and continuous character scoring (DC).

Node labels as in Fig. 4.

*Note: Auto Gamma Correction was used for the image. This only affects the reviewing manuscript. See original source image if needed for review. 


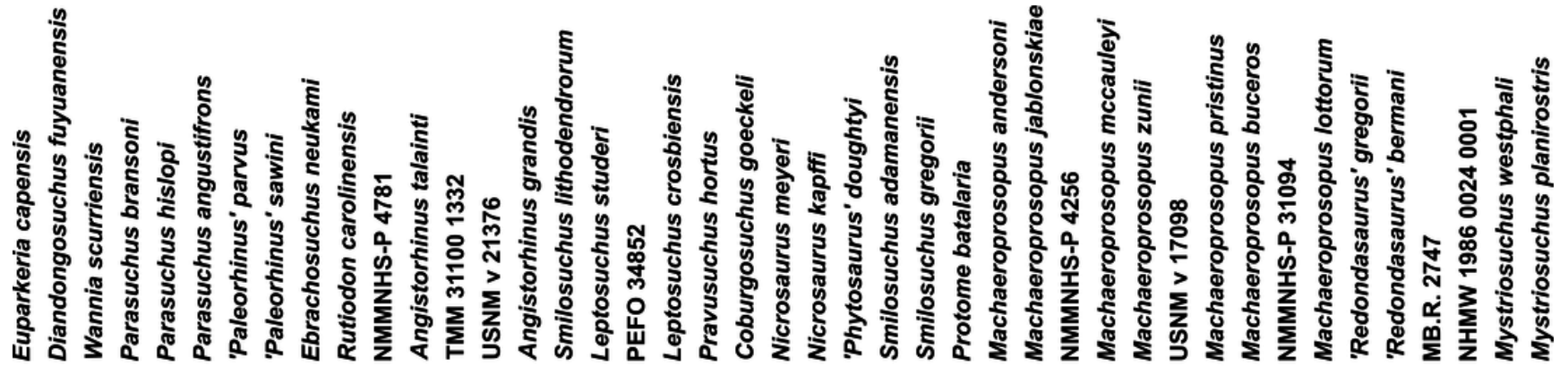

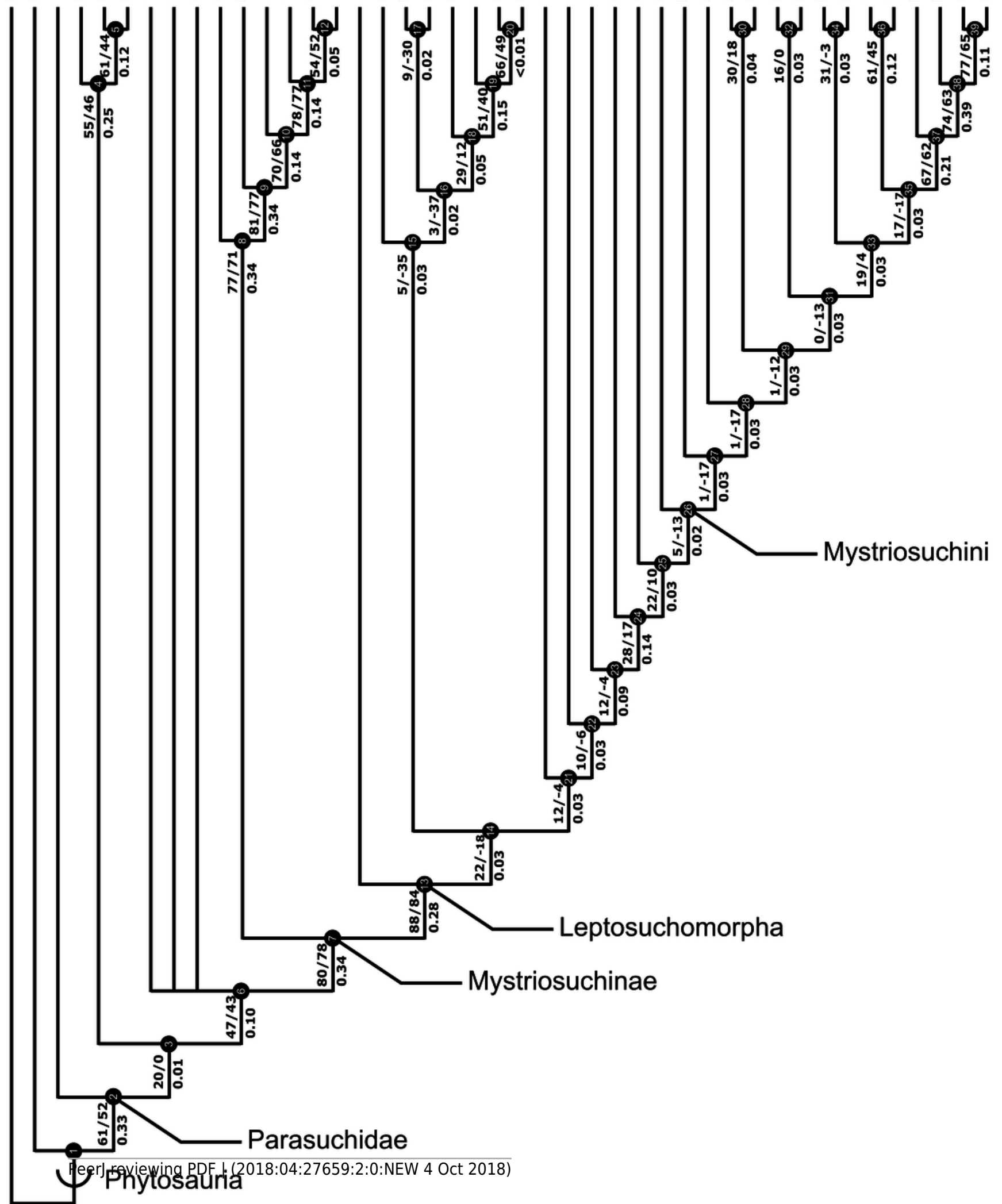




\section{Figure 6}

Single tree resulting from the treatment incorporating discrete and geometric morphometric character scoring (DM).

Node labels as in Fig. 4.

*Note: Auto Gamma Correction was used for the image. This only affects the reviewing manuscript. See original source image if needed for review. 


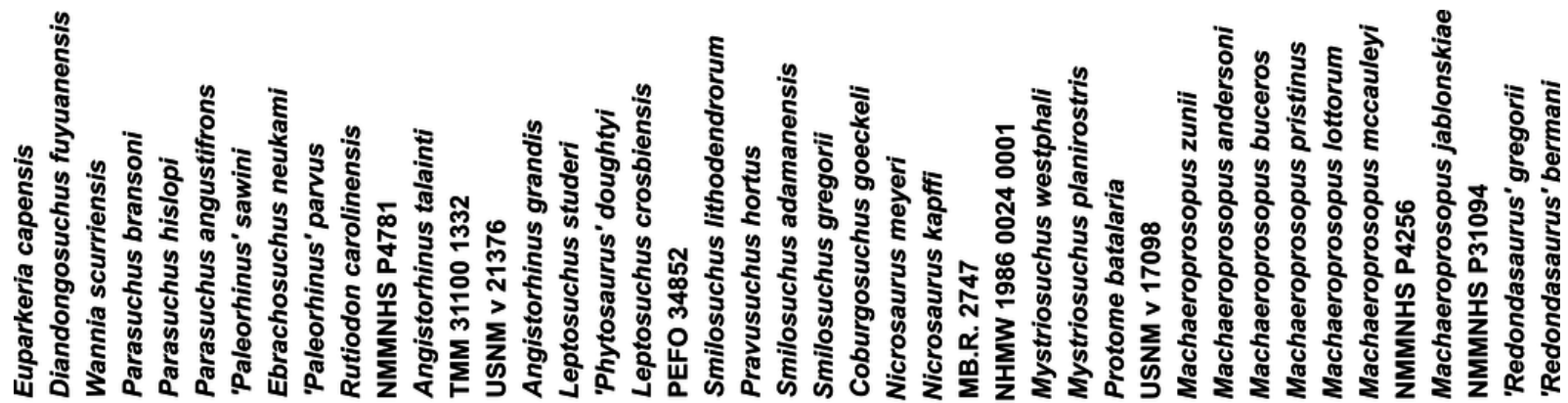

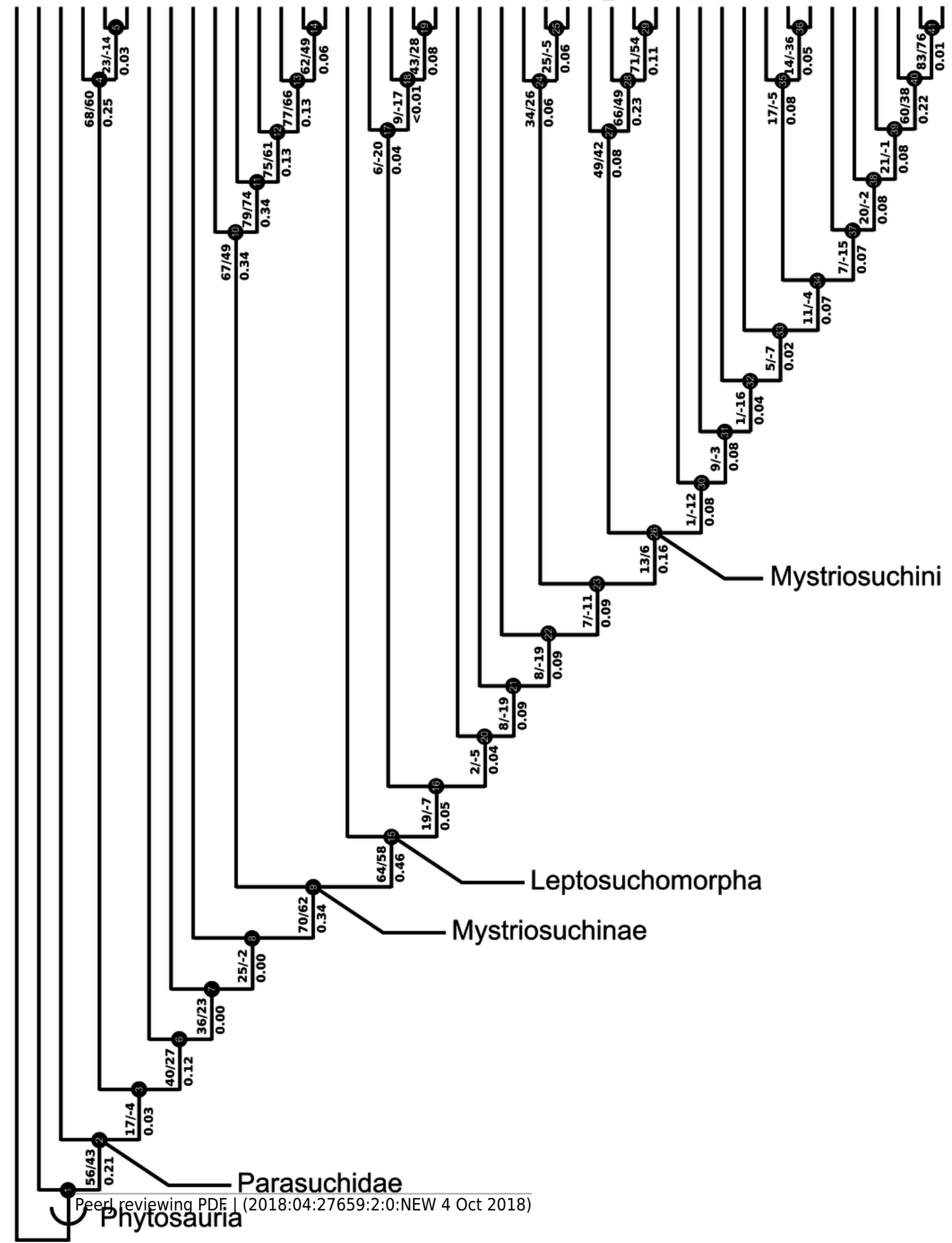




\section{Figure 7}

Single tree resulting from the treatment incorporating all three character scoring methods; discrete, continuous and geometric morphometric (DCM).

Node labels as in Fig. 4.

*Note: Auto Gamma Correction was used for the image. This only affects the reviewing manuscript. See original source image if needed for review. 


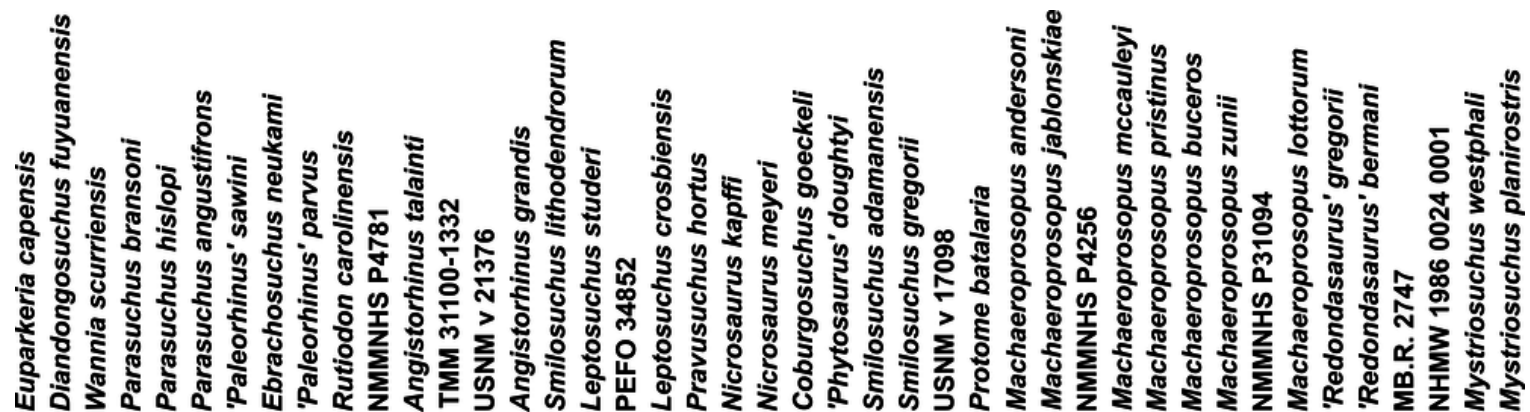

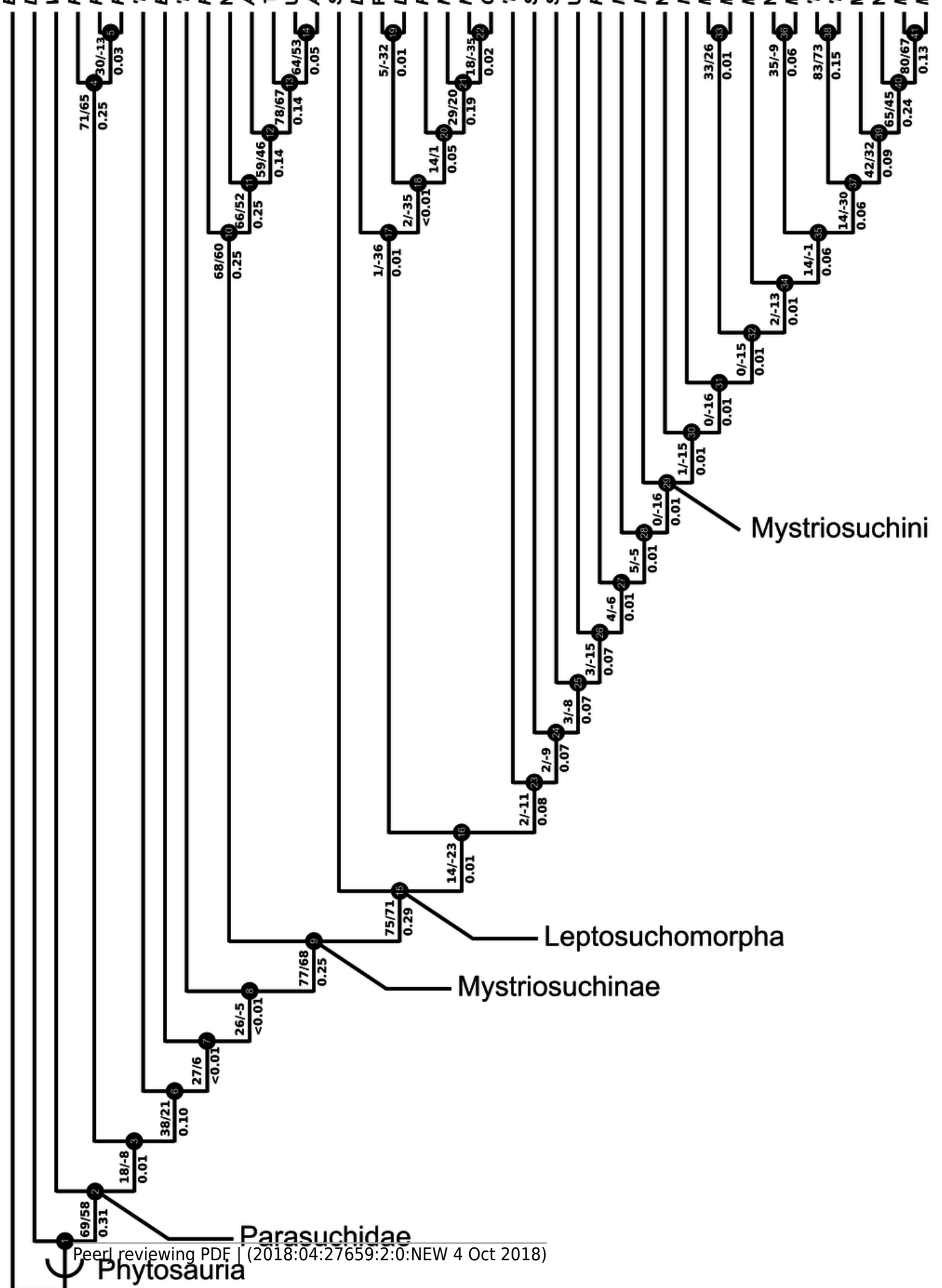




\section{Figure 8}

Strict consensus tree constructed with the four trees presented in Figs. 4, 5, $6 \& 7$ (D, $D C, D M \& D C M)$.

All photographs were taken by Andrew Jones.

*Note: Auto Gamma Correction was used for the image. This only affects the reviewing manuscript. See original source image if needed for review.

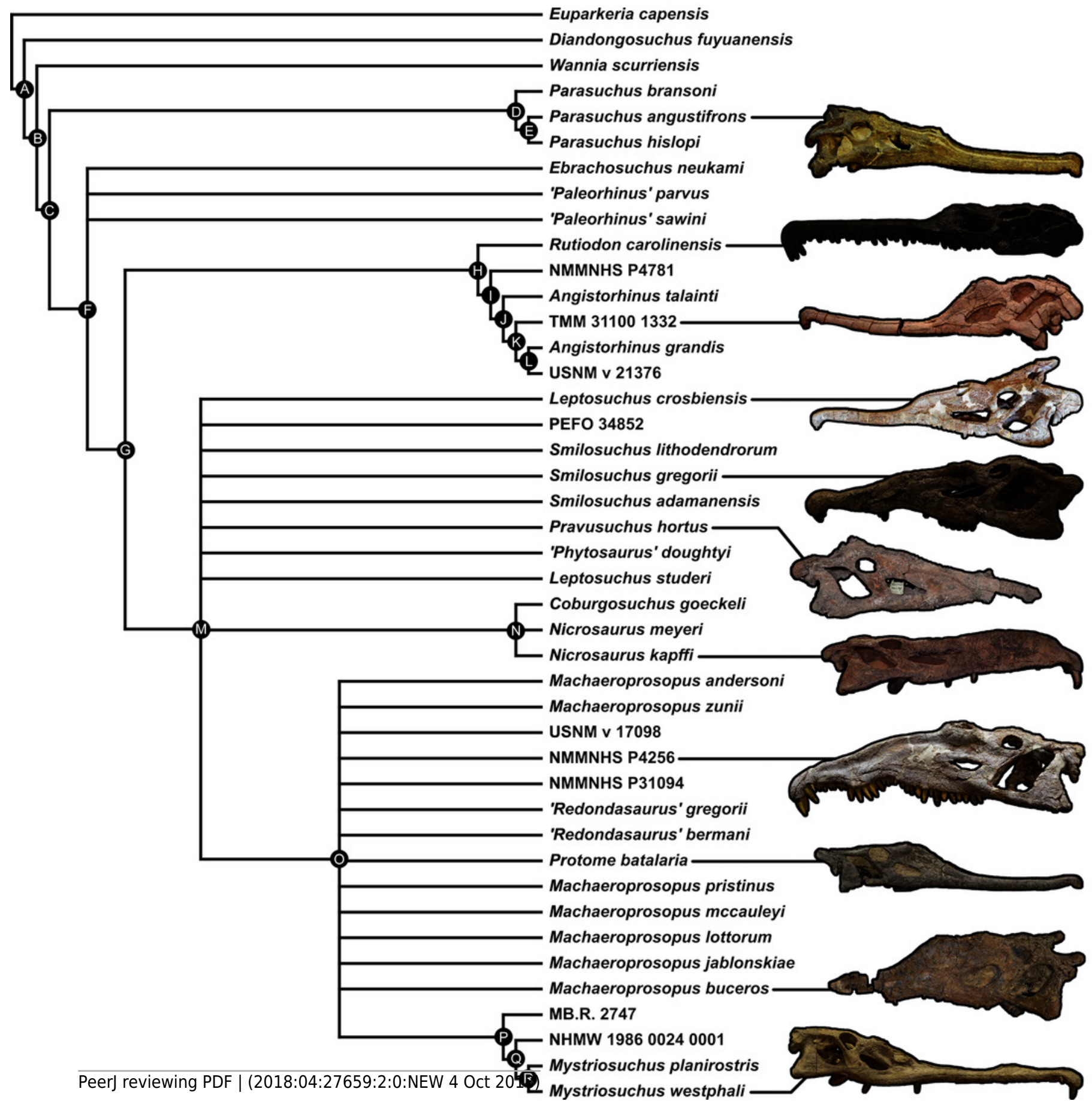




\section{Table 1 (on next page)}

Details of all previous cladistic studies of the ingroup relationships of Phytosauria. 


\begin{tabular}{|c|c|c|c|c|}
\hline & $\begin{array}{l}\text { Phyto. } \\
\text { OTUs }\end{array}$ & Characters & Notes on Matrix & Purpose of Analysis \\
\hline Ballew (1989) & 11 & $\begin{array}{l}64 \text { (39 } \\
\text { autapomorphic, } \\
\text { five for missing } \\
\text { clade) }\end{array}$ & Novel matrix & $\begin{array}{l}\text { First attempt to resolve the } \\
\text { ingroup taxonomic } \\
\text { relationships of Phytosauria } \\
\text { using cladistic methods. }\end{array}$ \\
\hline $\begin{array}{l}\text { Hungerbühler } \\
\text { (1998) }\end{array}$ & 22 & 49 & $\begin{array}{l}\text { Novel matrix. Characters } \\
\text { and scorings based on } \\
\text { first-hand study only of } \\
\text { European taxa; others } \\
\text { based on literature. }\end{array}$ & $\begin{array}{l}\text { Tests the proposed } \\
\text { monophyly of 'Paleorhinus' } \\
\text { and clarifies the position of } \\
\text { Mystriosuchus. }\end{array}$ \\
\hline $\begin{array}{l}\text { Hungerbühler } \\
\text { (2002) }\end{array}$ & 10 & 47 & $\begin{array}{l}\text { Heavily revised matrix } \\
\text { of Hungerbühler (1998). } \\
\text { All scorings based on } \\
\text { first-hand study. }\end{array}$ & $\begin{array}{l}\text { Assesses the taxonomic } \\
\text { position of Mystriosuchus } \\
\text { generally, and specifically the } \\
\text { newly named species } M \text {. } \\
\text { westphali. }\end{array}$ \\
\hline $\begin{array}{l}\text { Parker \& Irmis } \\
\text { (2006) }\end{array}$ & 11 & 47 & $\begin{array}{l}\text { Matrix of Hungerbühler } \\
\text { (2002), plus } \\
\text { Machaeroprosopus } \\
\text { jablonskiae. }\end{array}$ & $\begin{array}{l}\text { Establishes the taxonomic } \\
\text { position of the newly } \\
\text { described species } M \text {. } \\
\text { jablonskiae. }\end{array}$ \\
\hline Stocker (2010) & 19 & 43 & Novel matrix. & $\begin{array}{l}\text { Clarifies the interrelationships } \\
\text { of Leptosuchus and } \\
\text { previously associated taxa, } \\
\text { and finds the position of the } \\
\text { newly described Pravusuchus } \\
\text { hortus. }\end{array}$ \\
\hline Stocker (2012) & 19 & 43 & $\begin{array}{l}\text { Matrix of Stocker } \\
(2010) \text {. }\end{array}$ & $\begin{array}{l}\text { Describes and taxonomically } \\
\text { places Protome batalaria. }\end{array}$ \\
\hline Stocker (2013) & 19 & 43 & $\begin{array}{l}\text { Matrix of Stocker } \\
(2010) \text {. }\end{array}$ & $\begin{array}{l}\text { Identifies and descries } \\
\text { Wannia scurriensis as the } \\
\text { most basal phytosaur, and } \\
\text { discusses the paraphyly of } \\
\text { 'Paleorhinus'. }\end{array}$ \\
\hline $\begin{array}{l}\text { Hungerbühler } \\
\text { et al. (2013) }\end{array}$ & 12 & 41 & Novel matrix. & $\begin{array}{l}\text { Assesses the } \\
\text { interrelationships of } \\
\text { Machaeroprosopus and } \\
\text { 'Redondasaurus', and } \\
\text { provides a description and } \\
\text { taxonomic placement for } M \text {. } \\
\text { lottorum. }\end{array}$ \\
\hline
\end{tabular}




\begin{tabular}{|c|c|c|c|c|}
\hline $\begin{array}{l}\text { Butler et al. } \\
\text { (2014) }\end{array}$ & 22 & 46 & $\begin{array}{l}\text { Matrix of Stocker (2010) } \\
\text { plus Ebrachosuchus } \\
\text { neukami, Parasuchus } \\
\text { angustifrons \& } \\
\text { Machaeroprosopus } \\
\text { jablonskiae, and three } \\
\text { additional characters. }\end{array}$ & $\begin{array}{l}\text { Redescribes Ebrachosuchus } \\
\text { neukami and 'Francosuchus' } \\
\text { angustifrons; tests and } \\
\text { establishes a new } \\
\text { monophyletic definition of } \\
\text { 'Paleorhinus'. }\end{array}$ \\
\hline $\begin{array}{l}\text { Kammerer et } \\
\text { al. (2015) }\end{array}$ & 24 & 48 & $\begin{array}{l}\text { Matrix of Butler et al. } \\
\text { (2014) plus Parasuchus } \\
\text { hislopi, Leptosuchus } \\
\text { imperfecta, and two } \\
\text { additional characters. }\end{array}$ & $\begin{array}{l}\text { Redescribes Parasuchus } \\
\text { hislopi, demonstrates the } \\
\text { seniority of the latter genus } \\
\text { over 'Paleorhinus', and } \\
\text { overhauls the names of } \\
\text { phytosaur sub-family groups. }\end{array}$ \\
\hline
\end{tabular}




\section{Table 2 (on next page)}

Higher-level taxonomic changes to family and sub-family group definitions.

Included are the two most recent revisions of Phytosauria (Stocker \& Butler, 2013; Kammerer et al., 2015) and the present study. 


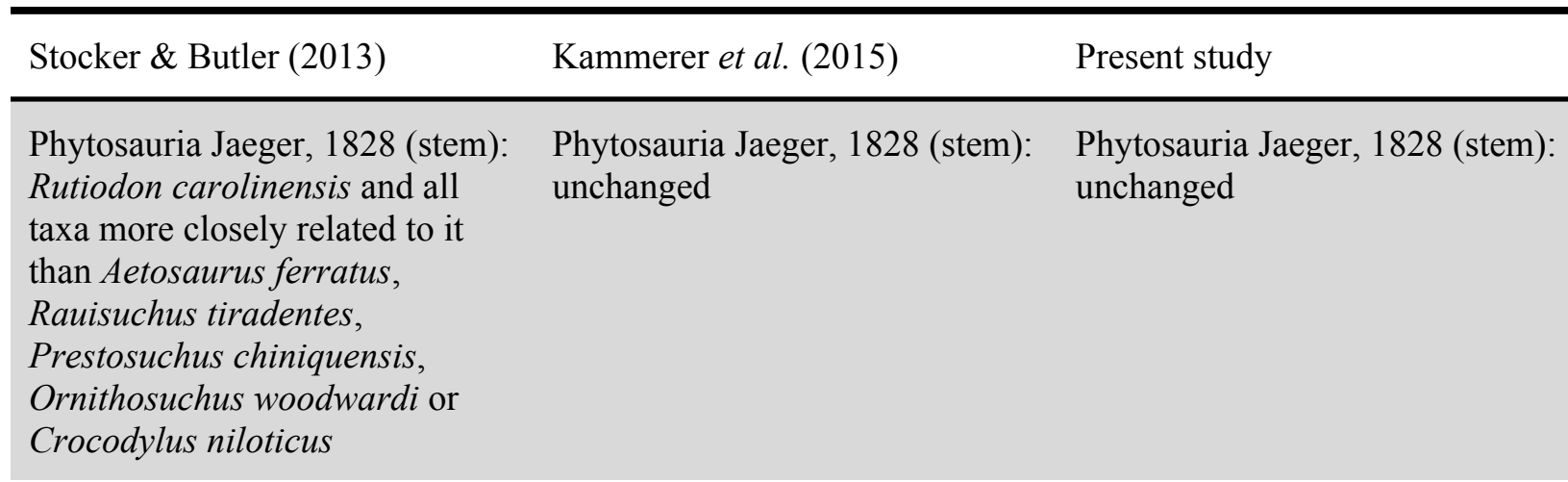

(Unnamed node)

Parasuchidae Lydekker, 1885

Parasuchidae Lydekker, 1885

(node): Wannia scurriensis,

(node): unchanged

Parasuchus hislopi,

Mystriosuchus planirostris and

all descendants of their most

recent common ancestor

Phytosauridae Jaeger, 1828

(node): Angistorhinus,

Leptosuchus studeri,

Mystriosuchinae von Huene,

1915 (node): Mystriosuchus

planirostris, Angistorhinus

Mystriosuchus westphali and all

descendents of their most recent

common ancestor

grandis and all descendants of

their most recent common

ancestor

Leptosuchomorpha Stocker, 2010 (node): Leptosuchus studeri, Machaeroprosopus pristinus and all descendants of their most recent common ancestor

Leptosuchomorpha Stocker, 2010 (node): unchanged
Mystriosuchinae von Huene, 1915 (node): unchanged
Pseudopalatinae Long and Murry, 1995 (node): Nicrosaurus kapffi, Mystriosuchus westphali, Machaeroprosopus pristinus, Redondasaurus gregorii and all descendants of their most recent common ancestor
Mystriosuchini von Huene, 1915 (node): Nicrosaurus kapffi, Mystriosuchus planirostris, Machaeroprosopus buceros and all descendants of their most recent common ancestor
Leptosuchomorpha Stocker, 2010 (node): Smilosuchus lithodendrorum, Leptosuchus studeri, Machaeroprosopus pristinus and all descendents of their most recent common ancestor

Mystriosuchini von Huene, 1915 (node): Mystriosuchus planirostris, Machaeroprosopus jablonskiae, Machaeroprosopus buceros and all descendents of their most recent common ancestor 


\section{Table 3(on next page)}

Summary of the character composition for all four datasets ( $D, D C, D M \& D C M)$ analysed in this study. 


\begin{tabular}{llll}
\hline & $\begin{array}{l}\text { No. of } \\
\text { characters }\end{array}$ & Description & $\begin{array}{l}\text { Characters encoded } \\
\text { using continuous or GM } \\
\text { methods }\end{array}$ \\
\hline D & 94 & Discretely encoded characters only & None \\
DC & 94 & $\begin{array}{l}\text { Discretely \& continuously encoded characters (no } \\
\text { characters scored using GM) }\end{array}$ & $\begin{array}{l}8,11,25,38,43,54,60, \\
87,89,94\end{array}$ \\
& & & \\
DM & 90 & $\begin{array}{l}\text { Discretely \& GM encoded characters (no characters } \\
\text { scored continuously) [Reduced character count, as }\end{array}$ & $\begin{array}{l}39,40,46,50,54,55,81, \\
89,91\end{array}$ \\
& & $\begin{array}{l}\text { GM characters often correspond to multiple discrete } \\
\text { characters] }\end{array}$ & \\
DCM & 90 & $\begin{array}{l}\text { Discretely, continuously \& GM encoded characters } \\
\text { (all scoring methods used) [Reduced character count, } \\
\text { as above] }\end{array}$ & $\begin{array}{l}8,11,25,38,39,40,43, \\
40,54,55,60,81,87, \\
89,91,94\end{array}$ \\
\hline
\end{tabular}

1 


\section{Table 4 (on next page)}

Consistency index $(\mathrm{Cl})$, retention index (RI) and 'tree-lengths' of the four phylogenetic trees corresponding to the four data treatments. 


\begin{tabular}{lccc}
\hline & Consistency Index (CI) & Retention Index (RI) & Tree Length \\
\hline Discrete only (D) & 0.383 & 0.689 & 31.90 \\
\hline $\begin{array}{l}\text { Discrete + Continuous } \\
\text { (DC) }\end{array}$ & 0.409 & 0.684 & 27.46 \\
\hline $\begin{array}{l}\text { Discrete + GM (DM) } \\
\begin{array}{l}\text { Discrete + Continuous }+ \\
\text { GM (DCM) }\end{array}\end{array}$ & 0.391 & 0.691 & 30.52 \\
\hline
\end{tabular}

1 


\section{Table 5 (on next page)}

Similarity of the trees from each coding treatment.

Trees are compared using number of taxa retained in their maximum agreement subtree (green), and the number of moves under SPR swapping to move from one tree to the other (blue). The pair of most similar trees are highlighted and emboldened in both comparison techniques. Multiple maximum agreement subtrees are frequently produced where several OTUs are in conflict with each other and when any combination of their pruning results in the same final subtree; the number of trees produced is also included in the table. 


\begin{tabular}{|c|c|c|c|c|c|}
\hline & $\begin{array}{l}\text { Discrete only } \\
\text { (D) }\end{array}$ & $\begin{array}{l}\text { Discrete + } \\
\text { Continuous } \\
\text { (DC) }\end{array}$ & $\begin{array}{l}\text { Discrete + GM } \\
(\mathrm{DM})\end{array}$ & $\begin{array}{l}\text { Discrete }+ \\
\text { Continuous }+ \\
\text { GM (DCM) }\end{array}$ & \\
\hline $\begin{array}{l}\text { Discrete only } \\
\text { (D) }\end{array}$ & & $\begin{array}{c}27 \text { taxa }(62.8 \%) \\
39 \text { trees }\end{array}$ & $\begin{array}{c}33 \text { taxa }(76.7 \%) \\
18 \text { trees }\end{array}$ & $\begin{array}{c}26 \text { taxa }(60.5 \%) \\
27 \text { trees }\end{array}$ & $\frac{3}{x}$ \\
\hline $\begin{array}{l}\text { Discrete }+ \\
\text { Continuous } \\
\text { (DC) }\end{array}$ & $\begin{array}{c}13 \text { moves } \\
\text { (Similarity: } \\
0.675)\end{array}$ & & $\begin{array}{c}24 \text { taxa }(55.8 \%) \\
36 \text { trees }\end{array}$ & $\begin{array}{c}38 \text { taxa } \\
(88.4 \%) 9 \text { trees }\end{array}$ & 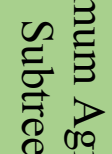 \\
\hline $\begin{array}{l}\text { Discrete + GM } \\
(\mathrm{DM})\end{array}$ & $\begin{array}{c}6 \text { moves } \\
\text { (Similarity: } \\
0.850)\end{array}$ & $\begin{array}{c}11 \text { moves } \\
\text { (Similarity: } \\
0.725)\end{array}$ & & $\begin{array}{c}26 \text { taxa }(60.5 \%) \\
6 \text { trees }\end{array}$ & $\stackrel{8}{8}$ \\
\hline \multirow[t]{2}{*}{$\begin{array}{l}\text { Discrete }+ \\
\text { Continuous }+ \\
\text { GM (DCM) }\end{array}$} & $\begin{array}{c}12 \text { moves } \\
\text { (Similarity: } \\
0.700)\end{array}$ & $\begin{array}{c}3 \text { moves } \\
\text { (Similarity: } \\
0.925)\end{array}$ & $\begin{array}{c}12 \text { moves } \\
\text { (Similarity: } \\
0.700)\end{array}$ & & \\
\hline & & SPR Distances & & & \\
\hline
\end{tabular}

1 


\section{Table 6(on next page)}

Similarity of tree topologies as measured using Robinson-Foulds distance.

The most similar combination of topologies, indicated by the shortest distance between input trees, is highlighted and emboldened. 


\begin{tabular}{|c|c|c|c|}
\hline & Discrete only (D) & Discrete + Continuous (DC) & $\begin{array}{l}\text { Discrete + GM } \\
\text { (DM) }\end{array}$ \\
\hline $\begin{array}{l}\text { Discrete }+ \text { Continuous } \\
\text { (DC) }\end{array}$ & 0.45122 & & \\
\hline Discrete + GM (DM) & 0.23171 & 0.48780 & \\
\hline \multirow[t]{2}{*}{$\begin{array}{l}\text { Discrete }+ \text { Continuous }+ \\
\text { GM (DCM) }\end{array}$} & 0.45122 & 0.21951 & 0.48780 \\
\hline & & Robinson-Foulds Distance & \\
\hline
\end{tabular}




\section{Table 7 (on next page)}

Bremer (above) and frequency (below) supports resulting from each of the four data conditions.

Values below which nodes were collapsed, were set as 0.08 and [0.11] for Bremer, and 10 for frequency supports. Largest values in each category are shown in bold. 


\begin{tabular}{|c|c|c|c|c|c|}
\hline & Discrete (D) & $\begin{array}{l}\text { Discrete + } \\
\text { Cont. (DC) }\end{array}$ & $\begin{array}{c}\text { Discrete + Morph. } \\
\text { (DM) }\end{array}$ & $\begin{array}{c}\text { Discrete }+ \\
\text { Cont. }+ \text { Morph. } \\
\text { (DCM) }\end{array}$ & \\
\hline $\begin{array}{l}\text { No. of nodes } \\
\text { retained }\end{array}$ & 15 [14] & 17 [15] & 23 [13] & 15 [12] & \multirow{3}{*}{ 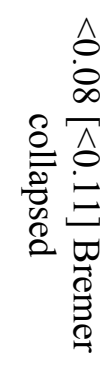 } \\
\hline $\begin{array}{l}\text { Total Bremer } \\
\text { support }\end{array}$ & $3.34[3.25]$ & $3.59[\mathbf{3 . 4 0}]$ & $3.86[3.04]$ & 2.86 [2.59] & \\
\hline $\begin{array}{l}\text { Mean Bremer } \\
\text { support }\end{array}$ & $0.22[0.23]$ & $0.21[\mathbf{0 . 2 3}]$ & 0.17 [0.23] & $0.19[0.22]$ & \\
\hline $\begin{array}{l}\text { No. of Nodes } \\
\text { retained }\end{array}$ & 29 & 30 & 29 & 26 & \multirow{3}{*}{ 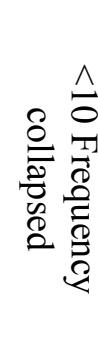 } \\
\hline $\begin{array}{l}\text { Total freq. } \\
\text { support }\end{array}$ & 1337 & 1416 & 1305 & 1207 & \\
\hline $\begin{array}{l}\text { Mean freq. } \\
\text { support }\end{array}$ & 46.10 & 47.20 & 45.00 & 46.42 & \\
\hline
\end{tabular}




\section{Table 8 (on next page)}

Mean Bremer supports calculated in five tree-regions within each of the four data conditions.

Largest values in each region are shown in bold. The data condition with the highest summed mean Bremer support is highlighted with a green border. 


\begin{tabular}{lc|c|cc}
\hline & Discrete (D) & $\begin{array}{c}\text { Discrete }+ \text { Cont. } \\
\text { (DC) }\end{array}$ & $\begin{array}{c}\text { Discrete }+ \\
\text { Morph. (DM) }\end{array}$ & $\begin{array}{c}\text { Discrete + Cont. } \\
\text { + Morph. (DCM) }\end{array}$ \\
\hline Region 1 Bremer mean & 0.15 & $\mathbf{0 . 1 6}$ & 0.09 & 0.11 \\
\hline Region 2 Bremer mean & $\mathbf{0 . 2 3}$ & $\mathbf{0 . 2 3}$ & 0.20 & 0.17 \\
\hline Region 3 Bremer mean & 0.06 & 0.07 & $\mathbf{0 . 1 0}$ & 0.09 \\
\hline Region 4 Bremer mean & 0.06 & 0.05 & $\mathbf{0 . 0 7}$ & 0.05 \\
\hline Region 5 Bremer mean & 0.14 & $\mathbf{0 . 2 4}$ & 0.14 & 0.16 \\
\hline Total & 0.64 & $\mathbf{0 . 7 5}$ & 0.60 & 0.58 \\
\hline
\end{tabular}

1 


\section{Table 9 (on next page)}

Mean frequency supports calculated in five tree-regions within each of the four data conditions.

Largest values in each region are shown in bold. The data condition with the highest summed mean frequency support is highlighted with a green border. 


\begin{tabular}{lc|c|cc}
\hline & Discrete (D) & $\begin{array}{c}\text { Discrete }+ \text { Cont. } \\
(\mathrm{DC})\end{array}$ & $\begin{array}{c}\text { Discrete }+ \\
\text { Morph. (DM) }\end{array}$ & $\begin{array}{c}\text { Discrete + Cont. + } \\
\text { Morph. (DCM) }\end{array}$ \\
\hline Region 1 freq. mean & 41.00 & $\mathbf{4 8 . 8 0}$ & 37.86 & 39.86 \\
\hline Region 2 freq. mean & $\mathbf{7 3 . 8 3}$ & 73.33 & 72.00 & 67.00 \\
\hline Region 3 freq. mean & 24.73 & $\mathbf{2 7 . 9 1}$ & 20.55 & 15.00 \\
\hline Region 4 freq. mean & 18.91 & 17.85 & $\mathbf{2 0 . 7 5}$ & 14.92 \\
\hline Region 5 freq. mean & 71.00 & $\mathbf{7 2 . 6 7}$ & 62.00 & 62.33 \\
\hline Total & 229.47 & $\mathbf{2 4 0 . 5 6}$ & 213.16 & 199.11 \\
\hline
\end{tabular}

1 


\section{Table $\mathbf{1 0}$ (on next page)}

Stratigraphic consistency metrics for each of the four tree topologies, compared with those of three previous phylogenetic analyses of ingroup phytosaur relationships.

Raw analysis output values are displayed on the left and significance values generated via random permutations are presented on the right. 


\begin{tabular}{|c|c|c|c|c|c|c|c|c|}
\hline & SCI & $\mathrm{RCI}$ & GER & MSM* & $\begin{array}{l}\text { P. Sig. } \\
\text { SCI }\end{array}$ & $\begin{array}{l}\text { P. Sig. } \\
\text { RCI }\end{array}$ & $\begin{array}{l}\text { P. Sig. } \\
\text { GER }\end{array}$ & $\begin{array}{l}\text { P. Sig. } \\
\text { MSM* }\end{array}$ \\
\hline $\mathrm{D}$ & 0.737 & -9.272 & 0.777 & 0.150 & $<0.0001$ & $<0.0001$ & $<0.0001$ & $<0.0001$ \\
\hline $\mathrm{DC}$ & 0.615 & -9.369 & 0.777 & 0.150 & $<0.0001$ & $<0.0001$ & $<0.0001$ & $<0.0001$ \\
\hline DM & 0.732 & -10.343 & 0.775 & 0.149 & $<0.0001$ & $<0.0001$ & $<0.0001$ & $<0.0001$ \\
\hline DCM & 0.634 & -11.032 & 0.773 & 0.148 & $<0.0001$ & $<0.0001$ & $<0.0001$ & $<0.0001$ \\
\hline $\begin{array}{l}\text { Kammerer et } \\
\text { al. }\end{array}$ & 0.750 & -16.042 & 0.805 & 0.291 & $<0.0001$ & - & 0.0002 & $<0.0001$ \\
\hline $\begin{array}{l}\text { Hungerbühler } \\
\text { et al. \#1 }\end{array}$ & 0.400 & 19.878 & 0.163 & 0.258 & 0.20 & - & 0.96 & 0.77 \\
\hline $\begin{array}{l}\text { Hungerbühler } \\
\text { et al. \#2 }\end{array}$ & 0.429 & 25.841 & 0.247 & 0.278 & 0.08 & - & 0.81 & 0.58 \\
\hline Parker \& Irmis & 0.700 & -57.830 & 0.797 & 0.389 & $<0.0001$ & - & $<0.0001$ & $<0.0001$ \\
\hline
\end{tabular}

